\title{
Go for less: the effect of feedback and goal setting on household energy and water consumption
}

Citation for published version (APA):

Völlink, T. (2004). Go for less: the effect of feedback and goal setting on household energy and water consumption. [Doctoral Thesis, Maastricht University]. Maastricht University. https://doi.org/10.26481/dis.20040326tv

Document status and date:

Published: 01/01/2004

DOI:

10.26481/dis.20040326tv

Document Version:

Publisher's PDF, also known as Version of record

\section{Please check the document version of this publication:}

- A submitted manuscript is the version of the article upon submission and before peer-review. There can be important differences between the submitted version and the official published version of record.

People interested in the research are advised to contact the author for the final version of the publication, or visit the DOI to the publisher's website.

- The final author version and the galley proof are versions of the publication after peer review.

- The final published version features the final layout of the paper including the volume, issue and page numbers.

Link to publication

\footnotetext{
General rights rights.

- You may freely distribute the URL identifying the publication in the public portal. please follow below link for the End User Agreement:

www.umlib.nl/taverne-license

Take down policy

If you believe that this document breaches copyright please contact us at:

repository@maastrichtuniversity.nl

providing details and we will investigate your claim.
}

Copyright and moral rights for the publications made accessible in the public portal are retained by the authors and/or other copyright owners and it is a condition of accessing publications that users recognise and abide by the legal requirements associated with these

- Users may download and print one copy of any publication from the public portal for the purpose of private study or research.

- You may not further distribute the material or use it for any profit-making activity or commercial gain

If the publication is distributed under the terms of Article $25 \mathrm{fa}$ of the Dutch Copyright Act, indicated by the "Taverne" license above, 


\section{GO FOR LESS}

The effect of feedback and goal setting on household energy and water consumption

Trijntje Völlink 



\title{
GO FOR LESS
}

The effect of feedback and goal setting on household energy and water consumption

\author{
PROEFSCHRIFT \\ ter verkrijging van de graad doctor aan \\ de Universiteit Maastricht \\ op gezag van de Rector Magnificus \\ Prof. Mr.G.P.M.F. Mols \\ volgens het besluit van het College van Decanen, \\ in het openbaar te verdedigen op vrijdag \\ 26 maart 2004 om 16:00 uur
}

door

Trijntje Völlink 
Promotor

Prof.Dr. N.K. de Vries

Co-promotor

Dr.R.M.Meertens

Beoordelingscommissie

Prof. Dr. G.J. Kok (Voorzitter)

Prof.Dr. Ir. J. Brug

Prof.Dr. Ir. W.E. Bijker

Prof. Dr. C.J.H. Midden (Technische Universiteit Eindhoven)

Prof.Dr.F.J.van Schooten

Colofon

Printing: Pons en van looijen

Vormgeving:Tim Schokker

Omslag foto: Libelle 1968, Spaarnestad fotoarchief, Haarlem

O T.Völlink

\section{ntưtim}

The study presented in this thesis was performed at the Nutrtion and Toxicology Research Institute Maastricht (INUTRIM) which participates in the Graduate School Vlag (Food Technology, Agrobiotechnology, Nutrion and Health Sciences), accredited by the Royal Dutch Academy of Arts and Sciences. 


\section{CONTENTS}

CHAPTER ONE Overview Of This Dissertation 7

CHAPTER TWO Innovating "Diffusion Of Innovation" Theory: 31

Innovation Characteristics And The Intention of

Utility Companies To Adopt Energy Conservation

Interventions

CHAPTER THREE The Effect of A Prepayment Meter On Residential

Gas Consumption

CHAPTER FOUR Goal-setting And Feedback Toward A Sustainable 69

Future: An Intervention To Reduce Household Water

And Energy Consumption

CHAPTER FIVE Goal-setting And Feedback Toward A Sustainable

Future: An Intervention To Reduce Household Water

And Energy Consumption

REFERENCES

NOTES

SUMMARY

SAMENVATTING

DANKWOORD

CURRICULUM

VITAE 
CHAPTER ONE

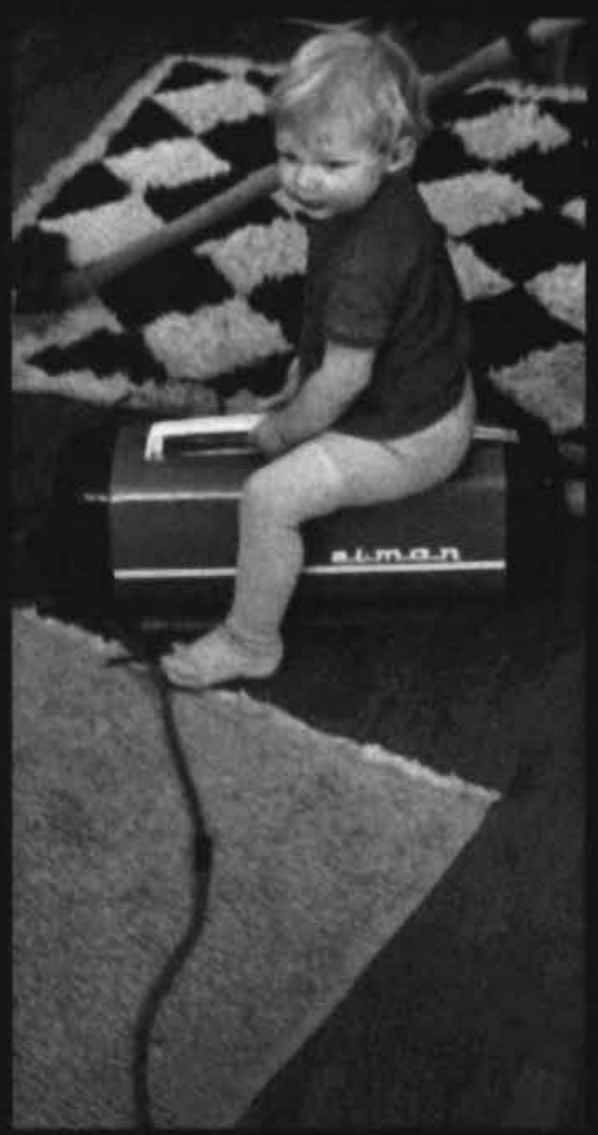


Overview Of This Dissertation

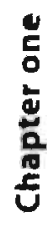

$|7|$ 


\section{INTRODUCTION}

W

estern countries are confronted with a variety of environmental problems, such as depletion of natural resources, continuing emișsion of greenhouse gașes leading to global warming and pollution of the environment with heavy metals, nitrates and pesticides. Households contribute significantly to some of these problems, for example to the emission of carbon dioxide $\left(\mathrm{CO}_{2}\right)$, the most important greenhouse gas, by burning fossil fuels. To prevent further damage to the environment, governments may promote the use of alternative energy sources like solar and wind energy and implement a variety of measures to reduce energy and water consumption, like subsidizing energy and water saving measures. In addition, governments may also utilize behavioral strategies to promote energy and water conservation. In this dissertation it is first investigated what kind of intervention would make a good chance to get widely accepted by relevant policymakers. Acceptation by relevant policymakers of effective interventions is important for its wide scale implementation, so that it can contribute significantly to the reduction of the $\mathrm{CO}_{2}$ emission by households. Then this dissertation focuses on the behavioral method that seems to be accepted best: providing feedback about energy and water consumption in relation to goals that are set by households to limit their water, gas and electricity consumption. The effect of feedback, in combination with performance goal setting, has proved effective in a wide variety of educational, organizational, industrial and laboratory settings (see Locke \& Latham, 1990).

The research projects reported on in this dissertation had practical as well as theoretical goals. The practical aims of these projects were: (1) to select an intervention that might be implemented on a large scale because it is favorably judged by relevant policymakers and (2) to examine the effectiveness of this selected intervention in saving household water, electricity and gas consumption. The theoretical aims of these projects were to provide more insight into (3) the effects of goal setting and feedback on cognitions and (energy-relevant) behavior and (4) the possible negative effects of repeated negative feedback on cognitions and water and energy saving behaviors. An intervention can only contribute to the solution of environmental problems if it is implemented on a large scale. Therefore, another theoretical aim of this thesis is (5) to shed some light on how responsible policymakers decide to reject or accept an innovative energy conservation intervention.

The remaining part of this overview addresses the following issues. First we elaborate on the problem area this dissertation is concerned with, that of water and energy conservation issues. The description of these problems is followed by an introduction to the theories that are relevant to this dissertation. After a discussion of the theoretical ideas behind goal setting and feedback, the next section summarizes the so-called "diffusion theory" proposed by Rogers (1995), a well-known theory concerned with the process of bringing an effective intervention into large-scale use. This is followed by a brief discussion of the 
findings of the studies reported on in this dissertation. Finally, the most important conclusions and recommendations are considered.

\section{A BRIEF OVERVIEW OF WATER AND ENERGY CONSERVATION ISSUES IN THE NETHERLANDS}

\section{Energy conservation}

Research on the effectiveness of behavioral interventions in reducing household energy use has a long tradition worldwide, starting in the 1970 s with the first oil crisis (see Geller, Winett \& Everett, 1982). Nowadays, energy saving practices are once again at the center of attention because burning fossil fuels is causing environmental problems like acidification, smog and the emission of greenhouse gases, leading to global warming.

Acidification is harming trees, lakes and rivers, and threatening the stability of ecosystems. This acidification arises from the reaction of air pollutants like ammonia $\left(\mathrm{NH}_{3}\right)$, sulfur dioxides $\left(\mathrm{SO}_{2}\right)$ and nitrogen oxides $\left(\mathrm{NO}_{\mathrm{x}}\right)$, with water in the air, forming strong acids. The contributors to acidification are not the same everywhere. In the United States, about $70 \%$ of the acidification comes from sulfur dioxides $\left(\mathrm{SO}_{2}\right)$, produced almost entirely by burning fossil fuels, whereas in the Netherlands acidification is mainly (about 55\%) caused by ammonia produced by agriculture. Other important contributors to acidification in the Netherlands are nitrogen oxides (about 25\%) and sulfur oxides (about 20\%), arising mainly from the production of electricity by power stations (United States Environmental Protection Agency [EPA], 2002; Ministry of Housing, Spatial Planning and the Environment [VROM], 1998).

Air pollution caused by the burning of fossil fuels can also result in the formation of smog. Gases like carbon monoxide $(\mathrm{CO})$ undergo chemical reactions when exposed to nitrogen oxides, heat and sunlight. These reactions form ground-level ozone $\left(\mathrm{O}_{3}\right)$, the principal component of smog (EPA, 2002).

The burning of fossil fuel contributes to the emission of carbon dioxide, which accounts for $60 \%$ of the human contribution to the greenhouse effect. In itself, the greenhouse effect is a natural process. Energy from the sun drives the earth's weather and climate, and heats the earth's surface; in turn, the earth radiates energy back into space. Atmospheric greenhouse gases trap some of the outgoing energy, retaining heat somewhat like the glass panels of a greenhouse. However, human activities are raising the concentration of atmospheric greenhouse gases, leading to "unnatural" (man-made) climate change. Scientists estimate that the average global surface temperature will rise by $0.6-2.5^{\circ} \mathrm{C}$ over the next fifty years, and by $1.4-5.8^{\circ} \mathrm{C}$ in the next century, with significant regional variations (EPA, 2002). In 1997, industrial countries met in Kyoto and agreed to reduce $\mathrm{CO}_{2}$ emissions to 5 percent below 1990 levels by 2012. In 2001, a total of 160 industrial countries ratified this agreement at Marrakech, the United States being a notable exception (EPA, 2002). In the Netherlands, it was found that total $\mathrm{CO}_{2}$ emissions had in- 
creased by $8 \%$ between 1990 and 1999, whereas the emission of other greenhouse gases had stabilized during this period (van den Wijngaart \& Ybema, 2002).

Household electricity and gas conservation can contribute significantly to diminishing environmental problems like acidification, smog, and the greenhouse effect. Dutch households are responsible for about $24 \%$ of the total electricity consumption and $14 \%$ of the natural gas consumption. In all, $80 \%$ of household gas consumption is used for heating. Improved insulation in particular led to a $30 \%$ decrease in household gas consumption between 1980 and 1991 (National Institute of Health and the Environment [RIVM], 2000).

However, electricity consumption increased by $16 \%$ between 1990 and 1998, particularly through increased diffusion of home appliances like tumble dryers, dishwashers, etc. The presence of tumble dryers in Dutch households, for instance, increased from $18 \%$ in 1987 to $56 \%$ in 1998, whereas dishwasher coverage increased from $8 \%$ in 1987 to $35 \%$ in 1998 (National Institute of Health and the Environment [RIVM], 2000).

\section{Water conservation}

Western countries have little experience with structurally promoting water conservation by behavioral interventions. So far, behavioral saving measures have been taken mostly in response to immediate water scarcity caused by severe droughts during the summer months (see Berk، Cooley، LaCivita, Parker, Sredl \& Brewer, 1980). Structural water conservation is important, however, since $60 \%$ of the clean drinking water is extracted from scarce groundwater, contributing $30 \%$ to soil dehydration processes (National Institute of Health and the Environment [RIVM], 2000). Since pollution is affecting the self-cleaning capacity of the groundwater, the production of clean drinking water is requiring more advanced and energy-intensive cleansing techniques. These advanced techniques cause increased production costs as well as increased amounts of polluted sludge. In other words, economical use of drinking water is important since it contributes to energy conservation and decreases environmental pollution.

The average daily consumption of clean drinking water per person in the Netherlands increased from 98 liters in 1970 to 131 liters in 1998. The total consumption can be divided into water use for personal hygiene ( 54 liters), flushing the toilet ( 36 liters), laundry (23 liters), washing dishes (6 liters), cooking and drinking (6 liters), and cleaning the house and other applications (6 liters) (National Institute of Health and the Environment [RIVM], 2000). Water conservation can be achieved by technical measures like water-saving showerheads, water saving devices in the toilet to reduce the volume of water used for flushing, a fixed spray nozzle to existing taps to reduce the water flow from the tap, etc. Besides these technical measures, behavioral changes like using rainwater instead of tap water to wash cars, taking a shower instead of a bath and having only full loads in the washing machine can also contribute significantly to reducing water use.

The next section introduces the feedback and goal setting theory and describes 
the theoretical issues and empirical findings that are relevant to the studies described in this dissertation. The subsequent section introduces the diffusion of innovation theory, proposed by Rogers (1995), which was used to examine the factors influencing the largescale acceptance of effective energy reducing interventions.

\section{FEEDBACK AND GOAL SETTING: A BRIEF OVERVIEW OF THE THEORY AND EMPIRICAL FINDINGS}

Eeedback and goal setting have been applied to enhance people's performance in a variety of fields, like exercising, weight loss, energy conservation, and job-related tasks. One of the most influential modern theories describing the mechanisms of goal setting and feedback is that developed by Locke and Latham (1990, 2002). To be effective, feedback and goal setting must meet certain criteria. Based on hundreds of studies, Locke and Latham conclude that a goal must be specific and challenging to enhance people's effort. If a goal is too vague or too generally phrased, for instance,"do your best,"it will have little effect, since it provides no clear standard to evaluate one's performance. Locke and Latham found that specific, challenging goals lead to higher performance levels than easy or vaguely formulated goals. When specific, hard goals are set, individuals will spend more effort and persist longer to attain their goal. Furthermore, such goals focus people's attention and actions better and motivate them to search for suitable task strategies. Finally, specific, hard goals lead to a better planning for target attainment. These mechanisms provide some insight into the reasons why specific challenging goals work. The following subsection outlines in more detail how feedback and goal setting motivates people.

\section{What motivates people: feedback or goal setting?}

From several theoretical points of view, researchers have been interested in the motivational forces of feedback and goal setting. Depending on their theoretical scope, researchers have stressed the importance of feedback (the behavioristic perspective), or the importance of goal setting as a motivational factor (the motivational and cognitive psychological perspective). According to the behavioristic perspective (Thorndike, 1927), behavior is controlled by consequences or effects. Feedback or knowledge of results is thus seen as a reinforcer of to-be-promoted behavior or a punisher of to-be-prevented behavior. Thus, in the case of energy-relevant behavior, goai setting and feedback is presumed to stimulate energy saving because energy saving activities are reinforced by feedback showing people that their target was achieved, and energy wasting activities are punished by feedback telling them they have exceeded their standard. Subsequently, people will try to avoid punishment (nor achieving the goal! and strive after positive reinforcements (achieving the goal) through performing energy reducing activities more consistently. 
In contrast to the behavioristic perspective, Locke and Latham (1990) argued that it is the goal that motivates people to perform better. According to them, a challenging goal is the motivator, whereas feedback only informs people how well or poorly they performed in relation to that goal. Based on empirical studies, they concluded that outcome feedback without an explicit or implicit goal does not lead to optimal performance. People do not succeed in achieving a target by repeating a reinforced response, but improve their performance by enhancing their effort as a result of a challenging goal.

Other scholars, like Cervone (1993) and Bandura (1997), have taken a stance in between these two extreme positions by stating that neither goal setting nor feedback in itself motivates people to work harder. They postulate that the motivation to try harder is triggered by an evaluation process of one's actual performance relative to a goal. Feelings of dissatisfaction about performance relative to a goal provide the motivation to try harder to improve performance. The activation of this self-referent thinking process requires both well-defined goals and feedback (see also Kluger \& Denissi, 1996). Although theorists may thus have different opinions about the relative importance of goal setting and feedback, they usually agree that it is the combination of the two that increases people's performance. Based on these theoretical insights and empirical findings about the motivational mechanisms of feedback and goal setting, we used both feedback and goal setting in our interventions to reduce household energy and water consumption.

Another important theoretical issue in the goal setting literature, which is also relevant to the present dissertation, is the relationship between goal difficulty and performance and the mediating role of cognitive factors. The next two subsections outline the most important theoreticai issues on this subject, as well as some empiricaì findings.

\section{Goal difficulty and performance}

One of the questions researchers have been interested in for a long time is how difficult a goal must be for an optimal effect on people's performance. One of the theories that have been very influential for many years assumes that people's performances are best for goals of moderate difficulty' (Atkinson, 1964). According to Atkinson, the relationship between goal difficulty and performance is curvilinear, as the probability of success and the value of attaining a goal are optimal for goals of moderate difficulty: the higher the goal the higher the value of the goal, but the lower the probability of success. A low probability of success may dampen people's effort to attain the goal, and lead to sub-optimal performance. The more recent goal setting theory by Locke and Latham (1990) criticized Atkinson on the basis of empirical evidence. Locke and Latham argued that no clear evidence has ever been found for this curvilinear relationship between goal difficulty and performance. They concluded that there is more evidence for a linear relationship between goal difficulty and performance, meaning that the more difficult the goal, the better people will perform. They found that this linear relationship holds when people remain committed to their goal and have a great sense of self-efficacy (i.e., their judgment of their 
capabilities to organize and execute courses of action required to attain designated types of performances; Bandura, 1997). Goal commitment is especially important when goals are difficult and attaining a goal requires great effort. A study by Erez and Zidon (1984) found that when goal commitment dropped in response to increasingly difficult goals, performance dropped accordingly.

\section{Goal difficulty, self-efficacy and goal commitment}

Self-efficacy affects the way people respond to negative feedback, as well as people's choice of goals (Locke $\&$ Latham, 2002). It has been found that high self-efficacy people respond more positively to negative feedback and use better task strategies to attain a goal than do people with low self-efficacy (Bandura \& Cervone, 1983; Locke \& Latham 1990). -People with high self-efficacy set higher goals and are more capable of intensifying their effort and persisting longer than people with low self-efficacy. People who distrust their capabilities give up faster when faced with failure (Bandura \& Cervone, 1983).

However, repeated failure as a consequence of difficult goals can also have a negative effect on people's high self-efficacy and high goal commitment, It was found that past experience provides the most influential source of self-efficacy information about one's, goal achievement (Bandura, 1979). Success raises self-efficacy perceptions whereas repeated failure lowers them. If the discrepancy between goal and actual performance is too large, perceived self-efficacy will be undermined and commitment to the goal will decrease (Bandura, 1997). This might cause a shift in attention from problem solving to thoughts about personal shortcomings. Under these circumstances, people may not persist in trying to ațain a goa, iou (î possidiej iower the goai or juage the goat to be unimportant and consequently abandon commitment to it (Cervone, Jiwani \& Wood, 1991; Sarason, Sarason \& Pierce, 1990; Wood, Bandura \& Baily, 1990). Nease, Mudgett and Quinos (1999) found that self-efficacy also mediates between repeated negative feedback and the acceptance of feedback information. They found that individuals with high self-efficacy who received repeated bogus negative feedback decreased their acceptance of the feedback information, whereas it did not affect their high self-efficacy perception. They also found that repeated bogus positive feedback clid not increase the self-efficacy of initially low self-efficacy individuals but instead decreased their acceptance of the feedback information.

In summary, much evidence is available that people's performance increases when specific, challenging goals are set and people's self-efficacy and goal commitment remain high (Locke and Latham, 1990). High self-efficacy people react more positively to negative feedback and use better task strategies to attain their goals (Bandura 8 : Cervone, 1983). On the other hand, repeated failure lowers high self-efficacy and/or activates alter= native coping mechanisms like lowering the goal, abandoning commitment to the goal or rejecting (bogus) negative feedback to deal with the gap between actual performance and the goal (Bandura, 1997; Nease, Mudgett \& Quinos, 1999). 
The next section outlines empirical findings concerning feedback and goal setting interventions, focussed on household energy consumption.

\section{STUDIES EXAMINING THE EFFECT OF FEEDBACK AND GOAL SETTING ON ENERGY CONSUMPTION BY HOUSEHOLDS: A BRIEF OVERVIEW}

$\mathrm{M}$ ost of the evaluation studies examining the effect of behavioral interventions on household energy consumption were conducted after the first oil crisis of the 1970 s. The first feedback and goal setting studies conducted in the late 70 s and early 80 s used written feedback. Examples of such written feedback include feedback cards or fliers delivered to the house each day by a research assistant (Bittle, Valeso, Thaler, 1979; Hayes \& Cone, 1977), weekly letters sent to participants (Hayes \& Cone, 1981), plastic numbers in Perspex frames attached to the outside of the kitchen window (Seligman \& Darley, 1977), and feedback sheets taped to the door every day (Katzev, Cooper \& Fisher, 1981). In these early feedback studies, meters were read daily or weekly by, for instance, a technician or a research assistant, and feedback was sometimes combined with other consequent strategies like monetary rewards (Hayes \& Cone, 1981: Midden, Meter, Weenig \& Zieverink, 1983; Winett, Kagel, Battalio \& Winkler, 1978; Winett, Kaiser \& Haberkorn, 1977). Although some of these feedback procedures proved to be very effective, they were too labor-intensive and too expensive for large-scale implementation.

At that time, only two alternatives were available that were less labor- and costintensive, making large-scale adoption more likely. These were less frequent (monthly) feedback and teaching consumers to generate frequent: feedback themselves (i.e., selfmonitoring). However, both strategies proved to be less effective than providing frequent feedback, and an additional disadvantage of self-monitoring proved to be that people may not persist in monitoring their energy consumption in the long run (Intomart, 1993).

The development of electronic feedback devices has opened up new opportunities for cost-effective large-scale implementation of frequent feedback interventions. An electronic feedback device replaces the written feedback messages and removes the need for door-to-door meter reading to provide households with feedback. The results of the first tests of electronic feedback indicators to reduce households' energy consumption have been inconclusive: energy consumption was only affected temporarily (McCleland and Cook, 1979), was only affected in some study groups (Hutton, Mauser, Filiatrault and Ahtola, 1986), or was only shifted from the (more expensive) peak periods to off-peak periods (Sexton, Brown Johnson and Konakayama, 1987).

In contrast with these studies, which lacked an energy savings target, van Houwelingen and van Raaij (1989) tested a device that gave households insight into their actual consumption relative to a consumption target. People were assigned a goal of $10 \%$ reduction in gas consumption relative to the year preceding the intervention. Fifty house- 
holds received an electronic indicator, a device installed in the living room that showed the daily gas used and a daily reference amount of gas that reflected the conservation goal. The reference norm was corrected for the outside temperature, helping residents to distinguish between high energy consumption attributable to cold weather and high energy consumption attributable to their own behavior. The study found that households in the experimental group achieved an average reduction of $12.3 \%$ in gas consumption. Although the electronic indicator thus proved successful, large-scale implementation of the device did not materialize.

The study by van Houwelingen and van Raay (1989) is one of the few examples of studies that combined frequent feedback with goal setting. In most of the studies conducted in the 1970 s and 80 s, people received feedback about their daily or weekly energy consumption compared to a baseline consumption level, without a savings target (Becker \& Seligman, 1978; Bittle, Valesano \& Thaler, 1979; Hayes \& Cone, 1977; Hayes \& Cone, 1981; Houten van, Nau \& Merrigan, 1981; Hutton et al., 1986; Kasulis, Huettner \& Dikeman, 1981; Katzev, Cooper \& Fisher, 1981; McCleland \& Cook, 1979; Palmer, Lloyd \& Lloyd, 1977; Seligman \& Darley, 1977; Sexton et al.,1987). Other studies that also examined the combination of feedback and goal setting were a study by Becker (1978), one by Winett and colleagues (1982) and a study conducted more recently by Brandon \& Lewis (1999). All of these studies found the combination of frequent feedback with a savings target to be effective in reducing household energy consumption by $10 \%$ to $25 \%$.

The studies conducted in the 70 s and 80 s were characterized by their focus on regulating the inside temperature. At that time, most of the energy savings were indeed achievable by reducing the gas or electricity consumption for the purpose of heating (Van Raaij \& van Houwelingen, 1989; Winett et al., 1982) or air conditioning (Becker, 1978). However, as we saw above, the current increase in household energy consumption is mainly caused by the increased use of household appliancesi like microwaves, dryers, personal computers, etc. One study recently focused on the effect of feedback and goal setting on an apparatus level (McCalley \& Midden, 2002). McCalley and Midden investigated the effect of goal setting and feedback on the energy used by washing machines by influencing people's choice of washing programs. People in the goal groups (self-set or assigned goals) received feedback from an energy meter about the average amount of energy used per washing (in kWh). People had to choose a washing program on a simulated control panel of a washing machine and had to conduct a total of twenty washing trials. The study revealed that the goal groups reduced their energy consumption for washing by an average of $20 \%$.

As far as we are aware, no previous studies have examined the effect of feedback and goal setting on electricity consumption for electric appliances in general. Nor have studies been, carried out to examine the effect of feedback and goal setting on household water conservation, even though economical water consumption is of growing importance. 
The present dissertation supplements and extends available studies by describing the effect of feedback and goal setting on household gas, water and electricity consumption for appliances. To contribute to the reduction of household gas, water and electricity consumption, successful interventions have to be implemented on a large scale. Therefore, the next section outlines the diffusion theory developed by Rogers (1995), which illustrates how large-scale implementation takes place.

\section{ROGERS' DIFFUSION THEORY}

ccording to the diffusion theory developed by Rogers (1995), an innovation is an idea,
practice or object that is perceived as new by an individual or another unit of adoption. In his view, therefore, an energy and water conservation intervention can be regarded as an innovation. The diffusion theory describes the process of upscaling from small-scale to widespread implementation. The theory is particularly known for its adopter categories, the idea being that not all individuals in a social system adopt an innovation at the same time. Rogers defines five adopter categories: innovators, early adopters, early majority, late majority and laggards. Reaching the early adopters and the early majority is important for the success of the diffusion process, because people in these categories frequently serve as role models (early adopters) or interact regularly with their peers (early majority). Therefore, the adoption of an innovation follows a bell-shaped curve when the number of people who adopt the innovation is plotted against ume: cilifusion is atrfist'sibw; as there are relatively few innovators and adopters. However, as the early and late majority also start to adopt, the diffusion rate increases fast. The diffusion process slows down when the late majority is reached, which is followed by the hard-to-reach laggards. The adoption of the innovation is described as a process in which the perception of relevant attributes of the innovation affects its adoption rate. Innovations are evaluated on five innovation attributes, which are:

- relative advantage, which is the degree to which an innovation is perceived as being better than the idea it supersedes;

compatibility, which is the degree to which an innovation is perceived as consistent with the existing values, past experience and needs of potential adopters; complexity, which is the degree to which an innovation is perceived as relatively difficult to understand and use;

trialability, which is the degree to which an innovation may be experimented with on a limited basis;

observability, which is the degree to which the results of an innovation are visible to others.

Whereas complexity is negatively related to the adoption rate of an innovation, the other four attributes are positively related to it. Rogers (1995) further concludes that the five 
innovation attributes are relevant to the adoption of all kinds of innovations (although a particular attribute's relevance differs with the nature of the innovation) and seems to assume that all innovation attributes are relevant at the same time. Based on empirical studies, mostly conducted among farmers and schoolteachers, Rogers stated that $49 \%$ to $87 \%$ of the variance in the rate of adoption could be explained by these five attributes.

A few diffusion studies have been conducted in the field of energy conservation. Berkowitz and Haines (1980), Labay and Kinnear (1980), and Warkov (1981) examined the predictive value of the innovation attributes in relation to the adoption of solar heating systems. Consistent with Rogers' diffusion of innovations theory, Berkowitz and Haines and Warkov found that adopters tended to perceive a greater relative advantage of solar heating systems than non-adopters. Berkowitz and Haines and Labay and Kinnear found a positive relationship between the adoption of solar systems and compatibility. Finally, Labay and Kinnear found that adoption was inversely related to complexity.

Darley and Beniger (1981), however, concluded on the basis of a literature review that the five innovation attributes formulated by Rogers are too general to predict the diffusion of energy conservation innovations. Instead of Rogers' concept of relative advantage, they proposed two, more specific sub-dimensions of relative advantage: capital cost of the innovation and perceived savings. Similarly, they subdivided compatibility into attitude and lifestyle compatibility, and added three entirely new attributes: (1) certainty of savings, (2) dissatisfaction with the existing situation, and (3) efforts and skills involved in installing the innovation. Darley and Beniger's ideas, however, have not been tested empirically.

The present dissertation takes a closer look at the relevance of the five innovation attributes in explaining the variation in the intention among policymakers to adopt a successful energy conservation intervention. It also takes a closer look at the process behind the decision to accept or reject a successful energy conservation intervention.

\section{OVERVIEW OF THE STUDIES REPORTED ON IN THIS DISSERTATION}

T he main purposes of the research reported on in this dissertation were (1) to select an intervention that might be implemented on a large scale because it is judged favorably by relevant policymakers (2) to examine the effectiveness of this intervention in reducing household water, electricity and gas consumption, (3) to examine the consequences of goal setting and feedback on cognitions and (energy-relevant) behavior $(4)$ to examine the possible negative effects of repeated negative feedback on cognitions and water and energy saving behaviors, and (5) to shed some light on how responsible policymakers decide to reject or accept an innovative energy conservation intervention.

Four studies were conducted to meet these purposes. The study reported on in chapter two examined the judgment by relevant policymakers of four effective energy 
conservation interventions and the predictive value of the five innovation attributes defined by Rogers (1995) for rejection or acceptation of an innovation, as well as a first test of a refinement of the decision process for rejecting or accepting innovative energy conservation interventions. Chapters three and four describe studies that examined the effectiveness of various electronic devices providing personal feedback in combination with goal setting to households about their energy consumption (chapters three and four) and water consumption (chapter four). Furthermore, the studies reported in these chapters investigated the relationship between (changes in) self-reported specific saving activities and (changes in) objective consumption. Chapter five describes a study that examined the effects of repeated negative feedback on cognitions and performance. What follows below is a brief description of the results and conclusions from these studies.

\section{Study 1: Innovating "Diffusion of innovation" theory: innovation characteristics and the intention of utility companies to adopt energy conservation interven- tions}

This study examined which of four selected energy conservation interventions might be widely employed because of a favorable judgment by policymakers. Also, the value of compatibility, trialability, complexity and advantage in predicting adoption intentions were examined, and a first test was conducted of some refinements to Rogers' theory, proposed by Darley \& Beniger (1981). The predictive value of 'observability' was not investigated, because observability of the innovation results was considered mainly relevant at the level of the end-user. We furthermore studied the predictive value of 'advantage' instead of 'relative advantage' because there usually were no ongoing energy saving interventions where policy makers could base their judgment of relative advantage on. Finally, the study examined whether the assessment of innovation attributes is a stepwise process: it was hypothesized that not all innovation attributes are relevant at the same time in the decision process and that potential adopters use a non-compensative decision rule to judge an energy conservation intervention on its attributes. Policymakers were expected. to be first of all interested in the relative advantage (like the cost-effectiveness) of an energy conservation intervention. If this relative advantage reaches a minimum cut-off value, the next step would involve judging the intervention on the degree of compatibility.

To examine these issues, foụ successfụl energy conservation interventions were selected from a literature review, revealing 35 relevant studies in household settings and 22 relevant studies in non-residential buildings and retail trade settings. These studies were evaluated on the following five criteria: (1) the design of the evaluation study had to be adequate: preferably a pretest-posttest design with a control group, (2) the innovation at hand should not already have been implemented on a large scale in the Netherlands, (3) preference was given to innovations that had proven to be effective in more than one study, (4) the utility companies (or comparable organizations) had to be able to play a key role in the diffusion of the intervention, and (5) there had to be an indication that large- 
scale implementation of the intervention was cost-effective.

The selected interventions were: (1) load management for washing machines, which means that a washing program can only be started during off-peak periods; (2) electronic feedback on household energy consumption combined with goal-setting (the "electronic indicator"); (3) a community-based communication intervention aimed at stimulating the adoption of insulation and energy saving behavior; and (4) personalized advice on energy savings given to the retail trade by a consultant of the utility companies.

A brief description of these interventions was sent to 41 coordinators of the Environmental Action Plan of the Dutch energy distribution companies, the persons who had to decide, for instance, whether a particular energy conservation innovation would be offered to households. They gave their opinion in face-to-face interviews and structured questionnaires.

Of the 42 coordinators of the Environmental Action Plan, 41 agreed to participate in this study. The results showed that $38 \%$ of the coordinators were moderate to very positive about adopting load management for washing machines and $48 \%$ of the coordinators had a moderately to highly positive intention to adopt the electronic indicator. Scores on the adoption of the community project and personalized advice to the retail trade were $40 \%$ and $32 \%$, respectively.

Furthermore, it was found for three of the four energy conservation interventions (not for personalized advice to the retail trade) that the greater the compatibility of the intervention was judged to be, the greater the intention to adopt the intervention. Likewise, we found that the greater the perceived advantage, the greater the intention to adopt the electronic indicator, whereas lower complexity correlated with greater intention to adopt load management for washing machines.

Furthermore, in line with the proposed stepwise process, we found that for two of the four innovations, potential adopters were initialiy interested in the (relative) advantage of an innovation. Only when advantage was considered sufficiently high, did they seem to proceed with evaluating the intervention on compatibility. When the advantages of the intervention were considered minor, they rejected the innovation on the basis of this attribute alone.

Furthermore, $34 \%$ of the coordinators were afraid that in the long term, households would cease to pay attention to the electronic indicator. From this outcome it was concluded that supplementing the five innovation attributes with an additional attribute, "certainty of savings", seems relevant. It was concluded from the interviews that specification of the type of cost (e.g., high initial cost, cost effectiveness, etc.) also seems worthwhile to increase the predictive value of the innovation attributes.

The overall conclusions are (1) that compatibility is the most general predictor of the intention to adopt an energy saving innovation, and (2) that the capability of the innovation attributes to predict the intention to adopt an energy conservation intervention 
could be enhanced by (a) adding specific innovation attributes like "certainty of savings" and (b) regarding the evaluation of the innovation attributes as a stepwise decision process.

\section{Study 2: The effect of a prepayment meter on residential gas consumption}

In the second study we examined the effect of a prepayment meter as a feedback instrument to inform households about their gas consumption. The prepayment meter required households to pay for their gas as they used it, and people could press a button beside the display on the front of the meter to check the amount of credit left, the emergency credit and the price of gas per $\mathrm{m}^{3}$. Additionally they could see the cumulative amount of gas used.. The prepayment meter warned households by means of a beeping signal if their credit was almost zero. The prepayment meter used in the present study was charged by means of a smartcard that could be recharged at the local supermarket.

In contrast with previous feedback and goal setting interventions, the prepayment meter project was initiated by an umbrella organization of the utility companies, in association with a specific utility company that would be responsible for the trial. The fact that the project was an initiative of the utility companies (and not of scientists or the government) was expected to improve the diffusion of this innovation, should it prove successful.

This study examined the effect of prepayment gas meters as a feedback instrument on household gas consumption, as well as the level of satisfaction with the meter and its effect on behavioral determinants of gas consumption reducing activities. Since it was expected that the prepayment meter alone without a reference use would provide meaningless feedback, half of the participants were asked to set a personal savings target of $5 \%, 10 \%$ or $15 \%$. Household's who had set such a savings target received a notebook to compare their target gas consumption per degree-day with their actual gas consumption per degree-day. The term "degree-day" was introduced as a quantitative indication of the level of heating needed on a particular day with a particular outdoor temperature, one degree-day being a downward deviation of the average outside daytime temperature from $18^{\circ} \mathrm{C}$ by one degree. Participants hadl to calculate their actual gas consumption per degree-day themselves and had to contact the utility company by phone to find out the degree-days. The participants to this project were people who renteci or owned houses at a new housing development in a Dutch village. Most of the houses were apartment blocks or duplex houses. After stratification for income (low, average, and high), households were randomly assigned to one of the two intervention groups (with or without a notebook) or to the control group. The final sample for this study consisted of 116 households, divided over three groups: households with a prepayment meter and a notebook, households with only a prepayment meter, and a control group. It was found that households with a prepayment meter reduced their gas consumption by $4.7 \%$ relative to the control group. A reduction effect of $4.7 \%$ is comparable to that of self-monitoring of energy consump- 
tion (Hayes \& Cone, 1981). However, people may not persist in monitoring their energy consumption in the long run (Intomart, 1993). A prepayment meter forces them to persist in monitoring to secure gas provision, so in the long run a prepayment meter might have a greater effect on gas consumption.

The notebook, allowing a comparison between actual gas consumption and target consumption, did not lead to greater reductions in gas consumption than the prepayment meter alone. Perhaps filling out the tables of the notebook each time before charging was too laborious and calculating current gas consumption per degree-day was too complex. It was also found that the households (who had participated voluntarily) were satisfied with the prepayment meter, and that the perceived disadvantages tended to decrease over time, which seems promising for the public acceptance of a prepayment meter system. The reduction effect of the prepayment meter might improve if the meter allowed actual consumption to be compared with a goal (corrected for the outdoor temperature).

Finally, we found that changes in the attitude toward engaging in gas saving activities were positively related to changes in objective gas conservation, whereas changes in specific gas consumption reducing activities were not significantly related to objective changes in gas conservation. One explanation is that people find it easier to report attitudes than to report actual performance for gas, since behavior requires retrospective assessment of past behavior, whereas a question about one's attitude is an introspective question. Another explanation is that we may not have measured the right specific gas saving activities.

\section{Study 3: Goal-setting and feedback for a sustainable future: an intervention to reduce household water and energy consumption}

This study examined the gas, electricity and water saving effect of five TV information pages providing weekly feedback on household energy and water consumption related to a self-set goal. Furthermore, it assessed the relationship between objective energy and water savings and changes in specific gas, electricity and water saving activities.

The study used a pretest-posttest design with three groups; an experimental group, a waiting-list control group from the same district, and a comparable additional control group from another district. The households from the experimental and waitinglist control groups were all homeowners living in the same energy-efficient new housing development in a Dutch village. A total of 62 houses were randomly assigned to an experimental group or a waiting-list control group. The additional control group consisted of 22 households living in a comparable new housing development. The reason for using the additional control group was that we wanted to take into account the possibility that households in the waiting-list control group became motivated to save water and energy by the information they received about the electronic feedback project, leading to test effects.

Energy and water consumption data were gathered from meter readings, where- 
as structured questionnaires were used to examine changes in specific energy and water saving activities.

Our study revealed that the information pages were effective in reducing household water and electricity consumption. A comparison of the experimental group with the waiting-list control group revealed reductions of $15 \%$ for water consumption and $22 \%$ for electricity consumption in the experimental group. No significant differences between the experimental and waiting-list control groups were found for changes in gas consumption. A comparison of the experimental group with the additional control group showed reductions of $15 \%$ in water consumption, $11 \%$ in electricity consumption and $25 \%$ in gas consumption in the experimental group.

Furthermore, the results gave some further insights into changes in gas consumption reducing activities and the type of activities households are willing to change to reduce their electricity and water consumption. Households reported that they had turned back the thermostat to $15^{\circ} \mathrm{C}$ one hour before bedtime and turned off the radiator after taking a bath or shower more consistently during the intervention than they had done before the start of the intervention. Furthermore, people seemed willing to use appliances efficiently but were less inclined to use their appliances selectively. For example, the respondents reported that they were very consistent in turning on the dishwasher only when it was fully loaded, but they also reported that they almost never did the dishes by hand instead of using the dishwasher. It seems that changing daily patterns in response to goal setting and feedback is limited to behavioral patterns that do not interrupt the performance of daily activities and that do not decrease convenience and comfort.

This study proved the effectiveness of feedback and goal setting in reducing household water and electricity use. The effectiveness of the TV information system in reducing household gas consumption was somewhat less clear. The absence of a significant reduction effect in household gas consumption between the experimental and waitinglist control groups may have been due to test effects in the waiting-list control group (for example, because they filled out the questionnaires). Another explanation may be that previous energy saving interventions had mainly focused on regulating the inside temperature. This may have made it relatively difficult for the participants to further reduce their gas consumption, because there was little room left for improvement. This seems plausible since reduction of gas consumption has already received much attention in the Netherlands compared to the reduction of household water and electricity consumption. Nevertheless, the experimental group did reduce their gas consumption substantially compared to the additional control group. This study also gave some insight into the specific daily activities which people will or will not change to attain their conservation target. 


\section{Study 4: Effects of repeated negative feedback on behavioral and cognitive factors in an intervention to motivate energy and water conservation by house- holds}

The main aim of this study was to examine the effect of repeated negative feedback on people's cognitions and the energy and water consumption reductions they achieved, after 14 and 26 weeks of feedback. We expected that repeated negative feedback. would negatively affect people's self-efficacy, success expectancy, goal commitment and motivation to attain their target. Furthermore, we expected that when negative feedback continued, it could also affect people's performances. This study used the data from the experimental group of the field study described in chapter three. We gathered the necessary data for this group and examined the association between the number of times people had received negative feedback and their cognitive and behavioral reactions.

Results showed that the number of times households received negative feedback negatively affected their self-efficacy and success expectancy after 14 and 26 weeks of feedback (confirmed for water and electricity). Furthermore, analyses revealed that the number of times households received negative feedback negatively affected their goal commitment after 14 weeks (confirmed for water) and after 26 weeks of feedback (confirmed for water and gas). The number of times households received negative feedback did not affect changes in their consumption levels after 14 weeks of feedback. However, in the long run (after 26 weeks of feedback) the number of times they received negative feedback did negatively affect the reduction in water and gas consumption they achieved, as expected. In addition, analyses revealed that the relations between repeated negative feedback and sbanogs in housebold ronsumntion levels were not mediated hy the roanitive factors examined in this study (i.e., changes in self-efficacy, success expectancy, goal commitment and motivation to attain a goal).

These results show that repeated negative feedback may unfavorably affect people's cognitions and performances. First, repeated negative feedback seems to affect people's self-efficacy, success expectancy and commitment to the goal. Then, when negative feedback continues over a longer period of time, it may also decrease people's performances. These consequences of repeated negative feedback may be specifically related to the setting of our study, since, unlike most studies referred to by Locke and Latham (1990), we used a non-hierarchical and non-competitive setting. 


\section{MAIN CONCLUSIONS}

The above section gave a brief overview of the studies described in this dissertation. The major findings of these studies can be summarized by answering seven questions:

(1) Which intervention might be widely employed because relevant policymakers judge it favorably?

The results of study one (see chapter two) showed that policymakers in the utility companies were most positive about large-scale adoption of the electronic indicator: $48 \%$ of the coordinators were positive about adopting an electronic feedback intervention in the near future. However, the policymakers still had their doubts about the feasibility of largescale implementation, because of the expected high initial costs and uncertainty about the long-term effects. We ourselves doubted whether feedback and goal setting could still contribute to reducing household energy conservation at a time when most houses are well insulated and much attention has already been paid (at least in the Netherlands) to energy saving activities. Based on these results, we decided to examine the effects of electronic feedback and goal setting on household water, gas and electricity consumption in the present situation and in the short and the long term.

(2) Are the innovation attributes defined by Rogers (1995) strong predictors of the adoption of successful energy conservation interventions by policymakers?

According to Rogers, relative advantage, compatibility, observability, trialability and complexity affect the adoption rate of an innovation. In our study we found that compatibility was the strongest predictor of the intention to adopt energy conservation interventions. Relative advantage was only a significant predictor of the intention to adopt the electronic indicator, while complexity was only a significant predictor of the intention to adopt the "load management for washing machines" intervention. Supplementary to Rogers' five attributes, we found that an additional attribute, defined as certainty of savings, was also relevant in the assessment of the electronic indicator, which means that policymakers doubted the long-term effects of the electronic indicator. We also found that financial costs, mentioned by Rogers as one of the sub-dimensions of relative advantage, is a very broad dimension and specification of the type of cost might increase the predictive value of relative advantage.

\section{(3) Is the decision to adopt on innovation a stepwise process?}

Earlier diffusion researchers have worked on the assumption that all innovation attributes are relevant at the same time. According to this assumption, policymakers who are exposed to a new energy conservation intervention assess the innovation on its relative advantage, compatibility, complexity, trialability and observability before they express an opinion. However, we argued that rejecting an innovation could be based on one single in- 
novation attribute that is perceived as the most important and does not meet a standard. This would mean that not all innovation attributes are relevant at the same time, and that judging an innovation on its attributes is a stepwise process. An innovation might first be judged on its relative advantage. If this relative advantage over the intervention it replaces proves too small, the innovation is rejected. Only if the relative advantage is large enough, will potential users judge the innovation on the next innovation attribute, and so on.

The results of our first study did indeed show that judging an innovation (i.e, an energy conservation intervention) on the five attributes defined by Rogers (1995) might be a stepwise process. They confirmed our assumption that an energy conservation intervention is rejected or adopted by relevant policymakers following a conjunctive decision rule, which means that a decision-maker defines a minimum cut-off point for each attribute.Some evidence was found that an energy conservation intervention was first judged on its relative advantage. If the relative advantage was perceived as minor, the evaluation process stopped and the intervention was rejected, whereas if the advantage was perceived as sufficiently great, the evaluation process was continued for compatibility.

These findings supplement Rogers' diffusion theory by showing that not all innovation attributes are relevant at the same time, that is, evaluation of the innovation attributes may take place step-by-step. This finding has not only theoretical, but also practical implications. Practitioners who try to promote the diffusion of a particular innovation should realize that certain attributes are more relevant than others at a particular stage and, for example start by convincing potential adopters of the advantage of an innovation.

(4) Are goal setting and feedback effective in reducing household water consumption? This question had our special interest in the third study (see chapter four) because the effect of feedback and goal setting on household water consumption had, to our knowledge, never been examined before. We found that the TV information system we used was very effective in reducing household water consumption. Households in the experimental group reduced their water consumption by $15 \%$ compared to a waiting-list control group and an additional control group. This reduction effect persisted during the one-year intervention period.

(5) Are goal setting and feedback effective in reducing household gas and electricity consumption?

In the 1970s and 1980s, the effect of the use of feedback with or without goal setting on household energy consumption was examined in terms of the regulation of the inside temperature. Today, it is environmental concerns that make energy conservation necessary, not the threat of politically motivated oil supply cutoffs and rapidly escalating prices, as in the 1970s. Furthermore, at that time energy conservation was a relatively new concept, whereas nowadays gas consumption by individual households has already de- 
creased substantially, particularly through better insulation. Before our study, we doubted whether the success of previous feedback and goal setting interventions to reduce energy consumption would still hold nowadays. Therefore, firstly we were interested to see whether or not feedback and goal setting could still contribute to reducing household gas consumption.

Secondly, we were interested in the effect of outcome feedback and goal setting on household electricity consumption. In the Netherlands, electricity is not usually used for heating, but only for lighting and household appliances like washing machines and stereos. Little is known about the effects of goal setting and feedback on electricity consumption for such applications, and this is of increasing relevance, as there is a tendency towards increasing household electricity consumption by the large-scale use of dryers, dishwashers, etc. The study described in chapter four found that the TV information system successfully reduced household electricity consumption by $22 \%$. The studies described in chapters three and four both examined the effect of feedback (with and without goal setting) on household gas consumption. The results of these studies showed that reducing household gas consumption by means of feedback and goal setting is difficult. Feedback by means of a prepayment meter (as described in chapter three) reduced household gas consumption by only $4.7 \%$, whereas the effects of the TV information system on household gas consumption (chapter four) were not consistent. In the latter study, households in the experimental group reduced their gas consumption by $25 \%$ relative to the additional control group, but comparison of changes in gas consumption between the experimental group and the waiting-list control group revealed no significant difference. One of the explanations might be that there is little room left for reduction in gas consumption, since households have already paid much attention to economizing on household gas consumption through the regulation of the inside temperature, by means of insulation and behavior change.

In summary; goal setting and feedback seem to constitute an effective way to reduce electricity and water consumption, and perhaps also gas consumption. The intervention described in chapter 4 (the TV information system) seems quite effective as it is, while the intervention described in chapter 3 (the prepayment meter) would probably be more effective if it were slightly changed (allowing correction for outdoor temperature and goal comparison). What is more, the interventions we examined fulfill two important criteria for large-scale implementation: policymakers showed an interest in large-scale implementation of a feedback and goal setting intervention, and the responses of the participating households to the information system and the prepayment meter were very positive. Therefore, these interventions might indeed be implemented on a large scale and contribute substantially to the reduction of household water, electricity and gas consumption (and hence to $\mathrm{CO}_{2}$ emission reduction).

(6) Is there a relationship between changes in objective gas, electricity and water consumption 
and changes in reported specific gas, electricity and water reducing activities and cognitions? This dissertation complements previous studies about the effect of feedback and goal setting on household energy use by examining the relation between changes in objective energy or water consumption and changes in reported specific energy and water reducing activities and cognitions. The studies described in chapters three and four systematically measured changes in relevant water and energy saving activities. On a behavioral level, the study described in chapter four revealed that reductions in household gas consumption could be partly explained by more consistent lowering of thermostat settings to $15^{\circ} \mathrm{C}$ one hour before bedtime and turning off the radiator after taking a bath or shower. These results were not confirmed by the study described in chapter three. Although the qualitative data of the study described in chapter four provide no clear insights as to which specific daily activities households changed to reduce their electricity and water consumption, some clues were provided by the face-to-face interviews, like limiting the use of a solarium and less frequently sprinkling the garden. Participants also told that the information system had made them just that little more alert to consistent performance of daily energy and water saving behaviors. It may be the sum of these small effects which has resulted in the reported reduction effects. In goal setting terminology, these results confirmed at least two of the mechanisms that are brought about by difficult goal setting according to Locke and Latham (1990): (1) people invested more effort in implementing well established energy and water saving activities, and (2) people searched for new strategies to attain their energy and water savings targets.

In summary, studies two and three (chapters three and four) revealed that although we have gained some insight into changes in specific activities to reduce energy and water consumption, it remains very difficult to find out which precise activities people changed to attain their reduction goals. This could actually be the greatest advantage of goal setting and feedback: people are free to choose which behavioral changes they are willing or able to adopt.

Our second study provided some suggestions as to which changes in cognitions are related to changes in objective gas use. The results showed that changes in objective gas consumption were related to attitude changes about engaging in gas-saving activities. This is in line with the findings of a study conducted by Brandon and Lewis (1999). They compared different types of feedback in households and found that attitudes towards the environment were related (although only marginally significant) to objective changes in energy consumption during the feedback intervention.

(7) Does repeated negative feedback negatively affect energy and water related cognitions and savings?

Our fourth study investigated the effects of the number of times people received negative feedback on their cognitions and savings. Some evidence was found that the more often negative feedback was received, the more people's self-efficacy, success expectancy and 
goal commitment decreased. In the long run, the number of times people received negative feedback also negatively affected their reduction in consumption (confirmed for gas and water). We conclude that repeated negative feedback may activate other mechanisms to deal with the gap between actual performance and the target. Instead of increasing their efforts, people may lose commitment to their goal when they are exposed to failure too many times. This may be specifically true for situations where people have the opportunity to lose commitment to their goal, as in the case of voluntary goal setting related to aspects like losing weight, engaging in volunteer work or contributing to a sustainable environment. In such situations, one should be careful not to set goals too high, as very high goals usually lead to repeated negative feedback.

This dissertation has clear practical and theoretical implications. In practical terms, its main implication is that TV information system providing households with weekly feedback about their water, electricity and gas consumption (compared to a target consumption level) can reduce household water, electricity and (maybe) gas consumption. Our results look very promising, as reductions from 10 to $25 \%$ were found, which may be considered substantial. Given these positive results and given that the most important conditions for wide-scale use seem to be met, electronic feedback and goal setting interventions may considerably contribute to the solution of environmental problems like the greenhouse effect and the shortage of clean drinking water in the near future.

The main theoretical implication of this dissertation is that innovation attributes (e.g., relative advantage, compatibility) are not evaluated simultaneously, but one-by-one. This contribution to Rogers' (1995) diffusion of innovation theory deserves more research because of its practical as well as theoretical significance. 
CHAPTER TWO

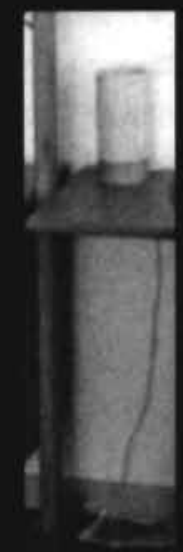


Innovating "Diffusion of Innovation" Theory:

Innovation Characteristles And The Intention Of Utility Companies

To Adopt Energy Conservation Interventions

Published (with minor adaptations) as:

Meertens, R., Völlink, T., \& Midden, CJ.H. (2002). Innovating "diffusion of innovation" theory: Innovation characteristics and the intention of utility companies to adopt energy conservation interventions. Journal of Environmental Psychology، 22, 333-344. 


\section{INTRODUCTION}

T he increasing use of fosșil fuels is causing environmental problems on a global, na. tional and local level. The burning of fossil fuel contributes to the emission of carbon dioxide $\left(\mathrm{CO}_{2}\right)$, the most important cause of the so-called greenhouse effect, leading to global warming. In addition, smog and acid rain are relatively local consequences of burning fossil fuel. In 1997, industrial countries agreed to reduce their $\mathrm{CO}_{2}$ emission by $5 \%$ over the period from 2008 to 2012, compared to the $\mathrm{CO}_{2}$ emission level of 1990 (Ellerman, Jacoby $\&$ Deceaux, 1998). In the short term, governments are attempting to reduce the emission of $\mathrm{CO}_{2}$ by promoting energy conservation.

Although results of evaluation studies conducted after the first oil crisis made it clear that psychological strategies can contribute to the reduction of energy use (Baum \& Singer, 1981; Cherulnik, 1993; Cook \& Berrenberg, 1981; Dwyer, Leeming, Cobern, Porter \& Jackson, 1993; Geller, 1989; McDougall, Gordon, Claxton, Ritchie \& Anderson, 1981; Seligman \& Hutton, 1981; Winett \& Neale, 1979; Kempton, Darley \& Stern, 1992) widespread use of such interventions has failed to occur. A proven record of effectiveness therefore seems to be no guarantee that these interventions will be widely employed. As might have been expected, neither consumers nor responsible policymakers seem to use or adopt successful interventions automatically.

In this paper we examine which innovation characteristics are relevant to the responsible policymaker's intention to adopt energy conservation interventions. We furthermore propose that deciding about the adoption of an intervention is a stepwise process, and we provide a first empirical test of this idea.

The process of upscaling interventions from small-scale to widespread use can be conceptualized as the "diffusion of an innovation." Rogers (1995) defines an innovation as an idea, practice or object that is perceived as new by an individual or another unit of adoption. According to Rogers (1995), the decision to adopt or reject an innovation is affected by five innovation attributes: observability, relative advantage, compatibility, trialability and complexity. The first four of these attributes are positively related to the rate of adoption, while complexity is asserted to be inversely related to the adoption rate of an innovation (Rogers, 1995).

The observability of an innovation is the degree to which the results of an innovation are visible to potential adopters. The relative advantage of an innovation is the degree. to which an innovation is perceived as being superior to current practice or to the interventions it replaces. The compatibility of an innovation is the degree to which an innovation is perceived to be consistent with social-cultural values and beliefs, previously introduced ideas and/or perceived needs. Trialability is the degree to which an innovation can be experimented with on a limited basis. Complexity' is defined by Rogers as the degree to which an innovation is difficult to use and understand. Rogers' ideas on the diffusion of innovations have had a tremendous impact on the field, and have placed diffusion theory 
in the spotlight in a variety of disciplines, like marketing, psychology and communication sciences.

Darley and Beniger (1981), however, concluded on the basis of a literature review that the five innovation attributes formulated by Rogers (1995) are too general to predict the diffusion of energy conservation innovations. Instead of Rogers' concept of relative advantage, they proposed two, more specific sub-dimensions: capital cost of the innovation, and perceived savings. Similarly, they subdivided compatibility into attitude and lifestyle compatibility. Furthermore, they added three entirely new attributes: 1) certainty of savings, 2) dissatisfaction with the existing situation, and 3) efforts and skills involved in installing the innovation. Darley and Beniger's ideas, however, have not been tested empirically. The present study investigated qualitatively whether Darley and Beniger's modifications of, and extensions to, Rogers' theory are useful alterations.

Previous research on the capacity of perceived innovation attributes to predict the adoption of energy conservation innovations is limited to three studies on end users. Berkowitz \& Haines (1980), Labay \& Kinnear (1980) and Warkov (1981) examined the predictive value of innovation attributes in relation to the adoption of solar heating systems. Consistent with the diffusion of innovation theory (Rogers, 1995), Berkowitz \& Haines and Warkov found that adopters tended to perceive a greater relative advantage in solar heating systems than non-adopters. Berkowitz \& Haines and Labay \& Kinnear found a positive relationship between the adoption of solar systems and compatibility. Finally, Labay \& Kinnear found that adoption was inversely related to complexity.

A common element in these earlier studies (as in many studies on Rogers' theory, see Tornatzky and Klein, 1982) is that the dependent variable (adoption of a solar system) is measured in the recent past, while the independent variables (the innovation attributes) are measured in the present. In such studies, ratings of innovation attributes may have been biased by the decision to adopt. In the present study we opteci for a different approach and first measured the adoption variables. The intention to adopt the innovation in the near future was used as the main dependent variable.

According to Rogers (1995), 49 to 87 percent of the variance in the adoption rate is explained by observability, relative advantage, compatibility, trialability and complexity. He assumes that the relative importance of the attributes differs with the nature of the innovation, although he remains rather vague about the decision rules behind the assessment of the five attributes.

If people are indeed, as Fiske and Taylor (1991) put it, "cognitive misers", striving towards relatively simple and heuristic methods of decision making, it seems very plausible that not all innovation attributes are rated before making the decision to reject or adopt an innovation. For instance, although an adoption decision might be based on an assessment of all innovation attributes, the decision to reject an innovation might be based on less information processing (e.g. why bother about trialability when the relative advantage of the innovation is not very obvious). 
We hypothesized that the decision to adopt an energy conserving innovation is a stepwise process, in which a conjunctive decision rule is applied. The use of a conjunctive decision rule implies that a decision-maker is supposed to define minimum cut-off points for each attribute. If an alternative does not exceed the cut-off point for one or more of the attributes, its adoption will be rejected. In this model, high values for one attribute cannot compensate for a below cut-off value for another attribute (Bettman, 1979). We assumed that not all the attributes are relevant to the potential adopter at the same time, so that the conjunctive decision rule is applied to one innovation attribute at a time. The decision process was presumed to stop as soon as a relevant innovation characteristic is rated as not reaching the minimum cut-off value (decision: no adoption), or when all innovation attributes have scored at least the minimum cut-off values (decision: adoption). Inherent to the goal of an energy conservation innovation, it was hypothesized that co-ordinators are above all interested in relative advantage (like the cost-effectiveness) of an innovation. In a second step, an energy conservation innovation would be judged on its cmpatibility with the existing structure. Figure 1 shows the stepwise model we proposed.

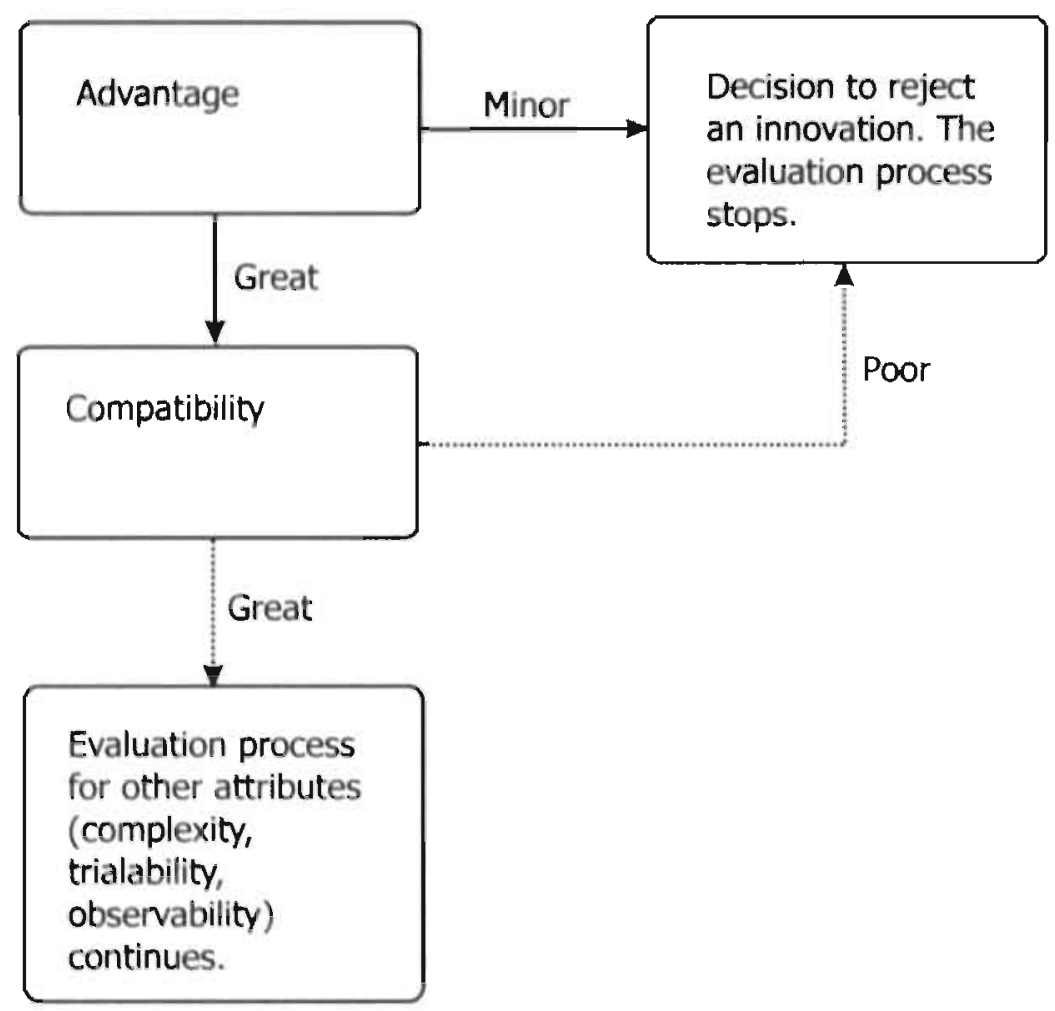

Figure 1 Stepwise process of assessing an innovation on its attributes 
In summary, the research goals of the present study were as follows. First, we wanted to assess the relative ability of the innovation attributes to predict the intention to adopt a particular energy conservation intervention. Secondly, the stepwise nature of the evaluation of innovations (Figure 1) will be explored in more detail. Finally, we investigated whether there was any support for the modifications and extensions of the innovation attributes proposed by Darley and Beniger (1981).

\section{METHOD}

\section{Participants}

It is only when energy conservation interventions are made available to the public by policy makers that they can contribute to the energy conservation policy. Dutch energy distribution companies have agreed to make a substantial contribution to the energy conservation policy. So-called 'co-ordinators of Environmental Action Plans' have a key position in these organizations, and have to decide, for example, whether a certain energy conservation innovation will be offered to households. Thus, before the diffusion of innovations among end-users is at stake, an innovation should be adopted by these co-ordinators of environmental action plans. At the time of our study, there were 42 different energy distribution companies in the Netherlands. All 42 co-ordinators of the Environmental Action Plan were asked to participate in our study.

\section{Selection of successful energy conservation interventions}

The selection of successful energy conservation interventions was based on a literature study, which revealed 35 relevant studies in household settings and 22 relevant studies in non-residential building and retail trade settings (Völlink, 1995; Völlink \& Meertens, 1997; Völlink \& Meertens, 2004). These studies were evaluated on the following five criteria: (1) the design of the evaluation study had to be adequate: preferably a pretest-posttest design with a control group, (2) the innovation at hand should not already have been implemented on a large scale in the Netherlands, (3) preference was given to innovations that had proven to be effective in more than one study, (4) the utility companies (or comparable organizations) had to be able to play a key role in the diffusion of the intervention, and (5) there had to be an indication that large-scale implementation of the intervention was cost-effective.

As far as the information was available, the interventions were compared on the basis of these criteria for each sector separately (households, non-residential buildings and retail trade). Table 1 shows the interventions that were finally selected. 


\section{Instruments}

Data were collected by means of face-to-face interviews and questionnaires. The interviews started with general questions (1) about the company's current energy saving policy, (2) about the interventions the co-ordinators used, (3) about the target population(s) that was/ were given priority, and (4) about whether the four energy conservation interventions were compatible with the co-ordinators' current energy conservation policy. After this general section, the following questions were asked about the four energy conservation interventions selected: (1) "Have you heard about this energy conservation intervention before?" (2) "Do you think this energy conservation intervention is relevant to your organization?" (3) "In your opinion, what are the most relevant advantages and disadvantages of this intervention?" (4) "Do you think that it is possible to implement this intervention?:"These yes-or-no questions were followed by open-ended questions allowing the respondent to explain his answers in more detail.

The structured questionnaire was based on diffusion theory (Darley \& Beniger, 1981; Leonard-Barton, 1988; Rogers, 1995), and had been pretested carefully among four policymakers working in energy distribution companies. There are no general or agreed innovation attributes scales, and researchers agree that operationalisations should differ for different innovations (Rogers, 1995; Zaltman, Duncan \& Holbeck, 1984). The questions in our questionnaire were therefore adapted from other studies to fit in with the innovations investigated in the present study.

In line with Darley and Beniger (1981), we excluded the concept of relative from our operationalisations since most utility companies had only just started with energy conservation policy. Advantage was measured using a two-item scale, containing the following statements (1) "This intervention is an effective instrument to save energy" and (2) "The performance costs of this intervention are too high". The three-item compatibility scale consisted of the following items (1) "This intervention is very consistent with our organization's energy conservation objectives", (2) "This intervention is highly compatible with our ideas about successful strategies to stimulate energy saving for that specific target group", and (3) "This intervention combines very well with other energy conservation interventions already being implemented". Trialability was measured directly by the following item: "This intervention is very easy to introduce on al small scale".

According to Leonard-Barton (1988), implementation complexity within an organization should be measured in terms of the number of people whose jobs would be affected, or the number of separate functional units that would be affected. Therefore our study measured complexity by a two-item scale that consisted of the following statements (1) this intervention will increase the workload for colleagues to an unacceptable level and (2) the widespread use of this intervention will lead to unacceptable co-ordination problems.

Observability of the outcomes of an innovation was not measured, because observability of the innovation results (e.g. the installation of an electronic indicator) is 


\section{Instruments}

Data were collected by means of face-to-face interviews and questionnaires. The interviews started with general questions (1) about the company's current energy saving policy, (2) about the interventions the co-ordinators used, (3) about the target. population(s) that was/ were given priority, and (4) about whether the four energy conservation interventions were compatible with the co-ordinators' current energy conservation policy. After this general section, the following questions were asked about the four energy conservation interventions selected: (1) "Have you heard about this energy conservation intervention before?" (2) "Do you think this energy conservation intervention is relevant to your organization?" (3) "In your opinion, what are the most relevant advantages and disadvantages of this intervention?" (4) "Do you think that it is possible to implement this intervention?"These yes-or-no questions were followed by open-ended questions allowing the respondent to explain his answers in more detail.

The structured questionnaire was based on diffusion theory (Darley \& Beniger: 1981; Leonard-Barton, 1988; Rogers, 1995), and had been pretested carefully among four policymakers working in energy distribution companies. There are no general or agreed innovation attributes scales, and researchers agree that operationalisations should differ for different innovations (Rogers, 1995; Zaltman, Duncan \& Holbeck, 1984). The questions in our questionnaire were therefore adapted from other studies to fit in with the innovations investigated in the present study.

In line with Darley and Beniger (1981), we excluded the concept of relative from our operationalisations since most utility companies had only just started with energy conservation policy. Advantage was measured using a two-item scale, containing the following statements (1) "This intervention is an effective instrument to save energy" and (2) "The performance costs of this intervention are too high". The three-itern compatibility scale consisted of the following items (1) "This intervention is very consistent with our organization's energy conservation objectives", (2) "This intervention is highly compatible with our ideas about successful strategies to stimulate energy saving for that specific target group", and (3) "This intervention combines very well with other energy conservation interventions already being implemented. Trialability was measured directly by the following item: "This intervention is very easy to introduce on a small scale".

According to Leonard-Barton (1988), implementation complexity within ar: organization should be measured in terms of the number of people whose jobs would be affected, or the number of separate functional units that would be affected. Therefore our study measured complexity by a two-item scale that consisted of the following statements (1) this intervention will increase the workload for colleagues to an unacceptable level and (2) the widespread use of this intervention will lead to unacceptable co-ordination problems.

Observability of the outcomes of an innovation was not measured, because observability of the innovation results (e.g. the installation of an electronic indicator) is 
mainly relevant at the level of the end-user.

Each item had five response categories, with values ranging from 1 (strongly disagree) to 5 (strongly agree). For each attribute, item responses were recorded when necessary, summed and then divided by the number of items. The intention to adopt an energy conservation intervention was measured by the following question: "Do you think this energy conservation intervention will be implemented in the future in your organization?"This item had also five response categories ranging from 1 (very sure) to 5 , (surely not).

\section{Internal consistency}

The correlations between the two items of the advantage scale varied from $r=.47 ; p$ $<.05$ (intervention 1) to $r=.59 ; p<.05$ (intervention 4) and those for the complexity scale from $r=.43 ; p<0.05$ (intervention 1) to $r=.81 ; p<.05$ (intervention 3). Cronbach's Alpha for the compatibility scale varied from .73 (intervention 4) to .88 (intervention 3). In general, internal consistency was considered satisfactory.

\section{RESUlts}

\section{Participation and intention to adopt the interventions}

In total 41 of the 42 (98\%) co-ordinators of the Environmental Action Plan agreed to participate in this study, and thirty-five participated in all parts of the study (83\%). The results showed that in total $38 \%$ of the co-ordinators had a moderate to very positive intention to adopt the intervention "load management for washing machines" and $48 \%$ of the co-ordinators had a moderate to very positive intention to adopt the electronic inclicator. Concerning the adoption of the community project and a personalized advice to retail trade these scores were respectively $40 \%$ and $32 \%$. Thus, in this study the electronic indicator came out best.

\section{Structured questionnaires}

Although we had tried to select only interventions that were not widely used, it was found that some companies or co-ordinators had already implemented one of the interventions. If this was the case, the co-ordinator was not included in the analyses for that specific intervention. First, the correlations between the innovation attributes and the intention to aciopt were computed. Table 2 shows that the assumed positive correlation between compatibility and the intention to adopt was confirmed for three of the four interventions: no significant correlations were found between the innovation attributes and the intention to adopt intervention 4 (personalised advice on energy saving given to the retail trade by a consultant of the energy distribution companies). Further, the assumed positive correlation between advantage and the 
intention to adopt an electronic indicator was indeed demonstrated. Also in line with Rogers' diffusion theory (1995), a marginally significant negative correlation ( $r=-.38 ; p$ <.06) was found between complexity and the intention to adopt intervention 1 , the load management of washing machines (see Table 2). 


\section{Innovating 'diffusion of innovation'theory}

Table 2

Pearson Correlation index of the innovation attributes and the intention to adopt intervention 1 to 4 .

\begin{tabular}{|c|c|c|c|c|c|c|c|c|c|c|c|c|c|c|c|c|}
\hline Intervention & 1 & 2 & 3 & 4 & 1 & 2. & 3 & 4 & 1 & 2 & 3 & 4 & 1 & 2 & 3 & 4 \\
\hline & \multicolumn{4}{|c|}{ Advantage } & \multicolumn{4}{|c|}{ Compatibility } & \multicolumn{4}{|c|}{ Complexity } & \multicolumn{4}{|c|}{ Trialability } \\
\hline Advantage & 1.00 & 1.00 & 1.00 & 1.00 & & & & & & & & & & & & \\
\hline Compatibility & $42^{\circ}$ & $76^{*}$ & 27 & $56^{-}$ & 1.00 & 1.00 & 1.00 & 1.00 & & & & & & & & \\
\hline Complexity & -.19 & -.26 & -.32 & $.70^{-}$ & -.09 & -.13 & -31 & $-.51^{\circ}$ & 1.00 & 1.00 & 1.00 & 1.00 & & & & \\
\hline Trialability & .26 & $.41^{\circ}$ & -.009 & $.62^{*}$ & .02 & $.45^{\circ}$ & .15 & $.46^{\circ}$ & $-.45^{\circ}$ & -.11 & .12 & $-.45^{\circ}$ & 1.00 & 1.00 & 1.00 & 1.00 \\
\hline $\begin{array}{l}\text { Intention to } \\
\text { adopt }\end{array}$ & 31 & $.45^{\circ}$ & 35 & .39 & $58^{-1}$ & $.52^{-\infty}$ & $.55^{\circ}$ & 38 & -.38 & -.29 & -.14 & -.09 & .32 & .12 & .03 & .35 \\
\hline
\end{tabular}

$\cdots p<.05 \cdots p<.01$

Intervention 1:

Intervention 2.

Load management for washing-machines to shift electricity use to off-peak periods ( $n=24)$

Intervention 3.

Electronic indicator providing feedback on in-home energy use $(n=29)$

Intervention 4.

Community intervention aimed at stimulating insulation and energy saving behavior $(n=24)$

Personalized advice to retail trade on energy saving given by a consultant of the utility companies ( $n=22)$ 
Table 2 also shows relatively high correlations between compatibility and advantage. According to Rogers (1995), innovation attributes are interrelated but nonetheless separate theoretical concepts. To assess the extent to which the four innovation attributes independently contributed to the explained variance in the intention to adopt, a linear regression analysis was performed.

Table 3 shows that, for three of the four interventions, compatibility of the intervention explains most of the variance in the intention to adopt. For one of the interventions (load management of washing machines) perceived complexity proved to be the second most important attribute explaining the variance in the intention to adopt the innovation (see Table 3). Contrary to Rogers' ideas (1995), trialability and advantage failed to explain a supplementary part of the variance in the intention to adopt.

\section{Table 3}

Summary of the significant predictors in a multiple linear regression analysis with co-ordinators intention to adopt the four energy conservation interventions as a dependent variable and advantage, compatibility, complexity and trialablity as predictors.

\begin{tabular}{|c|c|c|c|c|}
\hline Intervention & Variable & B & SE B & B \\
\hline $\begin{array}{l}\text { Load management for washing ma- } \\
\text { chines }(n=27)\end{array}$ & 1 compatibility & .62 & .17 & $.55^{*}$ \\
\hline $\begin{array}{l}\text { Electronic indicator providing feedback } \\
\text { on in-home energy use }(n=31)\end{array}$ & 2 complexity & .40 & .19 & $.32^{\circ}$ \\
\hline $\begin{array}{l}\text { Community intervention aimed at } \\
\text { stimulating insulation and energy sav- } \\
\text { ing behavior ( } n=26 \text { ) }\end{array}$ & 1 compatibility & .48 & .15 & $.52^{*}$ \\
\hline $\begin{array}{l}\text { Personalized advice to retail trade on } \\
\text { energy saving given by a consultant of } \\
\text { the utility companies }(n=23)\end{array}$ & 1 compatibility & .47 & .15 & $.55^{\circ}$ \\
\hline
\end{tabular}

Load management for washing machines: $R^{2}=.34(p<.05)$

Electronic indicator: $R^{2}=.27(p<.05)$

Community intervention: $R^{2}=.20(p<.05)$

Personalized advice to retail trade: n.s.

" $p<.05 ; *$ *" $p<.01$

One possible explanation for the absence of a relationship between some of the innovation attributes and the intention to adopt is the proposed stepwise process of judging an innovation on its characteristics. If it is true that potential adopters do not seriously assess the next attribute if the evaluation of the previous attribute is negative, one is not likely to find a relationship between intention to adopt and the next attributes. It was hypothesized that the correlation between compatibility and the intention to adopt is only 
significant under the condition that the perceived advantage is high. If the perceived advantage is minor, further evaluation of an innovation will not take place. This implies that in a low-advantage situation, compatibility and intention to adopt are not correlated, while in a situation where considerable advantages are perceived, compatibility is expected to be a strong predictor of the decision to reject an innovation.

In order to check whether advantage affects the correlation between compatibility and the intention to adopt, an interaction variable was added to the regression analysis.

\section{Table 4}

Summary of Hierarchical multiple linear regression analysis of co-ordinators' intentions to adopt four energy conservation interventions with an interaction variable (advantage * compatibility).

\begin{tabular}{|c|c|c|c|c|}
\hline Intervention & Variable & B & SE B & B. \\
\hline $\begin{array}{l}\text { Load management for wash- } \\
\text { ing machines }(n=27)\end{array}$ & $\begin{array}{l}\text { Step } 1 \\
\text { Advantage } \\
\text { Compatibility } \\
\text { Step } 2 \\
\text { Ad } \text { * com }\end{array}$ & n.s. & & \\
\hline $\begin{array}{l}\text { Electronic indicator provid- } \\
\text { ing feedback on in-home } \\
\text { energy use }(n=31)\end{array}$ & $\begin{array}{l}\text { Step } 1 \\
\text { Advantage } \\
\text { Compatibility } \\
\text { Step } 2\end{array}$ & $\begin{array}{l}1.07 \\
1.55 \\
-33\end{array}$ & $\begin{array}{l}.56 \\
.64 \\
.17\end{array}$ & $\begin{array}{l}0.85^{\circ} \\
1.69^{\circ}\end{array}$ \\
\hline $\begin{array}{l}\text { Community intervention } \\
\text { aimed at stimulating insula- } \\
\text { tion and energy saving } \\
\text { behavior }(n=26)\end{array}$ & $\begin{array}{l}\text { Step } 1 \\
\text { Advantage } \\
\text { Compatibility } \\
\text { Step } 2 \\
\text { Ad " com }\end{array}$ & $\begin{array}{r}1.70 \\
0.87 \\
-.44\end{array}$ & $\begin{array}{l}.52 \\
.30\end{array}$ & $\begin{array}{l}1.98^{* *} \\
1.05^{* *} \\
-1.93^{*}\end{array}$ \\
\hline $\begin{array}{l}\text { Personalized advice to retail } \\
\text { trade on energy saving given } \\
\text { by an advișer of the utility } \\
\text { companies }(n=23)\end{array}$ & $\begin{array}{l}\text { Step } 1 \\
\text { Advantage \& } \\
\text { Compatibility } \\
\text { Step } 2 \\
\text { Ad * com }\end{array}$ & n.s. & & \\
\hline
\end{tabular}

Table 4 shows that a stepwise regression analysis indicates that the interaction between compatibility and advantage was significant for the innovation "community intervention" and marginally significant for the innovation "electronic feedback", after correction for the 
main effects of compatibility and advantage ${ }^{2}$. Furthermore, as expected, none of the other two-way interactions (advantage $x$ trialability, advantage $x$ complexity, complexity $x$ trialability, compatibility $x$ complexity, compatibility $x$ trialability) corrected for the relevant main effects were significant for these two innovations (all ps $>.15$ ).

In order to find out whether compatibility only predicts the intention to adopt in a situation where the perceived advantage is great, the same analysis without the interaction was computed separately for respondents with a high score on advantage and respondents with a low score on advantage. The cut-off point for allocating respondents to the lower advantage or higher advantage group was the mean score on advantage. In the group of respondents with a high score on advantage, compatibility explained $44 \%$ $\left(R^{2}=.80, p<.01\right)$ (electronic indicator, $\left.M>2.8, n=18\right)$ and $52 \%\left(R^{2}=.84, p<.001\right)$ (community intervention, $M>3.4, n=17$ ) of the variance in the intention to adopt, whereas in the group of respondents with a lower score on advantage, compatibility was not entered into the analysis $(p>05)$. For two of the four interventions, these results supported our hypothesis of the existence of a stepwise evaluation process. Due to the small research population, the next steps of the model could not be tested (as for each decision step the group should be further divided into two smaller (low-high) subgroups).

\section{Face-to-face interviews}

Another method used to test the idea of a stepwise process was by analyzing the arguments mentioned by co-ordinators in the face-to-face interviews for rejecting or adopting a particular energy conservation intervention. During the face-to-face interviews, co-ordinators were asked to explain their opinion about the relevance of the energy conservation intervention. The attributes of and barriers to the energy conservation innovations they mentioned in answering this question were analyzed for those innovations for which we had found evidence of a stepwise reasoning process (i.e. the electronic indicator and the community intervention).

Based on the data from the structured questionnaire, the co-ordinators were divided into low and high perceived advantage groups (with respect to a particular intervention), using the mean score as the cut-off point. The attributes and barriers they mentioned in explaining their opinion on the relevance of the energy conservation interventions were then allocated by two independent judges to one of the categories "advantage" and "other innovation attribute". Agreement between judges was acceptable for the electronic indicator $(\alpha=86)$ as well as for the community intervention $(\alpha=.83)$. Differences in judgement were resolved by discussion.

Then, a chi-square test was done, using the following independent variables 1) advantage (low/high) of the electronic indicator as rated by the co-ordinators in the questionnaire and 2) aspects/barriers mentioned in the interview (dis)advantage/other aspects). This analysis resulted in a significant chi-square value for the electronic indicator $\chi^{2}(1, n=34)=4.15, p<.05$. A similar analysis of the data on the community intervention 
was not possible due to the presence of one cell with expected values below 5. It is recommend that Fisher's exact. test should be used in such cases (Cramer, 1998), and this test showed that the cells for the community intervention also differed significantly $(p<.05)$. Table 5 compares the observed and expected numbers of respondents per category.

\section{Table 5}

Number of respondents per category for the association between perceived advantage of the electronic indicator and mentioning other innovation attributes besides advantage

\begin{tabular}{lllll}
\hline & \multicolumn{2}{l}{ Electronic Indicator $(n=34)$} & \multicolumn{2}{l}{ Community intervention $(n=35)$} \\
\hline & \begin{tabular}{l} 
Low advantage \\
\cline { 2 - 5 }
\end{tabular} & High advantage & Low advantage & High advantage \\
\cline { 2 - 5 }$($ Expected $n)$ & $\begin{array}{l}\text { Observed } n \\
\text { (expected } n)\end{array}$ & $\begin{array}{l}\text { Observed } n \text { (ex- } \\
\text { pected } n)\end{array}$ & $\begin{array}{l}\text { Observed } n \text { (ex- } \\
\text { pected } n)\end{array}$ \\
$\begin{array}{l}\text { Only advan- } \\
\text { tage or disad- } \\
\text { vantage }\end{array}$ & $\begin{array}{l}7(6.1) \\
\begin{array}{l}\text { Other attri- } \\
\text { butes }\end{array}\end{array}$ & $4(6.9)$ & $6(2.7)$ & $6(9.3)$ \\
Total & 13 & $14(11.1)$ & $2(5.3)$ & $21(17.7)$ \\
& 21 & 8 & 27
\end{tabular}

As Table 5 shows, the results of the chi-square analysis support the presence of a stepwise decision process. Co-ordinators who perceived no great advantage of the electronic:

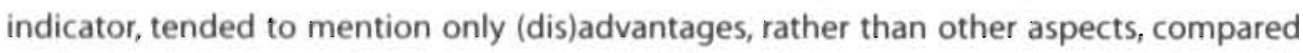
to those who perceived great advantages of the indicator. This suggests that they only continued the assessment process if the first step yielded a satisfactory result. The same conclusion can be drawn from the data on the community intervention: co-ordinators who perceived little advantage in community interventions tended to mention only (dis)advantages rather than other aspects, compared to those who perceived great advantage of community interventions.

It should also be noted that advantages were mentioned by almost all co-ordinators $(100 \%$ of the respondents in case of the electronic indicator and $88 \%$ of the respondents in case of the community project) when they were asked to explain their opinion about the relevance of the innovation. Moreover, the aspect of advantage was almost always mentioned first ( $91 \%$ of the respondents in case of the electronic indicator and $68 \%$ of the respondents in case of the community project).

The face-to-face interviews also gave some indications as to whether it is desirable to modify or extend the innovation attributes defined by Rogers (1995). Co-ordinators were asked to mention barriers impeding the adoption of the various energy conservation interventions. Table 6 shows the three barriers perceived by respondents to be the most important for each of the interventions. 


\section{Table 6}

The three most important barriers to adoption of the various energy conservation interventions spontaneously mentioned by the co-ordinators

\begin{tabular}{|c|c|c|c|c|}
\hline & $\begin{array}{l}\text { Intervention } 1 \\
(n=31)\end{array}$ & $\begin{array}{l}\text { Intervention } 2 \\
(n=41)\end{array}$ & $\begin{array}{l}\text { Intervention } 3 \\
(n=41)\end{array}$ & $\begin{array}{l}\text { Intervention } 4 \\
(n=41)\end{array}$ \\
\hline Barrier 1 & $\begin{array}{l}\text { Limiting people's } \\
\text { freedom in house- } \\
\text { keeping is not } \\
\text { desirable }(48 \%)\end{array}$ & $\begin{array}{l}\text { The initial costs } \\
\text { of the electronic } \\
\text { indicator are too } \\
\text { high }(34 \%)\end{array}$ & $\begin{array}{l}\text { The costs are too } \\
\text { high because } \\
\text { a community } \\
\text { intervention is too } \\
\text { labor-intensive } \\
(39 \%)\end{array}$ & $\begin{array}{l}\text { Energy conserva- } \\
\text { tion has little pri- } \\
\text { ority for the retail } \\
\text { trade }(37 \%)\end{array}$ \\
\hline Barrier 2 & $\begin{array}{l}\text { Another interven- } \\
\text { tion for energy } \\
\text { management has } \\
\text { priority }(32 \%)\end{array}$ & $\begin{array}{l}\text { Uncertainty about } \\
\text { the long-term ef- } \\
\text { fects (after a year) } \\
(32 \%)\end{array}$ & $\begin{array}{l}\text { Too much respon- } \\
\text { sibility is given to } \\
\text { the utility compa- } \\
\text { ny ( } 34 \% \text { ) }\end{array}$ & $\begin{array}{l}\text { The retail trade } \\
\text { has low priority in } \\
\text { our energy con- } \\
\text { servation policy } \\
(32 \%)\end{array}$ \\
\hline Barrier 3 & $\begin{array}{l}\text { This program is } \\
\text { not cost-effective } \\
(29 \%)\end{array}$ & $\begin{array}{l}\text { The target popula- } \\
\text { tion that will } \\
\text { adopt an electron- } \\
\text { ic indicator is too } \\
\text { small }(29 \%)\end{array}$ & $\begin{array}{l}\text { Households have } \\
\text { little interest in en- } \\
\text { ergy conservation } \\
\text { advice (24\%) }\end{array}$ & $\begin{array}{l}\text { The costs are too } \\
\text { high because per- } \\
\text { sonalised advice } \\
\text { for the retail trade } \\
\text { is too labour-in- } \\
\text { tensive (39\%) }\end{array}$ \\
\hline
\end{tabular}

Intervention 1. Load management for washing-machines, to shift electricity use to off-peak periods

Intervention 2. Electronic indicator providing feedback on in-home energy use

Intervention 3. Community intervention aimed at stimulating insulation and energy saving behaiour

Intervention 4. Personalised advice to retail trade on energy saving given by a consultant of the utility companies

Table 6 reveals that uncertainty about the long-term effects was mentioned by $32 \%$ of the co-ordinators as a barrier to adoption of the electronic indicator. Uncertainty about the effects (in the long term) is one of the attributes identified by Darley and Beniger (1981); they assumed a negative correlation between this factor and the intention to adopt an innovation. Darley and Beniger (1981) also mentioned high capital cost and low perceived savings as barriers to the adoption of an innovation. The initial costs of the electronic indicator were mentioned by $34 \%$ of the co-ordinators as a barrier to its adoption. Perceived savings have to do with the cost-effectiveness of an innovation, and this factor was mentioned by $29 \%$ of the co-ordinators as a barrier to the adoption of load management for washing machines (see Table 6).

Table 6 reveals that the type of costs mentioned as a barrier differ between the various energy conservation interventions. Costs caused by the fact that the interven- 
tion would be labor-intensive were mentioned for the community intervention and for the personalized advice to the retail trade. Cost-effectiveness was mentioned as a barrier to adoption of load management for washing machines and costs of acquisition for the electronic indicator. Lack of confidence in the motivation of the target population to adopt the energy conservation measures was mentioned for the electronic indicator, a community intervention, and a personalized advice to the retail trade.

The present study found no evidence for the relevance of the other adjustments and extensions proposed by Darley and Beniger.Dissatisfaction with the existing situation may be too broad a category to be a strong predictor of the intention to adopt a specific energy conservation intervention. In proposing the attributes 'lifestyle compatibility' and 'efforts and skills involved in installing the innovation', Darley and Beniger (1981) clearly had end users in mind, rather than intermediaries like the policy makers of energy distribution companies.

\section{CONCLUSIONS AND DISCUSSION}

The main purpose of this study was to assess the capacity of the innovation attributes proposed in Rogers' diffusion theory to predict the intention to adopt energy conservation interventions. The results confirmed the hypothesized relationship between compotibility and the intention to adopt, for three of the four energy conservation interventions. Perhaps the absence of a significant correlation between compatibility and the intention to adopt intervention $\mathbf{4}$ (personalized advice to the retail trade) was influenced by the presumed lack of interest among the retail trade in saving energy. Thirty-seven percent of the co-ordinators mentioned in the face-to-face interviews that, according to them, energy conservation had little priority in the retail trade. Co-ordinators may therefore believe that no intervention will be effective in increasing the use of energy conservation in this sector. Nevertheless, the retail trade is one of the government's high-priority target groups and the energy companies have made a formal commitment to stimulate energy conservation among this target group. Thus, the intention to adopt may have been influenced by the feeling of being obliged to do something rather than being based upon a positive perception of the intervention, for example as regards perceived compatibility.

The results also showed a significant positive correlation between advantage and the intention to adopt in the case of the electronic indicator providing feedback on in-home energy use. Likewise, the inverse relationship between perceived complexity and the intention to adopt was confirmed in the case of load management for washing machines in the regression analysis. However, no significant relation was found between perceived trialability and the intention to adopt. The absence of a relationship between trialability and adoption is in line with the results of the study by Labay \& Kinnear (1980), who found that trialability was not related to the adoption of solar power. The significant 
relation between compatibility, advantage and adoption has also been found in earlier research (Warkov, 1981; Berkowitz \& Haines, 1980; Labay \& Kinnear, 1980).

Except for compatibility, the attributes do not seem to be very strong predictors of the intention to adopt energy conservation interventions. We feel that the hypothesized stepwise process is one of the main reasons for this low predictive value. This will be illustrated in more detail in the following paragraphs.

Earlier diffusion researchers have worked on the assumption that all innovation attributes are relevant at the same time. However, as the results of the present study suggest, potential adopters seem mainly interested in the advantage of an innovation. Only when advantage is considered sufficiently high, they proceed with evaluating the intervention on the basis of the other attributes. When the advantage is perceived as minor, the evaluation process is stopped. For two of the four interventions included in the present study, the results suggest that the co-ordinators continued evaluating the innovations for compatibility only when the outcome of the evaluation on advantage was positive. These results support the idea that decision making about an innovation is a stepwise process in which advantage is the first critical attribute for continuing or discontinuing the assessment of an innovation.

The attributes of (and barriers to) the adoption of the electronic indicator and community intervention mentioned in the face-to-face interviews confirm that advantage is the most important attribute for rejecting the electronic indicator and the community intervention (as it was often mentioned first and mentioned by nearly all the co-ordinators). Rejection of the electronic indicator was almost completely based on a lack of perceived advantage. Some co-ordinators based their rejection of the community intervention on other attributes as well, like "We will not initiate this intervention since its initiation is not our responsibility."It is likely that the type of intervention also plays a role in the decision which aspect to evaluate in which step, although perceived advantage may usually be expected to be important in the first step.

For both of these interventions, the results reveal that, provided they perceived the advantage to be sufficient, co-ordinators continued the decision process by judging the intervention on compatibility and sometimes on other attributes. In contrast with those co-ordinators who rejected the intervention, co-ordinators who perceived great advantage were deliberating on the conditions under which adoption could be realized. This finding suggests that practitioners who try to promote the diffusion of a certain innovation should start by convincing potential adopters of the advantages of the innovation. Only when they are convinced of the advantages, will they be interested in other aspects of the innovation.

The results suggest that Rogers' (1995) five innovation attributes might become stronger predictors if they are further specified and extended. Certainty of savings, one of the additional attributes proposed by Darley and Beniger (1981), seemed to be an important attribute for the assessment of the electronic indicator. A total of $34 \%$ of the co- 
ordinators were afraid that in the long-term (after a year) households would no longer pay any attention to the electronic indicator. Secondly, our results suggest that specification of the type of cost that is relevant to an intervention increases the importance of advantage as an attribute that predicts the intention to adopt an innovation. Instead of entering capital cost as a sub-dimension of advantage, as was suggested by Darley and Beniger, our results suggest that: different. aspects of financial costs are relevant to different types of innovations. Unacceptable high initial costs were mentioned as a barrier to the acloption of the electronic indicator, whereas cost-effectiveness was mentioned as a barrier to the adoption of load management for washing machines. Costs related to labor-intensive interventions were mentioned as a barrier to adopting a community intervention and personalizedl advice. No clear support was found for the other refinements proposed by Darley and Beniger.

However, while several adjustments to Rogers' theory would seem to be clearly useful, it is also clear that refinement of the attributes will be at the expense of the generality of the innovation attributes. It is obvious that other researchers, dealing with different energy conservation interventions in a different context, will find support for other adjustments of innovation attributes. A way out of this dilemma might be not to define the innovation attributes in advance, but to explore the perceived positive and negative outcomes by means of, for instance, a focus group interview (compare the procedure proposed by Ajzen (1991) to list, for example, the main beliefs relevant to a certain attitude). The most important pros and cons can then form the basis of the innovation attributes to be assessed.

The present study was subject to certain special strengths and limitations that deserve some attention. A first limitation of the study is that it concerned only the adoption stage of an innovation. The adoption of energy conservation interventions by decision-makers is the first necessary step in the diffusion process but is no guarantee of successful implementation. More research on the factors influencing the implementation and institutionalization stages seems important to stimulate the diffusion of successful energy conservation interventions. Secondly, this study was restricted to utility companies. The adoption of energy conservation interventions depends not only on the utility companies, but also on end-users and the readiness of other organizations (such as local govemments and housing companies) to cooperate with the utility companies. A third possible drawback of this study concerns the possibility that the co-ordinators gave socially desirable answers in the questionnaires and the interview. However, as the results clearly show, co-ordinators did not hesitate to mention negative as well as positive aspects of the interventions, so it seems that socially desirable answers were not a rnajor problem.

Despite the above limitations, the present study has provided relevant insights into the barrieis to and conditions for the widespread use of successful energy conserva. tion interventions. Our work is one of the few examples of research available in which factors promoting or preventing the adoption of successful energy conservation inter- 
ventions were examined systematically. Furthermore, evidence was found that not all innovation characteristics are important at the same time in the process of deciding on the adoption of an innovation, which is a potentially important theoretical contribution to diffusion theory. This insight into the evaluation process and adoption barriers has also led to concrete clues on how the widespread use of effective energy conservation interventions could be promoted. 


\section{CHAPTER THREE}

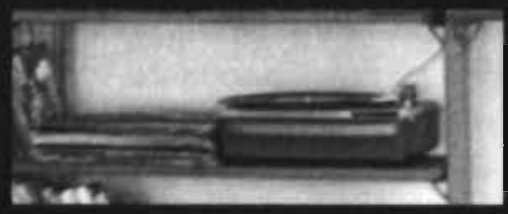


The Effect of A Prepayment Meter On Residential Gas Consumption

Submitted for publication as: Völlink, T., \& Meertens, R. (2003). The effect of a prepayment meter on residential gas consumption. 


\section{INTRODUCTION}

$\mathrm{O}$ ne of the most complex and difficult to solve environmental problems is the increased emission of carbon dioxide $\left(\mathrm{CO}_{2}\right)$, a gas which enhances the greenhouse effect. Scientists have shown that the increased $\mathrm{CO}_{2}$ emissions will have enormous impacts on the environment, including rising sea levels, retreating sea ice, decreasing snow cover, etc. (Houghton et al., 1996).

In the Kyoto agreement, the Netherlands committed itself to a reduction of $6 \%$ of its green house gas emissions in 2010, relative to 1990 emission levels (Wijngaart \& Ybema, 2002). In fact, however, total $\mathrm{CO}_{2}$ emissions in the Netherlands actually increased, due to a steady economic growth in recent years, accompanied by increased transportation (Department of Economic Affaires, 1999). To reduce $\mathrm{CO}_{2}$ emission levels in the short term, the Dutch government is attempting to reduce the burning of fossil fuels by promoting energy conservation. Households in the Netherlands are responsible for $14 \%$ of the total energy consumption, a large proportion of which is determined by natural gas used for heating (Department of Economic Affaires, 1999). Although gas consumption by Dutch households has already decreased, mainly because of better insulation and improved heating systems, changing behavioral patterns is thought to be a useful tool for further reduction (Department of Economic Affaires, 1999).

One of the most extensively studied and successful strategies to reduce household energy consumption is feedback, with or without goal setting (Becker, 1978; Becker

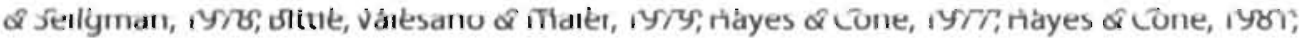
Houten van, Nau \& Merrigan, 1981; Houwelingen van \& Raaij van, 1989; Hutton, Mauser, Filiatraut, Athola, 1986; Kant \& Völlink, 1996; Kasulis, Huettner \& Dikeman, 1981; Katzev, Cooper \& Fisher, 1981; Paauw, Aarts, Wolsink, Smits \& Völlink, 1996; Palmer, Lioyd \& Lioyd, 1977; Seligman \& Darley, 1977; Sexton, Brown Johnson \& Konakayama, 1987; Winett, Kaiser \& Haberkorn, 1977; Völlink, 1995; Völlink \& Meertens, 1999; Winett et al., 1982). Studies revealed that frequent (weekly) feedback, in combination with a realistic but challenging goal, was an effective strategy, reducing the total energy consumption of households by 12.3 - 25\%. When feedback was provided less frequently (once every two weeks or once a month), the reduction decreased to $3 \%$, which could also be achieved by self-monitoring.

However, the success of the goal-setting and feedback strategy has not resulted in large-scale application, which makes the contribution of this strategy to the energy reduction policy minimal. Although weekly written feedback is too expensive for large-scale application, expectations for electronic feedback devices have run high (Van Houwelingen \& Van Raaij, 1989), though initial costs have been mentioned as a barrier to large-scale implementation of electronic feedback devices by utility companies (Völlink, Meertens \& Midden, 2002). In this respect, the so-called "prepayment meter" would seem to have a better chance of large-scale implementation, as it offers the utility companies some additional advantages. The current study examined the effect of a prepayment meter on 
gas consumption by households. Using a prepayment meter means that households pay for their gas as they use it and a display on the meter shows the amount of credit left, the cumulative amount of gas used and the price of the gas per $\mathrm{m}^{3}$. The prepayment meter used in the present study was charged by means of a smartcard. The prepayment meter is a modern version of the token meter, which disappeared in the Netherlands at the end of the sixties due to its susceptibility to fraud (Vermeer, 1998).

Unlike previous feedback and goal setting interventions, the prepayment meter project was initiated by an umbrella organization of the utility companies, in association with a specific utility company that would be responsible for the trial. That the project was an initiative of the utility companies (and not of scientists or the government) might improve the successful diffusion of this innovation, should it prove successful.

The prepayment meter was not originally designed to give feedback on gas consumption. It may even provide meaningless feedback, since it provides only information about the amount of credit left and does not indicate a reference consumption rate. This means that it is difficult for households to interpret their gas consumption in terms of high or low. Knowledge about gas consumption by itself may not have the power to initiate action (Locke \& Latham, 1990). However, as utility companies already have their reasons for introducing the prepayment meter on a large scale (see below), it is worthwhile to examine the success of this instrument as a feedback device, and if necessary to formulate recommendations for improvement.

From the utility company's point of view, one of the benefits of the prepayment meter over the current meter system is that it renders meter reading by an employee who goes from door to door superfluous. Reading the gas meter in the traditional way is becoming increasingly problematic, as the number of households where there is nobody at home during the daytime increases. Furthermore, a prepayment meter removes the need for sending monthly bills and reminders. Utility companies expect the meter reader to be replaced by automatic meter reading systems like telemetry or smartcards in the near future, since it reduces costs relative to the current metering system (Vermeer, 1998). The smartcard in the prepayment meter stores information about the customer's gas consumption, which is automatically downloaded to the utility company's computer each time the smartcard is recharged. This opens up new opportunities for the utility company, for example to analyze this data and to send regular monitoring reports to their clients as an extra service.

Another advantage is that the prepayment meter can also be used as an instrument to prevent defaulting. In the UK, where the energy market has, been liberalized, prepayment meters are used particularly by less affluent domestic customers, who are liable to defer paying their bills (Corporate and Consumer Affaires, 1998). In the Netherlands, households will be free to select their own utility company after the energy market becomes liberalized in 2004. Prepayment meters might then be introduced (or re-introduced) by the utility companies to reduce the cost of meter reading, to provide energy 
monitoring services to their customers but also to address the problem of defaulters (since customers only receive gas after having paid for it).

However, utility companies will probably not force the customers to install a prepayment meter, which makes the level of satisfaction with these meters an important factor in large-scale application. Therefore, the present study assessed the level of satisfaction with using the prepayment meter voluntarily. As was stated above, the feedback provided by the meter does not include a reference or target consumption, which makes it difficult for households to interpret the information in terms of high or low. According to the theory developed by Locke and Latham (1990), goal setting rather than feedback is the mechanism that motivates people to perform better, since it focuses attention, increases effort and stimulates people to persist longer. Feedback is only important insofar as it shows the progress made toward the goal. This has been confirmed in previous studies, in which feedback without goal setting had little or no effect (Becker, 1978; Katzev, Cooper \& Fisher, 1981; Winett, Kaiser \& Haberkorn, 1977).

Since earlier studies have shown that feedback with explicit, challenging goals is more effective than feedback alone, the present study examined whether the combination of a prepayment meter with a target consumption level would be more effective than a prepayment meter alone. To this end, one half of the households of the experimental group were issued a notebook in which they could compare the cost of their gas consumption per degree-day with the cost of a target consumption per degree-day (i.e., a goal was set). We predicted that the combination of the prepayment meter and a notebook would lead to greater reduction of gas consumption in these households than a prepayment meter alone.

A third focus of the present study was whether it would be possible to trace objectively measured gas consumption and the changes therein back to changes in selfreported daily gas-saving activities and changes in behavioral determinants. Few studies have assessed the behaviors and determinants that cause feedback and goal setting to change energy use.

Models in social psychology suggest that behavior is determined by three important factors: the attitude toward a particular behavior, the subjective norm and the perceived behavioral control. These three determinants have been summarized in the model of planned behavior (Ajzen,1991). According to the theory of planned behavior, behavior is primarily a result of behavioral intention, which in turn is influenced by the attitude toward the behavior, the subjective norm and the perceived behavioral control. External variables, such as socio-demographic factors, are assumed to influence behavior via determinants and intention.

Siero, Bakker, Dekker and Van den Bruggen (1996) compared the changes in behaviora! determinants between an intervention and a control group, based on the theory of reasoned action (specific attitudes and social norm). They implemented feedback interventions in two units of a metallurgical company, and found that behavioral changes were 
hardly accompanied by changes in behavioral determinants.

Brandon and Lewis (1999) compared different types of feedback in households and constructed a general environmental attitude scale consisting of items like:"Our present way of life is much too wasteful of resources.They examined the relationship between this environmental attitude and (1) historical energy consumption and (2) objective changes in energy use. Brandon \& Lewis found that the environmental attitude was not significantly related to historical energy consumption and that only environmental attitude was marginally significant related to objective changes in energy consumption during the feedback intervention. However, the relationship between attitude and behavioral change would probably have been stronger if attitudes had been measured at the same level of specificity as the energy conservation activities (Ajzen, 1991).

The present study examined the relationship between objective reduction in gas consumption and self-reported behavior and behavioral determinants, measured at the same level of specificity.

In summary, the questions our study tried to answer were as follows: (1) Are households satisfied with the prepayment meter and are their expectations in terms of advantages and disadvantages confirmed by its use or not? (2) What is the effect of the prepayment meter, with and without the notebook, on the gas consumption by the households? (3) Are (changes in) self-reported specific gas-saving activities and their determinants related to (changes in) gas consumption?

\section{METHOD}

\section{Participants and sampling}

The participants of this project were people who rented or owned houses at a new housing development in a Dutch village. All 1400 households, living in apartment blocks or duplex houses, received a letter from the utility company to participate voluntary. Initially, $25 \%$ of the households expressed an interest in participating in the project. After a meeting providing information about the project, 140 households filled out a form to indicate that they agreed to participate in the project. After stratification for income (low, average and high), households were randomly assigned to one of the two intervention groups (with or without a notebook) or to the control group.

Twenty-four households were removed from the analysis, 12 in the intervention groups and 12 in the control group. The reasons for removal were problems of accessing historical consumption ( $n=10$ in the intervention groups and $n=9$ in the control group), change of address ( $n=2$ in the intervention groups), or refusal to participate in the control group $(n=3$ ). The final sample therefore consisted of 116 households, divided over three groups as follows:

Group A: households with a prepayment meter and a notebook ( $n=43$ ) 
Group B: househoids with only a prepayment meter $(n=43)$

Group C: control group $(n=30)$

\section{Intervention}

Groups A and B had the prepayment meter installed in the meter box at such a level that its display could be easily read. People could press a button beside the display on front of the meter to get informed consecutively about the amount of credit left (R), the emergency credit ( $E$ ), and the price of the gas per $\mathrm{m}^{3}$. Additionally, they could see the cumulative amount of gas used above the display. The prepayment meter warned households if their credit was almost finished by a peep signal. Figure 1 shows a picture of the prepayment meter.

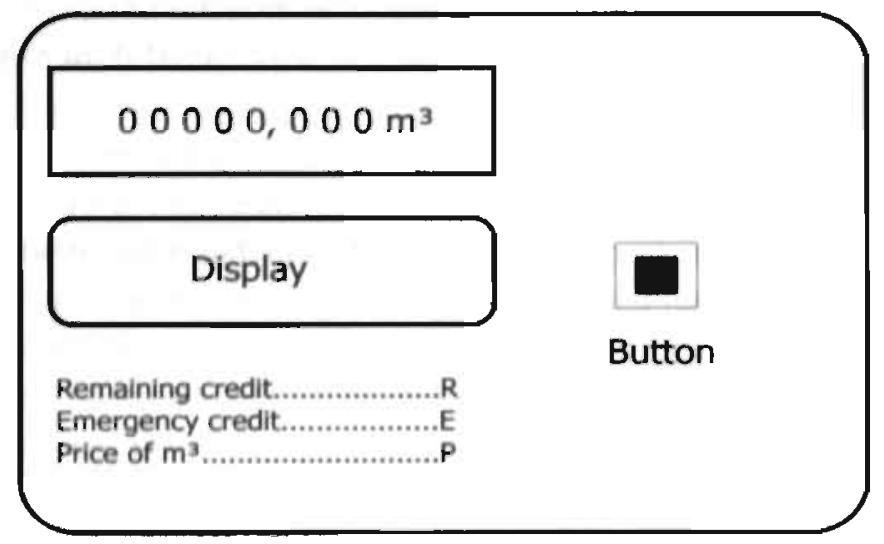

Figure 1 Display of the prepayment meter

Participants received two smartcards that were unique to their prepayment meter and that could be recharged at the local supermarket. The maximum amount transferable per transaction was 226 euros. Each time participants recharged their smartcard with a certain amount of credit, information was sent to the participating utility company's computer, which kept a record of each participant with respect to the date the smartcard was recharged and the amount of credit transferred to it.

\section{The notebook}

Participants in group $\mathrm{A}$ also received a notebook, in which they could set a personal savings target of 5,10 or $15 \%$. They were allowed to partiy set the goal themselves, to ensure that they could set goals that were realistic for their own situation. The gas consumption of the year preceding the prepayment meter project (1997/1998) was used as the baseline. Based on the savings target, a target consumption per degree-day was calculated for them, which they could find in their notebook. The aim of the notebook was to allow households to compare their target gas consumption per degree-day with their actual 
gas consumption per degree-day. They had to calculate their actual gas consumption themselves. Table 1 shows the seven calculation steps of the target consumption per degree-day, as presented in the notebook.

\section{Table 1}

Seven steps presented in the notebook to allow consumers to assess their target gas consumption per degree-day.

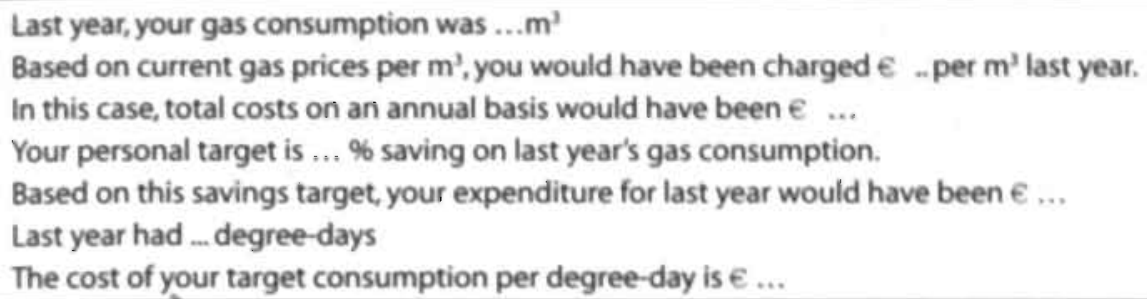

The gas consumption per degree-day was calculated by dividing the amount of credit used between two recharge moments by the total number of degree-days in that period. The households contacted the utility company by phone to find out the number of degree-days for a particular period.

\section{Procedure}

Interested individuals present at an information meeting a few weeks before the start of the project were thoroughly informed about the advantages and disadvantages of prepayment meters. Households were, for instance, told to be prepared for high expenditure during the cold months, and about the responsibility of regularly checking the credit left on the meter to ensure their own gas supply. The regular feedback was mentioned as a benefit of the project. Households were also told that their agreernent to participate did not guarantee they would get a prepayment meter, because of the random assignment to one of the study groups. Those who agreed to participate filled out a form to confirm their participation in the project, as well as a short questionnaire with questions about sociodemographic background information, to enable stratification of the households in three different income categories. As a reward for their participation, all participating households were promised a $10 \%$ reduction on their yearly gas bill. Households assigned to the control group (i.e., those who did not receive the prepayment meter) were told that they would receive a reward of about $€ 10$ after filling out the three structured questionnaires.

Two weeks before the project started, households in the group with both a prepayment meter and a notebook (group A) received a form on which they could set a personal savings target of $5 \%, 10 \%$ or $15 \%$. A covering letter gave some information about the effort required to achieve targets of $5 \%, 10 \%$ or $15 \%$ reduction. Participants were told that a $5 \%$ reduction target was quite easy to achieve, while a $10 \%$ target was challenging but realistic and a $15 \%$ target would in most cases be very hard to achieve and would require 
comfort to be sacrificed. At the start of the project, the households in group A received their notebook with the request to fill out the tables each time before charging the meter. If they had any questions about the notebook, they could call the investigator, and if they needed technical assistance they could phone the utility company. At the end of the project, households were asked to send back their notebook, so that we could check whether people had filled in their notebooks correctly.

The intervention groups and the control group received three questionnaires during the prepayment meter project, one before the start of the project (T1), one after 9 months ( $(\mathrm{T} 2)$ and one al week after the conclusion of the one-year project (T3). Furthermore, 14 households with a prepayment meter were requested to participate in an interview lasting about half an hour. Those who agreed were visited at home and received a gift token worth about $€ 4$.

\section{Measures}

Data were gathered by structured questionnaires, objective measurement of gas consumption levels and face-to-face interviews. The structured questionnaires included one short questionnaire with questions about non-behavioral background variables and three structured questionnaires measuring the level of satisfaction with the prepayment meter, the frequency with which the meter had been checked, specific gas-saving activities and determinants of the specific gas consumption reducing activities. The questionnaires for the control group included only questions about specific gas-saving activities and determinants of the specific gas consumption reducing activities.

\section{Nonbehavioral background variables}

Three questions were asked to assess nonbehavioral background variables of the participating households: net monthly income (as an indication of socio-economic status). number of household members and the presence of people in the house during working hours. Net monthly income of households was divided into six different categories: (1) $€$ 407 to $€ 611,(2) \in 611$ to $€ 814$, (3) $€ 814$ to $€ 1017,(4) \in 1017$ to $€ 1425,(5) \in 1425$ to $€$ 2036 and $(6) € 2036$ or more. The number of household members was assessed by means of an open question, while the presence of people in the house during normal working hours was measured on a dichotomous scale (yes or no).

\section{Level of satisfaction}

In the households with a prepayment meter (intervention groups $A$ and $B$ ), five items were used to assess the level of satisfaction with the project as a whole (Cronbach's $\alpha=.81$ ). These five items were:(1) "I am satisfied with my decision to participate in the prepayment meter project", (2) "I would think twice if I had to do it all over again", (3) "My decision to participate in the prepayment meter project was right", (4) "I have a bad feeling about my decision to participate in the prepayment meter project,"(5) "I think it was the right choice 
to participate in this project:" Each of the five items could be scored on five-point scales ranging from strongly disagree (1) to strongly agree (5). In addition to the level of satisfaction with the prepayment meter project as a whole, the pros and cons of the prepayment meter were assessed separately. A total of five pros and three cons of the prepayment meter were measured on five-point scales ranging from strongly disagree (1) to strongly agree (5). An example of an advantage of the prepayment meter we measured was: "The prepayment meter gives me a better idea of the amounts of gas consumed by my household"; an example of a disadvantage was: "A disadvantage of the prepayment meter is that I frequently have to check the amount of credit left on the meter:

\section{Frequency of meter checks}

The frequency with which the households checked their meter was measured by the following item: "How often do you check the amount of credit left on the meter?" This item could be scored on a five-point scale ranging from never (1) to every day (5).

\section{Sum scores of gas-saving activities}

Sum scores were calculated of the following 5 relevant specific gas-saving activities: (1) "Do you lower the thermostat setting to $15^{\circ} \mathrm{C}$ one hour before bedtime? (or if you have a thermostat with a timer, does its setting automatically switch to $15^{\circ} \mathrm{C}$ one hour before bedtime?)" (2) "Do you lower the thermostat setting to $15^{\circ} \mathrm{C}$ or less when nobody is home?", (3) "Do you close the outside door when leaving the house and the inside doors after leaving a room?", (4) "Is the heater off in rooms where nobody is present?" (5) "Do you use gas efficiently in your daily activities?" These specific gas-saving activities were measured on five-point scales ranging from never (1) to always (5) (Cronbach's $\alpha=.44$ at T1 and Cronbach's $\alpha=.55$ at T3).

\section{Sum scores of the determinants of specific gas-saving activities}

Intention, attitude, subjective norm and perceived behavioral control were measured separately for each specific gas-saving activity. Afterwards, the sum scores of these deter minants were computed.

Intention was measured by the question: "Do you intend to..." followed by ore of the specific gas-saving activities, measured on a five-point scale ranging from "certainly not" (1) to "definitely" (5) (Cronbach's $\alpha=.31$ at T1 and Cronbach's $\alpha=.57$ at T3). The attitude was measured on a five-point scale by the following item:"1 think it is very bad..." (1) or "I think it is very good..." (5), to ...,"followed by one of the specific gas-saving activities (Cronbach's $\alpha=.37$ at T1 and Cronbach's $\alpha=.49$ at T3). The subjective norm was measured by the item:"I feel that important others think that I should" followed by one of the specific behaviors, measured on a five-point scale ranging from "strongly disagree" (1) to "strongly agree $e^{\prime}$ (5) (Cronbach's $\alpha=.76$ at T1 and Cronbach's $\alpha \cong .82$ at T3). Perceived behaviorai control was measured by the question:“Do you think you will in all circumstances succeed 
in ...,followed by one of the specific gas-saving behaviors, measured on a five-point scale ranging from "No, I will not succeed" (1) to "Yes, I am very sure I will succeed" (5) (Cronbach's $\alpha=.59$ at $\mathrm{T} 1$ and Cronbach's $\alpha=.76$ at T3).

\section{Gas consumption}

The main dependent variable in this study was the percentage of gas consumption saved per household, which was calculated from the following equation:

(Gas consumption per houshold in the previous year ${ }^{2}$ in $\mathrm{m}^{3}-$ gas consumption per houshold during the intervention in $\mathrm{m}^{3}$

Percentage savings $=$ Gas consumption per houshold in the previous year in $\mathrm{m}^{3}$

* $100 \%$

The utility company provided the gas consumption data to the researchers. The face-toface interviews consisted of general open-ended questions about the prepayment meter system as a whole, the prepayment meter as a product, the smartcards and recharging the cards at the local supermarket. Respondents were asked, for example, to mention any unexpected problems with the system, the pros and cons of the prepayment meter, the way they handled recharging the meter, etc. The main goal of the face-to-face interviews was to ensure that we had not missed any important information by using only structured questionnaires.

\section{Results}

$\mathrm{T}$ his section starts with a description of the income categories of the participating households. Then, the results will be presented with regard to the participants' level of satisfaction with the prepayment system and the frequency of meter checks. Subsequently the influence of a prepayment meter on gas consumption is analyzed and self-reported gas-saving activities, are related to gas consumption and changes in gas consumption. Finally, analyses are reported that shed light on the question as to whether the determinants of the theory of planned behavior can explain behavioral intentions and gas-relevant activities.

\section{Income of the participants}

The participating households ( $n=116$ ) represented the following income categories: $7.4 \%$ of the households could be categorized as a minimum income group (net monthly income between $€ 407$ and $€ 814$ ). Furthermore, $10.5 \%$ of the households had an income just above minimum ( $€ 814$ to $€ 1017$ ), $52 \%$ of the households were middle class families with a net monthly income between $€ 1017$ and $€ 2036$ and $30.1 \%$ of the households could be categorized as a higher income group ( $€ 2036$ or more). 


\section{Satisfaction with the prepayment meter and frequency of meter checks}

Overall, the sum score of the satisfaction scale shows that $75 \%$ of the households ( $n=83$ ) in groups $A$ and $B$ were highly satisfied with their decision to participate in the prepayment meter project after one year of use. It was found that satisfaction was not correlated with income $(r=.17, p=.80)$. Others were slightly satisfied $(18 \%)$ or neutral $(7 \%)$ and no one was definitely dissatisfied with his or her choice to participate. The prepayment meter thus seems to have met the expectations of the households that participated voluntarily in the project. Participants were also asked to rate the project on the advantages and disadvantages they had expected before the start of the project (T1), and those experienced after 9 months of using the prepayment meter (T2) and after one year of use (T3). The mean scores at $\mathrm{T} 2$ and $\mathrm{T} 3$ were compared with those at $\mathrm{T} 1$ using a MANOVA for repeated measures. Table 2 shows the mean scores for the salient advantages and disadvantages at $\mathrm{T} 1, \mathrm{~T} 2$ and $\mathrm{T} 3$.

\section{Table 2}

Mean scores and standard deviations of advantages and disadvantages of the prepayment meter at $\mathrm{T} 1, \mathrm{~T} 2$ and $\mathrm{T} 3$, on a five-point scale ranging from strongly disagree (1) to strongly agree (5).

\begin{tabular}{|c|c|c|c|}
\hline & $\mathrm{T1}$ & $\mathrm{T} 2$ & T3 \\
\hline & $M(S D)$ & $M(S D)$ & $M(S D)$ \\
\hline \multicolumn{4}{|l|}{ The prepayment meter... } \\
\hline $\begin{array}{l}\text {-gives me a better idea of my family's } \\
\text { gas expenditures }\end{array}$ & $4.58(0.76)_{a}$ & $4.58(.71)$ & $4.32(1.25)_{a}$ \\
\hline $\begin{array}{l}\text {-gives me a better idea of my family's } \\
\text { gas consumption }\end{array}$ & $4.45(0.97)_{a}$ & $4.48(.79) a$ & $4.21(1.29)_{a}$ \\
\hline $\begin{array}{l}\text {-reduces my family's gas consumption } \\
\text { during the whole year }\end{array}$ & $4.79(0.99)$ & $4.79(1.22)$ & $4.76(1.38)_{a}$ \\
\hline $\begin{array}{l}\text {-reduces my family's gas consumption } \\
\text { during the cold months only }\end{array}$ & $3.73(0.97)_{\mathrm{a}}$ & $3.66(1.31)$ & $3.72(1.45)$ \\
\hline $\begin{array}{l}\text {-has the advantage that fuel expendi- } \\
\text { tures are low in summer }\end{array}$ & $4.05(1.27)_{a}$ & $4.16(1.11)$ & $4.11(1.47)_{3}$ \\
\hline $\begin{array}{l}\text {-has the disadvantage that I have to } \\
\text { check the amount of credit left on the } \\
\text { meter very regularly }\end{array}$ & $3.56(1.19)_{a}$ & $2.96(1.47)_{a b}$ & $2.78(1.54)_{b}$ \\
\hline $\begin{array}{l}\text {-has the disadvantage that I have } \\
\text { to ensure my own gas supply if I am } \\
\text { not at home for a longer period of } \\
\text { time }\end{array}$ & $4.18(1.23)$ & $3.19(1.49)_{b}$ & $3.32(1.58)_{b}$ \\
\hline $\begin{array}{l}\text {-has the disadvantage that fuel expen- } \\
\text { ditures are high during winter }\end{array}$ & 3.67 (1.33)。 & $3.05(1.54)_{a b}$ & $2.97(1.53)_{b}$ \\
\hline
\end{tabular}

Note. Mean scores for questions with different subscripts differ significantly, $p<.05$ 
Table 2 shows that participants had high expectations of the advantages of the prepayment meter (T1). MANOVA for repeated measures, revealed no effect of time for any of the advantages, indicating that using the meter confirmed the advantages households had expected in advance. The expected disadvantages of the prepayment meter had decreased after the prepayment meter had been used for one year. The expected disadvantage that "you regularly have to check the amount of credit left on the meter" decreased over time, $F(2,70)=8.09, p<.001$ especially from $T 1$ to $T 3 ; F(1,71)=15.13, p<.001$. The disadvantage that "you have to ensure your own gas supply when you are not at home for a longer period of time" also decreased over time, $F(2,70)=17.47, p<.001$, both between T1 and $T 2 F(1,71)=10.26, p<.001$ and between $T 1$ and $T 3 F(1,71)=18.00, p<.001$. Finally, the expected disadvantage that "expenditure will be high during the winter" also decreased over time, $F(2,71)=7.38, p<.001$, especially from $T 1$ to $T 3, F(1,72)=13.41, p<.001$. These results show that the high expectations participants had in advance were confirmed and that disadvantages were less than expected.

Apart from satisfaction with the prepayment meter, its success as a feedback instrument is also influenced by the frequency with which the amount of credit left on the meter has to be checked. The results showed that $57 \%$ of the respondents checked their prepayment meters at least once a week, while $30 \%$ did so once every two weeks and $13 \%$ checked their meters about once a month. The face-to-face interviews confirmed the results with respect to satisfaction and frequency of checking, and revealed no additional or comflicting inormation.

\section{Effects of the prepayment meter on gas consumption}

The second question of interest in the present study was whether households with a prepayment meter (with or withour a notebook) reduced their gas consumption more than the control group. A comparison between the percentage decrease in gas consumption in groups $A$ and $B(M=-2.57, S D=13.20)$ and the percentage increase in gas consumption in the contral group $(M=2.11, S D=10.26)$ showed a significant difference between the two groups (one-tailed) $\left(t(114)=1.76, p_{1}<0.05\right)$. The prepayment meter reduced the gas consumption of households in the experimental groups by $4.7 \%$ compared to the control group. One might suggest that households that received feedback at least once a week, that is checked their meters regularly, might save more gas. We examined whether there was a difference in gas saving between respondents of the experimental groups who checked their meters once a week or more often $(n=45)$ and respondents who checked their meters only once in twa weeks or less $(n=31)$. However, a T-test revealed no difference in percentage savings between these two groups $(t(74)=-.35, p<.73)$.

In addition, it was analyzed whether the notebook had an extra gas-saving effect. Analysis of the percentage change in the intervention groups $A$ and $B$ revealed no significant differences $(t(83,86)=.53, p=.60)$, so our hypothesis that the combination of a notebook and the prepayment meter would lead to greater reductions was not confirmed. 


\section{Relationship between specific gas-saving activities and their determinants and historical gas consumption levels}

A hierarchical multiple regression analysis was conducted to analyze the relation between the specific gas-saving activities selected and objective gas consumption after correction for the relevant background variables, using historical gas consumption as the dependent variable. The relevant background variables (number of occupants, income, presence of people in the house during normal working hours) were entered in step one, while step two involved entering the five specific self-reported gas-saving activities'. Table 3 presents the variables included in the final model.

Table 3

Results of the multiple regression analysis with historical gas use as the dependent variable and the number of occupants, monthly net income, presence of people during normal working hours and the 5 specific reported behaviors at pretest as predictors. $(N=84)$.

\begin{tabular}{llll}
\hline Independent variables & 8 & SE B & $B$ \\
Number of occupants & 162.22 & 63.59 & $.26^{*}$ \\
$\begin{array}{l}\text { Monthly net income } \\
\text { Lowering the thermostat setting to } 15^{\circ} \mathrm{C} \text { one hour }\end{array}$ & 219.17 & 75.46 & $31^{\circ}$ \\
before bedtime \\
$\begin{array}{l}\text { Lowering the thermostat setting to } 15^{\circ} \mathrm{C} \text { or less when } \\
\text { nobody is home }\end{array}$ \\
$\begin{array}{l}\text { Note. } \mathrm{R}^{2}=.34, p<.001 \\
{ }^{*} P<.05\end{array}$
\end{tabular}

Table 3 shows that, after correction for the background variables, it were particularly two specific gas-saving activities, "lowering the thermostat setting to $15^{\circ} \mathrm{C}$ one hour before bedtime" and "lowering the thermostat setting to $15^{\circ} \mathrm{C}$ or less when nobody is home", that helped to explain the variance in gas consumption. The other two specific gas-saving activities, "closing the outside door when leaving the house and the inside doors after leaving a room" and "turning the heater off in rooms where nobody is present", and the more general "efficient use of gas in daily activities", had no influence on gas consumption.

\section{The relationship between the specific reported gas saving activities and their determinants}

In the next step we analyzed whether the determinants of the theory of planned behavior were able to predict the two specific gas-saving activities. A multiple linear regression analysis revealed that lowering the thermostat setting to $15^{\circ} \mathrm{C}$ one hour before bedtime was for $34 \%$ explained by people's perceived behavioral control $(\beta=.50, p<.001)$ and people's attitude (being borderline significant) $(\beta=.16, p<.06)$. The more perceived behavioral control people experienced and the more positive their attitude toward this specific behavior, the more consequently they reported to be in lowering the thermostat 
setting to $15^{\circ} \mathrm{C}$ one hour before bedtime. A second multiple regression analysis revealed that people's perceived behavioral control $(\beta=.31, p<.001)$ and attitude $(\beta=.53, p<.001)$ explained $61 \%$ of the variation in setting back the thermostat setting to $15^{\circ} \mathrm{C}$ or less when nobody was home. The more perceived behavioral control people experienced and the more positive their attitude toward this behavior the more consequently they reported to set back the thermostat. For both gas saving activities the analyses made clear that the subjective norm did not contribute to the prediction of engaging in these activities.

\section{Relationship between the sum scores of the determinants of the specific gas- saving activities and the intention to engage in these activities in the near future}

We were interested in how well the determinants of the specific gas saving activities might predict people's intention to perform the 5 specific gas saving activities in the future. For this analysis we used the computed sum scores for the specific gas-saving activities, intention, attitude, subjective norm and perceived behavioral control. A hierarchicall multiple linear regression analysis with the intention as the dependent variable and the three. determinants as predictors revealed that the determinants attitude, subjective norm and perceived behavioral control explained $50 \%$ of the variance in the intention to engage in gas-saving activities, $F(3,123)=41,30, p<.001$. Table 4 shows that all three determinants explained part of the variance in intention, but that attitude explained the largest share. or the variance.

\section{Table 4}

Results of a hierarchical multiple regression analysis with the sum score of the intention to engage in gas-saving activities in the near future as the dependent variable and the sum scores of attitude, subjective norm and perceived behavioral control as predictors $(\mathrm{N}$ $=127)$

\begin{tabular}{llcl}
\hline Independent variables & B & SE B & B \\
\hline $\begin{array}{l}\text { Sum score of the attitude toward gas-saving } \\
\text { activities }\end{array}$ & .45 & .078 & $.44^{* *}$ \\
$\begin{array}{l}\text { Sum score of the subjective norm toward gas- } \\
\text { saving activities }\end{array}$ & .14 & .053 & $.20^{*}$ \\
$\begin{array}{l}\text { Sum score of perceived behavioral control } \\
\text { regarding gas-saving activities }\end{array}$ & .17 & .054 & $.24^{*}$ \\
\hline
\end{tabular}

Note. $R^{2}=.41$ for step $1 ; R^{2}=.46$ for $\operatorname{step} 2 ; R^{2}=.50$ for $\operatorname{step} 3(p<.001)$

$" p<.05 ;{ }^{* *} p<.001$. 
Relation between changes in self-reported gas, consumption reducing activities/ relevant determinants and changes in objective gas consumption

We analyzed whether the $4.7 \%$ change in objective gas consumption in the intervention groups during the intervention was related to changes in self-reported gas-saving activities and/or changes in the determinants of these activities. A multiple linear regression analysis was performed with the change in annual gas consumption (annuall gas consumption in 1998 - annual gas consumption in 1999) as the dependent variable and changes (T1 - T3) in the sum scores of gas-saving activities and their determinants as the independent variables. The following independent variables were entered simultaneously: the sum score of changes in the self-reported gas-saving activities. (sum score of gas-saving activities at T1 - sum score of gas-saving activities at T3) and the sum score of changes in intention, attitude, subjective norm and perceived behavioral control concerning the daily performance of gas-saving activities (sum score at $\mathrm{T} 1$ - sum score at T3). The results of the multiple regression showed that changes in attitude about engaging in gas-saving activities explained $5 \%$ of the variance in changes in annual gas consumption, $F(1,101)=5,59, p<.05$. Contrary to what might be expected on the basis of the theory of planned behavior, changes in intention and changes in the other two determinants were not significantly related to changes in objective gas consumption.

\section{DISCUSSION AND CONCLUSIONS}

This study found that using a prepayment meter reduced the gas consumption of households living in a new housing development by $4.7 \%$, which is comparable to the effect of self-monitoring of energy consumption (Hayes \& Cone, 1981) (Hayes \& Cone, 1981), like the Dutch self-monitoring campaign: "Zuinig stoken, Zuinig aan"(Intomart, 1993). However, people may not persist in monitoring their energy consumption in the long run (Intomart, 1993), while a prepayment meter forces them to persist in monitoring to secure gas provision, so in the long run a prepayment meter might have a stronger effect on gas consumption.

Since the reactions of the households are important for widespread use of the prepayment meter, we were interested in finding out whether households had encountered unexpected disadvantages of the prepayment meter. The results showed, however, that the households who participated voluntarily gave a highly positive evaluation of the prepayment meter and were satisfied with it, and that perceived disadvantages tended to decrease over time. This is important for utility companies that want to introduce the prepayment system. However, it must be noted that the participants in this project participated voluntarily and generalization of their reactions to households that are forced to change to the prepayment system may be unjustified. Nevertheless, the resuits of the present study are promising with respect to the public acceptance of a prepayment meter 
system.

We cannot exclude the possibility that there was some kind of test effect in the control group, in that the questionnaire in which the control group had to report their energy-relevant behavior may have motivated them to use less energy than they would otherwise have done. We found some evidence for a test effect as a consequence of a comparable questionnaire in another study (Völlink \& Meertens, submitted). If this was. indeed also the case in the present study, it would mean that the difference between the intervention and control groups might have been more substantial if we had compared the experimental group with a control group that did not receive a questionnaire.

The use of a notebook, allowing a comparison between the actual gas consumption and the target consumption, did not lead to greater reductions in gas use. Households had to calculate and compare their current consumption with their target consumption per degree-day in their notebook each time before charging the prepayment meter, and phone in to ask for the number of degree-days. We checked whether people had indeed filed out the tables and phoned in for the number of degree-days. Of the 36 respondents $(89 \%)$ who returned their notebooks, 8 (22\%) had not asked for the degree-days and had not compared their actual consumption with their target consumption. They probably had felt that filling out the tables in the notebook each time before charging was too laborious and/or calculating their current gas consumption per degree-day was too complex. However, a comparison of the percentages saved by households in groups $A$ and $B$ excluding those respondents who did not fill out their notebook as requested or did not: sent back the notebook did not reveal any significant differences either $(t(77)=.80, p=$ 0.42). An explanation might be that some of the households without a notebook also kept track of their gas consumption, which may have minimized the additional effect of the notebook. Some of the participants without a notebook reported in the face-to-face interviews that they were keeping records of the dates when they recharged the smartcard at the supermarket and of the amount of credit transferred. This is in agreement with the assumption by Locke and Latham (1990) that the absence of explicit goal setting does not necessarily mean that no goal is set at all. People can set their own (internal) goals and use many clues to find out how well they perform. They can keep track of progress in their heads, comparing their current performance with previous performance. Nevertheless, the effect of the prepayment meter could probably be improved if the display showed not only the gas consumption level but also a target level.

The multiple regression analysis revealed that attitude change was positively related to changes in objective gas reduction. Interestingly, Brandon and Lewis (1999, see Introduction) also found that attitude was related to changes in objective energy consumption. By contrast, we found no relation between changes in self-reported gas-saving activities and objective changes in gas consumption. This is in line with the findings of the study by Olsen and Cluett (as cited in Oskamp, 1983), who found no relationship between self-reported energy conservation actions and actual household energy savings either. It: 
seems unlikely that the absence of this relation was a result of selecting the wrong gas consumption reducing activities, since the activities were selected from policy reports on energy and water conservation and since the relationship between two of the five specific gas-saving activities and historical gas consumption was confirmed in the present study. Another explanation could be that people find it easier to report attitudes than to report their actual performance of gas consumption reducing activities in the last few weeks, because a question about behavior requires retrospective assessment of past behavior whereas a question about one's attitude is an introspective question about how good or bad people think it is to behave in a certain way.

A limitation of the present study that may have undermined the households' gas-saving effort was that the households had been promised a 10 percent reduction of their gas consumption costs without any extra effort. This 10 percent reduction may also have influenced their appreciation of the prepayment meter system. However, a large majority of the participants preferred to keep the prepayment meter instead of returning to the usual gas meter, even without the 10 percent reduction.

The present study revealed that households opting for the prepayment meter were highly satisfied with it, even after one year of use. The prepayment meter might be introduced as a new product, since utility companies can save costs and are interested in enhancing relations with their customers in the coming liberalized energy market. Results also revealed that the households with a prepayment meter reduced their gas consumption by $4.7 \%$. The meter's feedback function could probably be improved by giving the households the opportunity to compare their gas consumption level with a target. 
CHAI'TER FOUR 
Goal-setting And Feedback Toward A Sustainable Future: An Intervention To Reduce Household Water And Energy Consumption

Submitted for publication as:

Völlink, T., \& Meertens, R. (2003). Goal-setting and feedback toward a sustainable future: an intervention to reduce household water and energy consumption. 


\section{INTRODUCTION}

Eeedback about in-home energy use with or without goal setting is one of the most often applied and examined methods for changing household energy consumption (Brandon \& Lewis, 1999; Geller, Winett \& Everett, 1982). Research shows that frequent (e.g. weekly) feedback in combination with a specific and challenging goal is very effective in reducing household energy consumption (Becker, 1978; Brandon \& Lewis, 1999; van Houwelingen \& van Raaij, 1989; Winett et al., 1982). Because it is expected that the production and distribution of drinking water will become increasingly difficult, insight into the effect of feedback and goal setting for water consumption is of growing relevance. The main purpose of this study is to examine this effect on household water consumption, as this has not yet been examined. In addition, this study is concerned with the reduction of household gas and electricity consumption.

The combination of goal setting and feedback motivates people to increase their efforts because it shows the gap between their actual consumption levels and the desired goals. However, as previous studies in the field of energy conservation focused on the effects of feedback and goal setting on outcomes (e.g. reduction of energy use), there is little insight into what impact goal setting and feedback has on specific energy-and water-saving behaviors. Thus, it is not clear which mechanisms of goal setting and feedback are especially relevant for changing energy use. Do people try to save energy more consistently when a goal is set, or do they seek new energy-saving strategies? The current study extends and complements previous studies by measuring specific gas-, electricity-, and water-consuming activities, and it examines the relationship between these activities and objective reductions in gas, electricity, and water use.

\section{Trends in water, gas, and electricity consumption}

\section{Water}

Household water consumption in the Netherlands (as in most other European countries) increased spectacularly until the 1990s, but the production and distribution of drinking water becomes more difficult and expensive every year (Ministry of Housing, Spatial Planning and the Environment [VROM], 1998). The average water consumption per person per day increased from 98 liters in 1970 to 131 liter in 1998. Every day, one person uses an average of 54 liters for personal hygiene, 36 liters for flushing the toilet, 23 liters for laundry, 12 liters for doing the dishes, cooking, and drinking, and 6 liters for cleaning, etc. (National Institute for Public Health and the Environment [RIVM], 2000). Encouraging households to economize on the consumption of fresh drinking water is of great importance because, in the European Community, $65 \%$ of the drinking water comes from groundwater reserves, which are threatened by pollution with pesticides, heavy metals, 
nitrates, etc. (European Community, 2000). Due to the long time it takes before the pollutants reach the groundwater, the decline of its quality will continue (European Community, 2000). As a consequence, waterworks will have to increase their efforts to produce highquality drinking water.

\section{Electricity and gas}

In the Netherlands, gas is the main fuel used for heating. Households are responsible for $24 \%$ of the total electricity use and $14 \%$ of the natural gas consumption (Energy Center Netherlands [ECN], 1999), which contributes considerably to $\mathrm{CO}_{2}$ emission. This $\mathrm{CO}_{2}$ emission is responsible for $60 \%$ of the greenhouse effect leading to global warming. Developed countries have made a commitment in the Kyoto protocol to reduce the emission of greenhouse gases in the years 2008-2012 by an average of $5 \%$ of the level in the years 1990-1995 (Ellerman, Jacoby \& Deceaux, 1998).

In the preceding years, the gas consumption of individual Dutch households and those of most other western countries has been reduced. Better insulation and the installation of more efficient central heating boilers have caused a 30\% decline of gas consumption between 1980 and 1998 (ECN, 1999). In contrast to the reduction for gas, the electricity consumption of Dutch households shows the opposite tendency, as do those of most other western countries. Households consumed five times more electricity in 1990 than in 1950 due to an increase of electrical appliances (ECN, 1999). Household appliances became more energy efficient, but the proliferation of personal computers, microwave ovens, dryers, and dishwashers was rapid (ECN, 1999).

Besides structural changes such as insulation and equipment that uses energy and water more efficiently, changes in daily activities can contribute significantly to reducing household water and energy consumption. Water consumption can be reduced by $10 \%$ to $15 \%$ by changing daily routines. One of the things that one can do is to take a 5 -minute shower instead of a bath (an average saving of 55 liters). The electricity and gas consumption can be reduced also by $10 \%$ to $15 \%$ by changing daily routine. Some things that one can do to reduce the electricity and gas use is to turn off the television set and the stereo installation rather than leaving them on stand-by and to turn down the thermostat 1 hour before bedtime (ECN, 1999).

\section{The goal setting and feedback intervention}

In the current study, households received feedback on their water, gas, and electricity consumption on five information pages on channel 37 of their television sets. These pages: contained the personal water and energy consumption levels for the last 4 weeks, which were compared to a target. Decisions had to be made about three characteristics of the goal setting and feedback message for the content and layout of the information pages. These were (1) frequency of feedback, (2) goal difficulty, and (3) type of information (percentage change, cost or amount of energy). As already mentioned, feedback has proven 
to be most effective in reducing household energy use when it is provided frequently (weekly), resulting in energy savings between $12.3-25 \%$ (Becker, 1978; Brandon 8 \& Lewis, 1999; van Houwelingen \& van Raaij, 1989; Winett et al., 1982. When feedback is less frequently received (once every 2 weeks or monthly), reduction decreases to $4 \%$ (Hayes \& Cone, 1981). Goal difficulty has been shown to affect the relative success of a goal-setting strategy. Specific, challenging goals improve performance by motivating people to try harder, persist longler and invent new strategies (Locke \& Latham, 1990). However, the best type of information (e.g., $\mathrm{kWh}$ or $\mathrm{m}^{3}$, percentage change and/or cost) with respect to clarity and effects remains unclear in earlier studies (Geller, Winett \& Everett, 1982). Different kinds of information may provide consumers with different insights, so giving all kinds of information may be the best solution.

To make it easier for the participating households to save water and energy, feedback and goal setting were combined with prompts. Prompts are specific reminders to change common daily activities. Geller, Winett and Everett (1982) mention four characteristics that enhance the success of a prompt. A prompt must (1) be provided in close proximity to the requested response, (2) specifically clarify what response is desired, (3) request a response that is relatively convenient, (4) be given in polite, undemanding language.

In summary, the purpose of the present study is to examine whether frequent feedback and goal setting are effective in reducing household water, electricity, and gas consumption. In addition, we examine which conservation activities households specifically changed to reduce their gas, electricity, and water use.

\section{METHOD}

\section{Participants and design}

This study combines an experimental design with a quasi-experimental pretest/post-test design: subjects. were randomly assigned either to an experimental group or a waitinglist control group, and there was an additional control group (to which subjects were not randomly assigned) because of the expected test effects.

The heads of the households in the experimental and waiting-list control groups were all homeowners living in the same energy-efficient new housing development in a small Dutch village. A total of 62 houses were randomly assigned to an experimental group ( $n=29)$ or a waiting-list control group $(n=33)$. Two households assigned to the experimental group were removed from the analyses due to a lack of data about their energy and water consumption caused by technical problems. Twelve households in the waiting-list control group were removed because one refused to participate, three others did not respond to the written questionnaires and eight were removed due to technical problems.

The 22 houses for the extra control group were selected at random from a com- 
parable energy-efficient new housing development, where only monthly meter readings were collected. One household was removed due to incomplete meter readings. The reason for the extra control group was that we wanted to take into account possible test effects in the waiting-list control group. Test effects might be expected because the waitinglist control group was well informed about the electronic feedback project; the modem for reading out the water, gas, and electricity meters was already installed, and the group repeatedly had to fill out questionnaires, with questions about specific gas-, electricity-. and water-saving behavior.

\section{Procedure}

The household received a form for setting a personal conservation goal of $5 \%, 10 \%$, or $15 \% 2$ weeks before the experimental group and the waiting-list control group received the information pages. These goals were not assigned, but participatively determined to enhance the chance of the participants setting a realistic but challenging goal. A covering letter gave some information about goal difficulty and the effort necessary to achieve a reduction goal of $5 \%, 10 \%$, or $15 \%$. The participants were told that a reduction goal of $5 \%$ was in general very easy to attain, that a goal of $10 \%$ was challenging but realistic, and that a $15 \%$ goal would be very hard to achieve in most cases and would necessitate the sacrifice of comfort.

The intervention with the information pages, started 4 months earlier for the experimental group than for the waiting-list control group. In the first 2 months, the experimental group received the information pages weekly without an energy or water-saving prompt. In the last 2 months, they also received a weekly prompt. After 4 months, the waiting list control group also received the information pages.

Just 1 week before the intervention started, the households in the experimental group and the waiting-list control group received the first structured questionnaire (T1). Both groups received the second questionnaire 1 week before the prompts were added (T2, 2 months after the start of the intervention) and the third questionnaire 1 week before the waiting-list control group started receiving the information pages (T3,4 months after the start of the intervention). The fourth questionnaire was sent out 7 months after the start of the intervention in the experimental group (T4); and the last questionnaire 1 year after the start of the intervention in the experimental group (TS). Each respondent who did not return the questionnaires on time received a reminder. The five questionnaires had to be filled out by the same person - the one who had most housekeeping responsibility.

Meter readings were collected automatically for the experimental and waitinglist control groups $\mathrm{s}^{4}$. In the experimental group, meter readings started 1 month before the experimental group received the information pages (TO). At the same time, a meter reader started to read out the gas meters monthly for the extra control group.

To complement the quantitative data, face-to-face interviews were held with 14 
participants, who also filled in the structured questionnaires. The interviews lasted a maximum of 45 minutes.

\section{Intervention}

Apart from conventional water, electricity, and gas meters, there was a separate unit collecting data from the three meters. These data were sent via TV cable to the utility company's computer network. The utility company analyzed the data and sent feedback to the participants. The weekly feedback of their water, electricity, en gas consumption was presented to the participants on five information pages that were shown on channel 37 of their television sets, at home. The pages were updated every week. Participants were able to consult the pages continuously. The gas, electricity, and water consumption levels. of the previous week were compared with the target levels.

The estimated annual consumption preceding the intervention minus the conservation goa! of $5 \%, 10 \%$, or $15 \%$ was the target. usage. The estimated year consumption levels for water, electricity and gas were calculated by the utility company on basis of characteristics of the house and the monthly consumption levels of the households preceding the intervention. The targlet usage for gas was corrected for the outside temperature by the degree-day method. On page 1, households were told whether their water and energy consumption was less or more than their target for that week by three smiles or frowns (one for gas, one for electricity, and one for water). The faces looked neutral when their current use was less than $3 \%$ above the target usage, they smiled when they achieved the target usage, and frowned when the usage was more than $3 \%$ above the target.

On the following three pages, consumption for the last 4 weeks, compared with the target usage, was shown by means of histograms. A table on the last page informed the participating households about the cumulative gas, electricity, and water consumption levels, their savings, and their cumulative costs. In addition, the annual total consumption costs were estimated on the basis of the cosits already made.

Prompts were added in the second period of the intervention (after 2 months) and consisted of concrete, simple iterns, on conservation activities like: "Taking a bath takes. 112 liter of water, but a 5-minute shower takes 57 liters of water." The prompts reminded people of simple daily activities and indicated how much they could save when they changed their behavior patterns. The prompts were provided only when the target usage was exceeded. They received not more than one prompt per week, although they could exceed more than one target. When households succeeded in achieving the target usage for gas, electricity, and water, they received an incentive such "all smiles this week, your conservation is very good, keep up the good work!"

\section{Measurements}

Structured questionnaires, meter readings, and face-to-face interviews were used to collect data. Energy and water consumption was determined on the basis of the automatic 
meter readings. The information pages were evaluated by means of the structured questionnaires, and changes in specific gas, electricity, and water usage were assessed. Face-toface interviews were used to complement the structured questionnaires.

\section{Meter readings}

The main dependent variables were the gas, water, and electricity consumption. The relevant data were collected by automatic meter readings ${ }^{4}$ (experimental group and waitinglist control group), a meter reader (extra control group), and by utility company records.

\section{Evaluation questions}

Three items assessed the number of times the information pages were consulted by the respondent, partner, and/or children. These items were determined by scales ranging from 1 (never) to 5 (several times a week).

The perceived reliability of the feedback pages was assessed separately for water, gas, and electricity with the question: "How reliably do you think the information pages inform you about your water, gas, and electricity consumption?" The choice of answers was scaled from 1 (completely unreliable) to 5 (completely reliable).

The comprehensibility of the page content was assessed with the question: "What do you think of the content of the information pages?", which was measured on a scale of 1 (very incomprehensible) to 5 (very comprehensible). The last question was: "Do you discuss the information pages with other family members?" This was measured on a scale from 1 (yes, we often discuss the information pages) to 5 (no, we never discuss the information pages).

Exposure to the prompts was measured separately with two questions: (1) "The weekly prompt gets my attention." and (2) "I always read the weekly prompt." Each was assessed on a scale from 1 (totally disagree) to 5 (totally agree).

\section{Background variables}

The net monthly income, number of family members, level of education, and gender were determined to check whether the experimental and waiting-list control groups were comparable with respect to their background. To prevent any possible test effects in the extra control group we did not collect background variables in this group.

The net monthly incomes were classed in four categories; a monthly average income of $€ 1225$ taken as the standard. The categories were: 1 (less than $€ 1225$ ), 2 (about $€ 1225$ ), 3 (between $€ 1225$ and $\in 2450$ ), and 4 (more than $€ 2450$ ). The number of household members was assessed by means of an open question. Education was divided into six categories, varying from basic (elementary school, vocational education), middle (high school, other secondary education) to highly educated (professional or university education). 


\section{Gas-, electricity-, and water-saving activities}

In order to get insight into the behavioral changes that might be brought about by the information pages, we measuredi five water-corıserving activities, six specific gas-conservingl activities, and ten electricity-conserving activities. The selection of the activities was based on consumer research done by the energy distribution companies. The respondents could indicate how often they took part in these activities on a scale from ? (never) to 5 (always).

The five specific questions about water-saving activities were: (1) "Do you use the water saver when flushing the toilet?", (2) "Do you clean the car with buckets of water instead of a garden hose?", (3) "Do you use less water when you take a shower or bath?", (4) "Do you do the dishes by hand instead of using the dishwasher?", and (5) "Do you turn on the dishwasher only when it is fully loaded?"

The following gas-conserving activities were measured: (1) "Do you set the thermostar back to $15^{\circ} \mathrm{C} 1$ hour before bedtime? (in case you have a thermostat with a timer, will it autornatically revert to $15^{\circ} \mathrm{C} 1$ hour before bedtime?)", (2) "Do you set the thermostat to $15^{\circ} \mathrm{C}$ or less when nobody is home?", (3) "Do you close the outside door ancl other inside doors after leaving the room?", $(3)$ "Is the radiator off in rooms where nobody is present?" (4) "Do you dress more warmly instead of turning up the heat?" and (5) "Do you turn off the radiator after taking a bath or shower?"

The questions about electricity-conserving activities were: (1) "Do you dry the laundry outside on the clothesline instead of using the dryer?", (2) "Do you only do a load of washing when the washing machine is full?"; (3) "Do you do the white wash at $60^{\circ} \mathrm{C}$ or less?", (4) "Do you turn off the extractor fan immediately after cooking?", (5) "Do you consistently tum off the lights in rooms where nobody is, present?", (6) "Do you turn off any background lighting| to save energy?", (7) "Do you use low-energy light bulbs for frequently used light sources?", (8) "Da you leave off the exterior lighting when you are at home?", (9) "Do you choose to do things by hand although you possess an electric appliance to do it for you?", and (10) "Do you turn off all equipment and appliances otherwise on "stand-by" at nightit?"

The questionnaires also included questions about determinants of the energyand water-conserving activities. However, we do not elaborate: on these questions here because of space limitations:

\section{Face-to-face Interviews}

The interview scheme consisted of general open-ended questions about the information pages. The purpose of the interviews was to get supplementary information about their use. We tried to determine how much time the participants generally spent on the information pages; what kind of information gave rise to discussion; whether the participants showed these pages to other family members, their neighbors, or friends; what effect the pages had on the partner and/or children, etc. 


\section{Analyses}

With separate ANCOVAs, the mean consumption levels for water, electricity, and gas for the experimental group were compared with those of the waiting-list control group and the extra control group from another district. Firstly, the mean weekly consumption levels between $\mathrm{T} 1$ and $\mathrm{T} 3$ for the experimental group were compared with those for the waiting-list control group. The previous estimated annual norm consumption was included as a covariate in the analysis.

To examine whether the effects of the intervention were maintained in the long term, a MANOVA for repeated measures was conducted to compare the mean consumption levels within the experimental group between T1 and T3 (the first 4 months after the start of the intervention) with those between T3 and T4 (3 months after T3), and those between T4 and T5 (5 months after T4) .

Furthermore, the mean water, electricity, and gas consumption levels for the experimental group were compared with the mean consumption levels for the extra control group in separate ANCOVAs. The consumption levels for the month preceding the intervention (between T0 and T1) were included as a covariate. To explore the possible effects of the prompts, three separate ANCOVAs (water, gas and electricity) were conducted to compare the mean consumption levels of the experimental group with those of the extra control group at T3 ( 2 months later, when the prompts were added). The consumption levels between $\mathrm{T} 1$ and $\mathrm{T} 2$ were included as covariates. Before conducting the analyses, outliers in the baseline consumption levels (i.e., previous estimated year consumption and baseline monthly consumption levels) of the households in the experimental, the waiting-list control group and the extra control group were removed. The number of outliers ranged from $n=1$ to $n=3$. Furthermore, data were checked for equality of error variance and parallelity of the regression lines, as these are assumptions of (co) variance analysis. Levene's test revealed that the assumption of equality of error variance was not violated. Error variations in gas, electricity and water consumption from T1 to T3 in the experimental group did not significantly differ from the waiting list control group and the extra control group. However, the assumption of parallelity of regression lines was violated in the three analyses where the experimental group was compared to the extra control group In all these three cases the correlation between the covariate (consumption T0) and the dependent variable (consumption T1-T3) was substantially higher in the extra control group than in the experimental group. This indicates that in the extra control group consumption in the past is a very good predictor of consumption, while this is less the case in the experimental group. One explanation for this finding is that the intervention disturbs the predictive value of previous consumption, bringing other factors into play. One might argue that that is exactly what one wants to reach with an intervention. However, to be sure we take a conservative stand and will in the cases where the assumption of parallelity of regression lines was violated, do both a normal (linear) analysis of covariance and an analysis where the interaction between covariate and dependent variable was controlled 
for.

\section{Results}

In the experimental group, $47 \%$ of the respondents were men; as were $89 \%$ in the waiting-list control group, $x^{2}(1, n=53)=8.43, p=.05$. This large percentage of men, especially in the waiting-list control group, is striking, since it was stressed that the questionnaires ought to be filled in by the one who took the most responsibility for the housekeeping. The experimental group and the waiting-list control group did not differ for other background variables. In total, $39 \%$ of the households consisted of aduits only. Further, $22 \%$ of the respondents were categorized as highly educated, $46 \%$ had middle education, and $32 \%$ had basic education. In total, $69 \%$ of the families had above average incomes (a monthly net income of more than $€ 1225$ and $28 \%$ of the monthly net incornes were about average, and $3 \%$ were less than average. In our study househoids participated in setting a savings target of $5 \%, 10 \%$ or $15 \%$. A few households (7\%) choose the most difficult target of $15 \%$, $52 \%$ choose a less difficult target of $10 \%$ and $41 \%$ choose the easiest target of $5 \%$.

\section{Exposure to and evaluation of the information pages and the prompts}

Reduction effects can only be attributed to the information pages when households were really exposed to the pages. Exposure as reported by the respondents was measured from T2 toT5 for the respondents, the partner, and the children. In total, $77 \%$ of the respondents at $\mathrm{T} 2$ and $73 \%$ of the respondents at $\mathrm{T} 5$ reported that they consulted the information pages at least once a week. Furthermore, the majority of the respondents $156 \%$ at $\mathrm{T} 2$ and $54 \%$ at. T5i) reported that their partners also consulted the pages at least once a week. The rest of the respondents, as well as their partners, consulted the pages, but less frequently. At T5, only $12 \%$ of the respondents reported that they consulted the pages once a month ar less. Only $12 \%$ of the children consulted the pages every now and then; the rest never consulted the information pages. These percentages remained rather stable over time.

The weekly prompts appeared at T2, 2 months after the intervention started. In total, $58 \%$ of the respondents said that they paid attention to the prompts at T3 ( 2 months after the prompts appeared). At T4, this percentage was $83 \%$; at T5, $71 \%$. In total, $58 \%$ of the respondents in the experimental group agreed with the statement that they always read the prompt at T3; at T4 this percentage was $87 \%$, and at T5, it was $71 \%$.

\section{Comprehensibility and reliability of the information pages}

The respondents of the experimental group evaluated the content of the information pages for comprehensibility at T2 on a scale ranging from very incomprehensible (1) to very comprehensible (5). In total, $77 \%$ of the respondents judged the content very comprehensible, $15 \%$ found the content somewhat comprehensible, and $8 \%$ were neutral. The 
experimental group also judged the information about their gas, electricity, and water consumption for reliability. After 2 months of use (T2), $69 \%$ found the information pages very reliable, or reliable, for gas, as did $73 \%$ for electricity and $85 \%$ for water. After 1 year (T5), these percentages were $81 \%$ for gas, $69 \%$ for electricity, and $73 \%$ for water.

\section{Reduction of water, electricity, and gas consumption}

Although, the respondents were randomly assigned either to an experimental group or a waiting list control group, both group differed significantly on their water consumption preceding the intervention $F(1,55)=4.17, p=.05$. Households in the experimental group consumed more water preceding the intervention $\left(M=130.68_{1} S D=7.59\right)$ than households in the control group $(M=108.69$, $S D=7.64$ ) did. No significant difference were found between the experimental and waiting list control group concerning their gas consumption $F(1,57)=.03, p=.86$ and their electricity consumption $F(1,54)=.27, p=.61$ preceding the intervention. In addition we found that the experimental and extra control group differed on their gas consumption preceding the intervention $F(1,46)=120.46, p=.00$. Households in the experimental group consumed less gas $(M=132.31, S D=24.84)$ than households in the control group $(M=238.45, S D=41.32)$ did. No significant differences were found concerning their water $F(1,46)=.05, p=.82$ and electricity consumption levels $F(1,46)=.52, p=.48$ preceding the intervention.

Table 1 shows the mean monthly scores for water, electricity, and gas consumption levels, adjusted for the estimated consumption levels in the previous year. The results of the ANCOVAs reveal that, for water consumption, the adjusted mean score of the experimental group was significantly lower than that of the waiting-list control group; $F(1,45)=$ $7.46, p=.01$. The mean monthly water consumption per household from T1 to T3 of the experimental group was $1.51 \mathrm{~m}^{3}$ less compared to the waiting-list control, that is, the experimental group reduced their water consumption by $15 \%$. Furthermore, for electricity consumption the adjusted mean score of the experimental group is significantly lower than that of the waiting-list control group, $F(1,44)=14.25, p=.00$. The mean monthly electricity consumption per household of the experimental group was $67 \mathrm{kWh}$ less than the waiting-list control group. Households in the experimental group reduced their mean monthly electricity consumption by $22 \%$ in comparison to the waiting-list control group. The ANCOVA for gas consumption reveals no significant difference $F(1,47)=.55, p=.46$. 


\section{Table 1}

Mearr monthly gas, electricity, and water consumption from $\mathrm{T} 1$ to $\mathrm{T} 3$ for the experimental and waiting-list: control group, adjusted for the estimated consumption level of the year preceding the intervention.

\begin{tabular}{lll}
\hline & Experimental group & Waiting-list control group \\
\hline & $M(S D)$ & $M(S D)$ \\
Gas in $\mathrm{m}^{3}$ & $155.52(7.48)$ & $163.97(8.49 !$ \\
Electricity in kWh & $244.71(11.83)$ & $312.13(13.24)^{\circ}$ \\
Water in $\mathbf{m}^{3}$ & $8.51(.35)$ & $10.03(.40)^{\circ}$ \\
\hline
\end{tabular}

$p<.05$

Test effects in the waiting-list control group may have caused the absence of significant differences for gas consumption. As already stated, the participants in the waiting-list control group knew they were taking part in an energy- and water-saving project, and had to fill in almost the same questionnaires as, the experimental group. These questionınaires may have acted as a reminder to them to save water and energy, and they could get saving tips from them. Therefore, the experimental group's consumption levels and those of the extra control group (in the first 4 months) of the intervention were compared, adjusted for the month precedingl the intervention.

Table 2 shows the mean consumption in the first 4 months of the intervention (T1-T3), adjusted for the: mean consumption level for the first months preceding the intervention (T0- T'1).

\section{Table 2}

Mean monthly gas, electricity and water consumption from $\mathrm{T} 1$ to $\mathrm{T} 3$ from the experimental and extra control group, adjusted for the consumption level of the month preceding the. intervention.

\begin{tabular}{lll}
\hline & Experimental group & Extra control group \\
\hline & $M(S D)$ & $M(S D)$ \\
Gas in $\mathrm{m}^{3}$ & $160.96(7.82)$ & $213.97(8.71)^{--}$ \\
Electricity in kWh & $270.02(8.50)$ & $303.23(8.91)^{-}$ \\
Water in m & $8.51(.46)$ & $10.03(.4 .8)^{*}$ \\
\hline
\end{tabular}

$* p<.001, " p<.05$

The results of the ANCOVA analyses reveal that the mean consumption level for water in the experimental group was significantly, lower than that in the extra control group; $F$ ( 1 , $43)=5.28, p=.03$. The experimental' group also consumed significantly less gas; $F(1,44)=$ $12.72, p=.00$ and less electricity; $F(1,43)=7.02, p=.01$ than the extra control group.

Calculations show that households in the experimental group, in comparison with the 
extra control group, reduced their mean monthly water consumption by $15 \%$, their electricity consumption by $11 \%$, and their gas consumption by $25 \%$ during the first 4 months of the intervention. Because the assumption of parallelity of regression lines was violated in the comparisons of the experimental group with the extra control group, we also carried out the above analyses while controlling for the interaction of the covariate with the dependent variable, instead of controlling for the covariate. These analyses for water and electricity consumption showed about the same results as the covariance analyses. However, after controlling for the interaction, the gas consumption did not differ significantly any more between the experimental and the extra control group.

\section{Effects of prompts}

The experimental group was compared with the extra control group in an ANCOVA at T3. (the first 2 months after T2, when the prompts were added), which was adjusted for the first 2 months (T1-T2) without prompts. The analyses reveal' that the gas consumption level in the experimental group declined significantly more from $T 2$ to $T 3(M=257.07, S D$ $=12.67$ at $T 3)$ than in the control group $(M=348.79, S D=13.62$ at $T 3), F(1,43)=15.22, p$ $=.00$. The water and electricity consumption levels did not decrease significantly more in the experimental group from T2 to T3 than in the extra control group; $F(1,43)=.02, p=$ $.88, F(1,44)=.13, p=.72$, respectively. These results at T3, reveal that the prompts might have had an extra effect on gas consumption; in comparison to the extra control group,

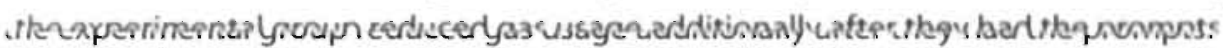

We also examined whether the reduction effects persisted in the experimental group in the long term (after 1 year). With a MANOVA for repeated measures, we examined whether the reduction effects for water, electricity, and gas consumption (per degree-day) in the experimental group persisted or even increased in the long term. Therefore, the mean weekly consumption levels of the experimental group at T4 ( 3 months after T3), T5 (after 1 year) were compared with those of $\mathrm{T} 3$ in an analysis for repeated measures. The results reveal that the water consumption did not change significantly over time after $\mathrm{T} 3[F(2,23)=2.35, p=.18]$, nor did the gas consumption $[F(2,22)=1.17, p=.33]$. For the electricity consumption, we found a significant effect for time $[F(2,24)=27.92, p=.00]$; the electricity consumption of the experimental group continued to decrease over time with a mean monthly decrease of $12.01 \mathrm{kWh}$ in the last 8 months of the intervention (TS compared to $T 3) ; F(1,25)=21.54, p=.00$. These results seem to indicate that the effects last over a longer period of time.

\section{Changes in specific activities}

The gas, electricity, and water consumption activities of the experimental group over time were analyzed (post-test mean scores T2 to T5 were compared with the pretest scores at T1). The mean scores over time from $\mathrm{T} 1$ to $\mathrm{T} 5$ of the specific daily activities were compared in a MANOVA analysis for repeated measures. Simple effects were also analyzed: the mean 
scores from $T 2$ to $T 5$ were compared with the mean scores at $\mathrm{T} 1$ (simple first). Preliminary analyses show that some of the water and energy saving activities were already being done extensively at $\mathrm{T} 1$ [more than four on a scale ranging from 1 (never) to 5 (always)], leaving almost no room for improvement. Only the activities that showed some room for improvernent were analyzed.

Only three of six gas activities scoredl less than four on a scale ranging from 1 (never) to 5 (always) at T1. These activities were: (1) "setting the thermostat back to $15^{\circ} \mathrm{C} 1$ hour before bedtime", (2) "turning off the radiator after a shower or bath", (3) "dressing more warmly instead of turning up the heat".The analyses for repeated measures reveal a significant effect for time for two of the six gas-conserving activities: "setting back the thermostat to $15^{\circ} \mathrm{C}$ 1 hour before bedtime" $[F(4,80)=2.77, p=.03]$ and "turning off the radiator after taking a bath or shower" $[F(4,80)=3.33, p=.02]$. The difference over time for setting back the thermostat could be attributed to doing so more consistently after the intervention started, significant simple effects: $\mathrm{T} 2(M=4.14, \mathrm{SD}=1.01)$ compared to $\mathrm{T} 1(M=3.18, S D=1.36), F$ $(1,20)=4.38, p=.05 ; T 3(M=4.29, S D=1.06)$ compared to $T 1, F(1,20)=4.48, p=.05 ; T 4(M$ $=4.57, S D=1.50$ ) compared to $T 1, F(1,20)=7.21, p=.02$. The simple effect analyses reveal an effect of time that could be attributed to more consistently turning off of the radiator after taking $a$ bath or shower after the intervention started (significant simple effects: T3 $(M=2.14, S D=1.38)$ compared to $T 1(M=1.71, S D=1.27), F(1,20)=3.86, p=.04 ; T 4(M=$ $2.24, S D=1.54)$ compared to $T 1, F(1,20)=5.76, p=.02 ; T 5(M=2.24, S D=1.51)$ compared to. T. . . $.(1.20)=5.76, n=\Omega 3)$

For changes in electricity-conserving activities, there were four of ten activities that scored below four at $\mathrm{T} 1$. These activities were: (1) "drying the laundry outside on the clothesline instead of using the dryer", (2) "turning off the background lighting to save energy", (3) "using low-energy bulbs for frequently used light sources", and (4) "choosing to do things by hand although you have ar electrical appliance to do it for you."The analyses for repeated measures only reveals an effect in time for "turning off the background lighting to save energly"; $F(4,80)=2.50, p=.05$. The simple-effect analyses reveal that the effect over time may be due to turning off background lighting more often; for $T 3(M=2.57, S D$ $=1.12)$ compared to $T 1(M=2.10,5 D=1.22), F(1,20)=4.09, p=.05$.

Changes in three of five water-conserving activities led to scores below four at $\mathrm{T1}$. These activities were: (1) cleaning the car with buckets of water instead of a garden hose, (2) using less water when taking a shower and (3) doing the dishes by hand instead of using the dishwasher. The repeated measurement analyses reveal no effect over time for the water-conserving activities.

\section{Face-to-face intervlews}

The face-to-face interviews reveal that the smiles and frowns were very appealing to small children. Children of ten years old or older found the information pages less interesting and consulted them less frequently. The respondents reported that they showed the 
pages to their neighbors, family, and friends, and they consulted the pages mostly in the evening during the commercials. They could not give a clear picture of their weekly gas, electricity, and water consumption, but they remembered very well whether or not they attained the target consumption level most of the time.

The face-to-face interviews reveal some alternative behavior changes that could account for the conservation of electricity and water. Participants said that they were more alert about the energy use of newly purchased appliances. One respondent said that the information pages made him aware of the wrong positioning of the refrigerator next to the radiator, so that one side of the refrigerator was constantly being heated. Limiting solarium use was another behavioral change mentioned. Some respondents mentioned that water savings were achieved by less frequently watering the garden.

\section{Discussion}

T The main purpose of this study was to examine whether weekly feedback combined with goal setting is effective in decreasing household water consumption. Secondary purposes were to examine and to explore the effects on electricity and gas consumption. We also explored which specific activities households changed to reduce their water, electricity, and gas consumption.

Two control groups were used to examine the effect of feedback in combination with goal setting in the experimental group: (1) a waiting-list control group of the same new housing development and (2) an extra control group from a comparable district.

These results proved clearly that feeclback and goal setting can have a considerable function in reducing household water consumption. Comparison of the experimental group with the waiting-list control group as well as comparison with the extra control group reveals a reduction of $15 \%$ in water use. The effects of this feedback and goal setting intervention is relevant in the context of the shortage of clean drinking water, which makes production and distribution more difficult and expensive. Furthermore, the results proved that feedback and goal setting can successfully reduce household electricity consumption. Comparison of the experimental group with the waiting-list control group reveals a reduction effect of $22 \%$; comparison with the extra control group reveals a reduction of $11 \%$ in electricity use. These effects are very relevant, in the context of the increasing electricity consumption by households due to the rapid proliferation of electric apparatus like microwaves, dryers, etc.

The present study also shows a reduction effect for gas of $25 \%$ in the comparison to the extra control group, although this finding is sornewhat debatable out of a statistic point of view (non-parallelity of regression lines). The effects for water and gas did not fade away in the long term (after 1 year), whereas electricity consumption continued to decrease after the first 4 months. However, the comparison of the experimental group 
to the waiting-list control group shows no significant effects of the intervention on gas consumption. As has been suggested before, this may be due to test effects in the waiting-list control group (for example, because they filled in the questionnaires). Another explanation may be that previous energy saving interventions mainly focussed on the regulation of the inside temperature. Reducing household electricity consumption applied for electric apparatus like microwaves, dryers, etc and water conservation may have been relatively unknown issues to the respondents in comparison to an efficient regulation of the inside temperature. The relatively low cost of water and the scarce attention to water and electricity (applied for electric apparatus) conservation might have caused less awareness of water and electricity consumption. Perhaps reducing water and electricity consumption was eașien than reducing gas consumption because they had never really tried it before, so there was more room for improvement. The possible contribution of this intervention to economizing on household energy consumption seems promising since policy makers showed an interest in implementing it on a large scale (Völlink, Meertens \& Midden, 2002).

The results of the study give some insight into the changes in gas and electricity' consumption activities. During the intervention, people reported that they set the thermostat back 1 hour before bedtime and turned off the radiator after taking a bath or shower more consistently. They also reported that they turned off the background lights more consistently. The face-to-face interviews gave an idea of which specific daily activities the households changed ta reduce their water consumption, such as watering the garden less frequently. The participants aiso said that the information pages made them a little more alert to consistently trying to save energy and water on a daily basis. The sum of these small effects might have caused the reported conservation effects. However, it must be noted that the behavior of only one family member per household was measured over time. The behavioral changes of other family members remain rather vague, even though their behavior may be very relevant to the explanation of the reduced consumption.

The results show much variation with respect to how consistently people repeat a specific water- or electricity-conserving activity. For instance, the respondents reported that they were very conșistent: in turning on the dishwasher only when it was fully loaded, but they also reported that they almost never did the dishes by hand instead of using the dishwasher. They sometimes chose to do things by hand although they had an electric appliance, but they did not seem very willing to do this more often to reduce their electricity and water consumption. It seems that people are willing to use appliances efficiently, but less willing to use them selectively. These results show that changing behavioral patterns to conserve energy and water is limited to behavioral patterns that do not interrupt daily activities too much.

In short, people seem to strive towards water and energy conservation goals by carrying out established conservation activities more consistently and by inventing new strategies to reach the goals. Thus, this study shows some evidence for all three of 
the mechanisms underlying the effects of goal setting that are mentioned by Locke and Latham (1990): trying harder, persisting longer and inventing new strategies.

The results of the study reveal that the information pages were a suitable instrument to inform the households about their water, electricity, and gas consumption. The participants evaluated the content of the pages as comprehensible and reliable, and a majority consulted the pages at least once a week.

The results reveal that the gas consumption of the experimental group declined from $\mathrm{T} 2$ to $\mathrm{T} 3$ more than that of the extra control group. Although this might be a learning effect of the feedback and goal setting intervention over time, it might also be an indication for an extra effect of the prompts on gas consumption, which where added at $\mathrm{T} 2$ for the experimental group. However, the design of this study was not particularly suited for a test of the beneficial effects of combining a goal setting and feedback intervention with prompts. A future study could compare the water and energy consumption levels of an experimental group with feedback, goal setting, and prompts to the levels of an experimental group with feedback and goal setting without prompts. The extra reduction effect between $\mathrm{T} 2$ and $\mathrm{T} 3$ in the experimental group was not confirmed for electricity and water consumption, so there is no indication of an extra effect of prompts in these cases.

Like every study, the present one has some limitations. There were some differences between the study groups at $\mathrm{T} 1$ (e.g., sex distribution), sometimes notwithstanding the random assignment to study groups. However, the idea that these differences influenced the results is not very plausible, since all analyses dealt with changes in dependent variables or controlled for differences at $\mathrm{T} 1$. The field setting of this experimental study caused some trouble: technical problems with the automatic meter reading caused the loss of some data. The lack of historical gas, electricity, and water consumption (the houses were newly built) was also a limitation. Nevertheless, conducting the study in a field setting among families living in energy-efficient new houses is also a strength. It proves that: changes in daily activities are important, even while structural measures like insulation; energy-efficient appliances, and water savers on toilets already have been taken.

This study indicates the appropriateness of the information pages for reducing household water consumption and electricity use (not related to temperature regulation). Within the framework of the current developments, the success of this feedback and goal-setting intervention is very promising and has, as far as we know, never been demonstrated before. These findings stress the usefulness of giving outcome feedback instead of specific tips or behavior feedback because households can choose which behaviors they want to change. 
CHAPTER FIVE 
Effects Of Repeated Negative Feedback On Cognitive Factors And Performance in A Non- Hierarchical And Non-competitlve Field Setting

Submitted for publication as:

Völlink, T., \& Meertens, R. (2003). Effects of repeated negative feedback on cognitive factors and performance in a non- hierarchical and non-competitive field setting. 


\section{INTRODUCTION}

n goal setting and feedback interventions, people receive frequent feedback about their progress towards a goal. Although feedback and goal setting can be applied separately, it is the combination of both methods that leads to the best performance (Bandura, 1997; Cervone, 1993). The effect of goal setting and feedback on performance has been the topic of many studies carried out in for example educational, organizational, industrial, and laboratory settings, and applied to a diversity of fields like energy conservation, weight loss, sports and exercise. On the basis of a meta-analysis, Locke and Latham (1990) concluded that setting a goal in combination with feedback is a powerful strategy to improve performance in a variety of settings. Furthermore, they concluded that the more difficult the goal set, the better the performance, provided that people have an adequate sense of selfefficacy, that the limits of ability are not reached and that people remain strongly committed to their goal. In other words, the higher the goal the better people perform, as long as the above conditions are met. Numerous laboratory and field studies have confirmed this linear relationship between goal difficulty and performance (see Cervone, 1993).

However, many of the experiments with the level of goal difficulty involved a single effort to achieve an individual goal (Bandura, 1997), whereas in the longer term, difficult or very difficult goals may relatively often lead to negative feedback, that is, to the message that one did not succeed in attaining the goal. Initially, negative feedback may result in people trying harder, persisting longer and seeking other strategies to attain the goal. When this does not lead to success, however, people may conclude that the goal is impossible to reach for them, and their self-efficacy and success expectancy will decline (Bandura, 1997). Eventually, this may lead to loss of goal commitment and/or to a drop in performance.

Although Locke and Latham (1990) acknowledge these possible negative effects of difficult goal setting via repeated negative feedback, they do not recommend more moderate goal setting. Instead, they recommend maximizing both performance and satisfaction by using goals for motivational purposes and by rewarding performance to prevent dissatisfaction.

These recommendations may be especially suitable for the type of hierarchical and/or competitive settings (like organizational or behavioral research settings) in which most of these studies were conducted. In all, 239 of the studies reviewed by Locke and Latham (1990) were done in a behavioral research ('laboratory') setting, versus 156 in a field setting. Although the overview of the tasks that were used in the studies reviewed by Locke and Latham does not always clearly show in what kind of settings the field studies were conducted, most of the tasks indicate that the studies were done in hierarchical and/ or competitive settings, involving tasks like management and supervision $(n=14)$, factory work $(n=11)$, course work $(n=11)$, sales $(n=8)$, etc.

In an organizational setting, managers can reward their employees, and commit. 
ment to the organization's goals is an agreed-upon characteristic of a good employee. In non-hierarchical and non-competitive settings, however, for example at home or in recreational settings, rewarding performance is often difficult and people may easily drop their commitment to the goal. What is more, people usually have to combine many, more or less specific goals at home (e.g., exercising for an hour a day, saving energy, painting the walls, spending more time with the children), and dropping one goal often means that achieving another goal becomes more likely. Hence, in fields like health promotion, energy conservation and litter control, difficult goals and the consequent repeated negative feedback may easily lead to a drop in goal commitment and performance.

In the present study, we examined the effect of repeated negative feedback on the credibility of feedback information, goal commitment, self-efficacy, expectancy of success and motivation to attain a goal. Households in our study received weekly feedback about their gas, electricity, and water consumption in relation to weekly targets. Data for the present study were gathered from a larger study evaluating the energy and water consumption reducing effect of five information pages provided via people's television sets, giving weekly feedback about household energy and water consumption relative to a goal (Völlink \& Meertens, submitted). In this non- hierarchical and non-competitive setting, commitment to a goal might be less self-evident, and rewards for trying would be more difficult to distribute. Therefore, households might use alternative coping mechanisms to deal with the gap between performance and goal after repeated failure. Instead of enhancing their effort, people may lower their goal, abandon commitment to their initial goal and/or eliminate the discrepancy by rejecting the feedback message (Bandura, 1997; Campion \& Lord, 1982; Nease, Mudgett \& Quinos, 1999).

The effect of repeated negative feedback on cognitions like self-efficacy and goal commitment on the one hand and performance or behavior on the other has not received much attention from researchers. According to Bandura (1997), negative feedback about one's performance in relation to a goal activates feelings of dissatisfaction that motivate people to perform better. The response to negative feedback is mediated by self-efficacy, which means that high self-efficacy people increase their effort after failure, while low selfefficacy people decrease their effort (Bandura \& Cervone, 1983). In the long term, however, when more effort and persistence does not lead to success, high self-efficacy people may conclude that the goal is impossible to reach for them, and their self-efficacy and success expectancy will decrease (Bandura, 1997).

Additionally, some studies have confirmed that repeated negative feedback may lead to other mechanisms than trying harder to reach the goal, for example to lowering the goal or rejecting the feedback. Campion and Lord (1982) found, for instance, that success tended to be more often followed by a raising and failure by a lowering of sub. sequent goals. Nease, Mudgett and Quinos (1999) examined the relationship between repeated negative feedback, self-efficacy and acceptance of feedback information. In their study, people received bogus negative feedback, which decreased the acceptance 
of the feedback message by high self-efficacy individuals, whereas bogus positive feedback lowered the acceptance of the feedback message by low self-efficacy individuals. Furthermore, Erez and Zidon (1984) found that when goal acceptance (a concept closely related to goal commitment) dropped in response to increasingly difficult goals, performance dropped accordingly.

Our study examined whether repeated negative feedback in a non-hierarchical and non-competitive setting has negative consequences in the long run. We expected that repeated negative feedback would first negatively affect relevant cognitions (i.e., self-efficacy, success expectancy, goal commitment and motivation to attain a goal). The feedback was designed to be as credible as possible, so we did not expect that repeated negative feedback would affect feedback credibility. Then after some time, we expected, it would also negatively affect their performance.

\section{METHOD}

\section{Participants and design}

Data for the present study were gathered from a larger study of 62 homes randomly as. signed to an experimental or a waiting list control group with a pretest-posttest design. The heads of the households were all home owners living in the same energy-efficient new housing development in a Dutch village. This study used only data from the experimental group ( $n=29)$, including the data of the pretest (T1) and those collected after 14 weeks of feedback (T2) and after 26 weeks of feedback (T3). Two households were omitted from the analyses due to technical problems with collecting their weekly gas, electricity, and water consumption data.

In all, $8 \%$ of the participants lived alone, $50 \%$ percent were young couples without children and $42 \%$ were families with children. In all $53 \%$ of the respondents in the experimental group were female.

\section{Procedure}

Two weeks before the start of the feedback and goal setting intervention, households received a form asking them to set a personal gas, electricity, and water conservation goal of $5 \%, 10 \%$ or $15 \%$. To increase the chance that participants would set a realistic but challenging goal, goals were not assigned; participants had to choose one of these goals. A covering letter gave some information about goal difficulty and about the efforts necessary to achieve a $5 \%$, $10 \%$, or $15 \%$ reduction goal. The participants were told that a $5 \%$ reduction goal would be easy to attain, a $10 \%$ goal would be challenging but realistic, and a $15 \%$ goal would be very hard to achieve in most cases and would require sacrificing comfort. Since the houses were newly built, the utility company estimated annual norm consumption levels for gas, electricity, and water on the basis of the energy and water consumption 
levels in the months preceding the intervention and characteristics of the house like insulation grade and the volume of the house in $\mathrm{m}^{3}$. The norm consumption level minus the personal conservation goal was the target saving. Respondents who did not return their questionnaires in time received a reminder. The questionnaires had to be filled out by the same person - the one who was responsible for most of the housekeeping.

The energy and water consumption in the month preceding the intervention (from To to T1) was used as a baseline. The numbers of times households received positive or negative feedback were counted after 14 weeks (T2) and 26 weeks (T3) of feedback.

\section{Feedback}

The weekly feedback on water, electricity, and gas consumption was presented to the participants on five information pages shown via a special channel on their television sets. The pages were updated each week. Participants were able to consult the pages at any time. Gas, electricity, and water consumption levels for the previous week were compared with their target consumption.

Page 1 told households whether their water and energy consumption was less or more than their target consumption for that week, using three smiling, frowning or neutral faces (one for gas, one for electricity and one for water). The faces looked neutral when households' current use was less than $3 \%$ above their target use, they' smiled when they had achieved their target use and frowned when their use was more than $3 \%$ above their target use. The following three pages showed consumption levels for the last 4 weeks, compared with a target, by means of histograms. The final page presented cumulative information about their consumption levels, savings and costs.

\section{Measurements}

Data was collected by means of structured questionnaires and meter readings. The structured questionnaires measured credibility of feedback information, goal commitment, self-efficacy, success expectancy and motivation to attain the goal.

Credibility of feedback information was measured by the following question: "How credible do you think the information pages are/will be in informing you about your water / gas / electricity consumption?" This item was answered on a scale ranging from 1 (very reliable) to 5 (very unreliable).

Goal commitment was measured using a six-point scale developed by Hollenbeck, Williams and Klein (1989) and consisting of the following items: (1) "I am strongly committed to achieving this goal", (2) "Quite frankly, I don't care if I achieve this goal or not:" (3) "It is quite likely that this goal might need to be revised depending on how things go", (4) "It wouldn't take much for me to abandon this goal", (5) "It is hard to take this goal seriously", and (6)"I think this goal is a good goal to shoot for". The items could be answered on a scale from 1 (strongly disagree) to 5 (strongly agree).

Self-efficacy to attain the goal was measured by a scale consisting of the following 
two items: (1)"Do you think you are able to achieve your gas / electricity / water consumption goal?" This item was measured on a scale ranging from 1 (very negative) to 5 (very positive). The second item was: (2) "Hovw much effort do you think it. will take you to achieve your goal?" This item was measured on a scale ranging from 1 (no effort at all) to 5 (very much effort).

Expectancy of success. was measured by the following item: "How great cio you expect the chance to be that you will attain your goal from now on?" This item could be answered on a scale ranging from 1 (very smalh) to 5 (very great).

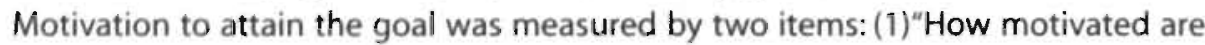
you to attain the gas / electricity' / water consumption target?"This question could be answered on a scale ranging from 1 (poorly motivated) to 5 (highly motivated) and (2) "I would describe myself as someone who is very motivated to save gas / electricity / water)"."This item was answered on a scale ranging from 1 (strongly disagree) to 5 (strongly agree).

\section{Positive and negative feedback}

The numbers of times households received positive. or negative feedback during the first 14 weeks (from T1 to T2) and during the first 26 weeks (from T1 to T3) were: counted. The feedback wasi considered positive when households had met their target or used less than their target. The feedback message was considered negative when households had exceeded their target.

\section{Meter readings and energy and water savings}

Gas, electricity, and water use data were collected by automated meter readings. The effects of repeated negative feedback were measured after 14 weeks (between T1 and T2) and 26 weeks of feedback (between T1 and T3). We first calculated changes in consumption after 14. weeks of feedback using the following equation: Mean weekly consumption levels from T2 to T3 - mean weekly consumption levels between TO and T1 (the month that preceded the interventionj. Secondly, we caiculated changes in consumption after 26 weeks of feedback. as follows: mean weekly consumption levels between T3 and T4 - mean weekly' consumption levels between T0 and T1 (the month that preceded the intervention).

\section{Internal consistency}

Cronbach's alphas for the commitment scale at T? were .7'6 for gas, .75 for electricity and 83. for water. This was considered satisfactory. Pearson correlations between the two items of the self-efficacy scale were. $28, p=.09$ for gas, $.29, p=.08$ for electricity and.44, $p=.05$ for water. Since this indicates a rather low internal consistency, the two items were not only analysed as a scale (which is defensible from a theoretical point of view), but also as separate ittems. Pearson correlations between the two items of the motivation scale were $.57 ; p=.05$ for gas, $.68 ; p=.00$ for electricity and $.67, p=.00$ for water, which was considered 
satisfactory.

\section{Analyses}

We used linear regression analyses to examine our expectation that the number of times households received negative feedback would negatively affect self-efficacy, success. expectancy, goal commitment and motivation to reach the goal. These analyses were conducted after 14 weeks and after 26 weeks, of feedback, respectively (comparing T2 and T3 with T1).

Secondly, we used hierarchical linear regression analyses to analyze the effects of the number of times households received negative feedback (after 14 weeks and 26 weeks of feedback) on gas, electricity, and water consumption. As it was to be expected that it would be easier for high-use consumers to save water and energy than for low-use consumers, the estimated previous annual consumption was entered in step one, followed by the number of times households had received negative feedback.

We then examined in more detail the possible mediating function of the cognitive factors between the number of times households received negative feedback and changes in gas, water, and/or electricity consumption. According to the instructions by Baron and Kenny (1986) a test for mediation consists of three separate regression equations, testing the following conditions. First, the independent variable (the number of times households had received negative feedback) should affect the mediators (changes in cognitions). Second, the independent variable should affect the dependent variable (changes in consumption level). Third, the effect of the independent variable (the num. ber of times households had received negative feedback) on the dependent variable (changes in consumption level) should become smaller when controlling for the mediators (changes in cognitions). The mediation is perfect if the independent variable has no effect on the dependent variable when the mediator is controlled for.

The estimated consumption for the previous year was entered in step one in all analyses that had consumption as the dependent variable. Furthermore, in the analyses testing the third condition for mediation, changes in cognitions were entered in step two, followed by the number of times households received negative feedback (entered in step three).

\section{Results}

Feedback credibility, goal commitment, self-efficacy, outcome expectancy, and motivation at $\mathrm{T} 1$

We tested whether people's judgment of the credibility of the feedback information was affected by the number of times they received negative feeclback. Linear regression analyses, with the number of times people had received negative feedback as the predictor 
and feedback credibility as the independent variable, revealed no significant effects on credibility of the feedback message among the households after 14 weeks of feedback for water $(\beta=.06, p=.80)$, electricity $(\beta=-.04, p=.86)$, and gas $(\beta=.30, p=.18)$ or after 26 weeks of feedback for water $(\beta=-.24, p=.27)$, electricity $(\beta=-.23, p=.38)$, and gas $(\beta=-.24$, $p=.35)$. As we expected, the credibility of the feedback information did not change during the feedback and goal setting intervention.

In our study, households participated by setting a savings target of $5 \%, 10 \%$ or $15 \%$. Few households $(7 \%)$ chose the most difficult target of $15 \%$, while $52 \%$ chose a less difficult target of $10 \%$ and $41 \%$ chose the easiest target of $5 \%$. Since the households set their own personall goals, we expected that goal commitment, self-efficacy, outcome expectancy and motivation to attain their goal would be equally high for households with the relatively easy $5 \%$ goal and those with the relatively difficult $10 \%$ and $15 \%$ goals. The results of the MANOVAs comparing the mean scores of these cognitions at $\mathrm{T} 1$, just before the start of the intervention, between the respondents with a difficult ( $10 \%$ or $15 \%$ ) goal and households with a relatively easy $(5 \%)$ goal confirmed this assumption for gas ( $F$ $(4,21)=.52, p=.72)$, electricity $(F(4,21)=.69, p=.61)$, and water $(F(4,21)=.86, p=.54)$.

The overall mean scores for goal commitment just before the start of the intervention (T1), measured on a five-point scale, were $M=4.24, S D=.52$ for gas, $M=4.24$, SD $=.46$ for electricity, and $M=4.22,5 D=.51$ for water, indicating quite high levels of commitment to the chosen goals. The mean outcome expectancy scores, also measured at $\mathrm{T} 1$ on a five-point scale, were $M=3.54, S D=.58$ for gas, $M=3.62, S D=.57$ for electricity, and $M$ $=3.58,5 D=.50$ for water, meaning that people were quite positive about attaining their savings targets. The overall scores of perceived self-efficacy at $T 1$, measured on a ten-point scale, were $M=7.77, S D=.99$ for gas, $M=7.35, S D=.98$ for electricity, and $M=7.23, S D=$ 1.28 for water, indicating that people's self-efficacy perceptions about attaining their savings goals were quite high. The mean scores for motivation to attain the goal, measured at $T$ l on a ten-point scale, were $M=7.54, S D=1.58$ for gas, $M=7.54, S D 1.56$ for electricity, and $M=7.62, S D=1.60$ for water, which means that people were quite motivated to attain their savings targets.

\section{Effect of repeated negative feedback on cognitive factors and on household gats , electricity, and water conservation}

We first examined the effect of repeated negative feedback after 14 weeks (T1-T2) and 26 weeks (T1-T3) of feedback on the following cognitive variables: self-efficacy, success expectancy, goal commitment and motivation to reach the goal.

\section{Changes in self-efficacy}

Regression analyses for water, using the number of times people had received negative. feedback as the predictor and changes in self-efficacy as the dependent variable, revealed that the number of times households had received negative feedback accounted for $47 \%$ 
of the variation in changes in self-efficacy $(\beta=-.68, p=.00)$ after 14 weeks of feedback, and $39 \%$ of the variance in changes in self-efficacy $(\beta=-.63, p=.00)$ after 26 weeks of feedback.

Analyses for electricity, using the number of times people had received negative feedback as the predictor and changes in self-efficacy as the dependent variable, showed that repeated negative feedback accounted for $43 \%$ of the variance in changes in self-efficacy ( $\beta=-.65, p=.00$ ) after 14 weeks of feedback, and $61 \%$ of the variance in changes in self-efficacy $(\beta=-.78, p=.00)$ after 26 weeks of feedback.

The analyses for gas, using the number of times people had received negative feedback as the predictor and changes in self-efficacy as the dependent variable, revealed that the number of times households had received negative feedback explained $16 \%$ of the variation in changes in self-efficacy after 14 weeks, which was borderline significant ( $\beta$ $=-.40, p=.07)$, whereas no significant effects on self-efficacy were found after 26 weeks of feedback $(\beta=.005, p=.98)$.

In all cases, a negative beta indicates that the more often people received negative feedback, the more their self-efficacy with regard to reaching their goal decreased. Analyses of the individual self-efficacy items led to the same conclusion: people's self-efficacy with regard to reaching their water and electricity targets was lower the more often they had received negative feedback about their water and/or electricity targets.

\section{Changes in success expectancy}

Regression analyses for water, using the number of times people had received negative feedback as the predictor and changes in success expectancy as the dependent variable, showed that the number of times households had received negative feedback about their water consumption level accounted for $51 \%$ of the variance in the changes in expectancy of success after 14 weeks of feedback ( $\beta=-.71, p=.00$ ) and $27 \%$ of the variance in changes in success expectancy after 26 weeks of feedback $(\beta=-.52, p=.01$ ).

Analyses for electricity, using the number of times people had received negative feedback as the predictor and changes in success expectancy as the dependent variable, revealed that $50 \%$ of the variance in changes in success expectancy $(\beta=-.71, p=.00)$ was explained by the number of times households had received negative feedback after 14 weeks of feedback. After 26 weeks of feedback, the number of times households had received negative feedback explained $37 \%$ of the variance in changes in success expectancy with regard to attaining the electricity savings target $(\beta=-.62, p=.01)$. The negative beta again means that the more often households received negative feedback, the more their expectancy about attaining their water and electricity savings targets declined.

Analysis for gas, using the number of times people received negative feedback as the predictor and changes in success expectancy as the dependent variable, showed that the number of times households had received negative feedback about their gas consumption did not significantly contribute to the explanation of the variance in changes 
in success expectancy with regard to attaining their gas savings target $(\beta=.16, p=.47)$ after 14 weeks, nor after 26 weeks of feedback $(\beta=.01, p=.98)$. These results show that the households' success expectancy with regard to attaining their gas savings target was not affected by the number of times they received negative feedback.

\section{Changes in goal commitment}

Regression analyses for water, using the number of times people had received negative feedback as the predictor and changes in goal commitment as the dependent variable, showed that the number of times households had received negative feedback about their water consumption level accounted for $24 \%$ of the variation in changes in commitment to their water savings goal after 14 weeks of feedback $(\beta=-.49, p=.02)$ and $17 \%$ of the variance in changes in commitment to their water savings goal after 26 weeks of feedback $(\beta=-.41, p=.05)$.

Regression analyses for electricity, using the number of times people had received negative feedback as the predictor and changes in goal commitment as the dependent variable, revealed that after 14 weeks of feedback, the effect of the number of times people had received negative feedback on changes in goal commitment was borderline significant (explaining 13\% of the variance in changes in goal commitment), ( $\beta=$ $-37, p=.09$ ). However, the same regression was not significant after 26 weeks of feedback $(\beta=-.39, p=.12)$.

The analyses for gas, using the number of times people had received negative feedback as the predictor and changes in goal commitment as the dependent variable, showed that after 14 weeks of feedback, the effect of the number of times households had received negative feedback about their gas consumption was marginally significant ( $\beta=-37, p=.09$ ), explaining $14 \%$ of the variance in changes in goal commitment. After 26 weeks, the same analysis revealed that $21 \%$ of the variance in changes in goal commitment was explained by the number of times households had received negative feedback $(\beta=-.46, p=.03)$. Negative betas indicate that the more often people received negative feedback, the more their commitment to their goal decreased.

\section{Changes in motivation}

Regression analyses, using the number of times people had received negative feedback as the predictor and the motivation to attain the savings target as the dependent variable, showed no significant results for water, $(\beta=.20, p=.35)$, electricity $(\beta=-.38, p=.09)$, or gas $(\beta=.09, p=, 68)$ after 14 weeks of feedback. After 26 weeks of feedback, the same analyses revealed no significant effects for water $(\beta=-.22, p=.30)$, electricity $(\beta=.35, p=.17)$, or gas $(\beta=.21, p=.33)$ either. These results indicate that people's motivation to reach their water, gas, and electricity goals was not affected by the number of times they received negative feedback. 


\section{Changes in water, electricity, and gas consumption}

Separate hierarchical linear regression analyses for gas, water, and electricity were conducted, with estimated consumption in the previous year entered in step one, the number of times households had received negative feedback entered in step two and changes in the household's consumption level as the dependent variable.

After 14 weeks of feedback we found that the estimated annual norm consumption prior to the intervention accounted for $42 \%$ of the variation in changes in household water consumption ( $\beta=-.59, p=.00$ ), while negative feedback did not contribute signifcantly $(\beta=-.26, p=.12)$. In addition, we found that the estimated annual norm consumption accounted for $43 \%$ of the variation in changes in household electricity consumption after 14 weeks of feedback $(\beta=-.64, p=.00)$, while repeated negative feedback did not significantly contribute to the variation in the dependent variable $(\beta=-.07, p=.71)$. The same analysis was not significant for gas, indicating that changes in people's gas consumption after 14 weeks of feedback were not affected by the estimated annual year consumption $(\beta=-.34, p=.14)$ nor by the number of times people had received negative feedback $(\beta=-.41, p=.08)$.

Results of the first two analyses showed that the higher the consumption at pretest, the more water and electricity was saved. The results also revealed that after 14 weeks of feedback, gas, water, and electricity consumption by the households was not affected by the number of times they had received negative feedback.

Subsequently, we examined the effect of repeated negative feedback after 26 weeks on changes in the water, electricity, and gas consumption by the households. The regression analysis revealed that the estimated annual norm consumption prior to the intervention explained $25 \%$ of the variance in changes in household water consumption ( $\beta$ $=-.53, p=.01$ ), while an additional $10 \%$ was explained by the number of times households had received negative feedback, being marginally significant $(\beta=-.34, p=.07)$.Furthermore, the analysis revealed that $31 \%$ of the variation in household electricity consumption after 26 weeks of feedback was explained by the estimated annual norm consumption ( $\beta=-.59$, $p=.01$ ) whereas the number of times households had received negative feedback did not significantly contribute $(\beta=-.24, p=.26)$. Additionally, we found that the estimated annual norm consumption accounted for $11 \%$ of the variation in changes in gas consumption by the households after 26 weeks of feedback $(\beta=-.68, p=.00$ ) whereas the number of times households had received negative feedback accounted for $14 \%$ of this variation $(\beta=-.42$, $p=.03$ ). The outcomes of the hierarchical linear regression analyses after 26 weeks of feedback again revealed that high-use consumers saved more water, gas, and electricity than low-use consumers. In contrast to the findings after 14 weeks of feedback, it was found that the number of times people had received negative feedback negatively affected the reduction of their water and gas consumption, although the regression for water was only marginally significant. This negative correlation between repeated negative feedback and conservation was not confirmed for electricity. 


\section{Mediating effect of cognitions on performances}

As was described above, an effect between independent and dependent variables can be regarded as being mediated by a third variable when three conditions are met: (1) the independent variable should affect the mediators, (2) the independent variable should affect the dependent variable, and (3) the effect of the independent on the dependent variable should become smaller when controlling for the mediators (Baron and Kenny, 1986). As described in the previous sections, the outcomes of the linear regression analyses revealed that, as regards water, conditions one and two were met for self-efficacy, success expectancy and goal commitment after 26 weeks of feedback, whereas for electricity, conditions one and two were never met. For gas, the analyses revealed that after 26 weeks, conditions one and two were met for goal commitment. In line with the instructions by Baron and Kenny, the hierarchical linear regression analyses to test condition three were conducted only for those cases for which the first two conditions were fulfilled. According to the third condition for mediation, the effect of the independent variable (i.e., the number of times people had received negative feedback after 26 weeks of feedback for water and gas) on the dependent variable (changes in water and gas consumption) had to be less when controlling for the mediator(s) (i.e., self-efficacy, goal commitment, success expectancy for water and goal commitment for gas).

A first hierarchical regression analysis was conducted with changes in water consumption after 26 weeks of feedback as the dependent variable. The estimated annual norm consumption was entered in step one, followed by changes in self-efficacy, success expectancy and goal commitment in step two, and the number of times households had received negative feedback in step three. The results revealed that the estimated annual consumption explained $33 \%$ of the variation in changes in water consumption ( $\beta=-.58$, $p=.011$; the more water households had consumed prior to the feedback and goal setting intervention, the more they saved during the intervention. After correction for the estimated annual consumption, changes in household water consumption were not significantly explained by changes in self-efficacy $(\beta=-.04, p=.91)$, changes in success expectancy $(\beta=.43, p=.24)$, changes in goal commitment $(\beta=-.22, p=.38)$ or changes in the number of times households had received negative feedback $(\beta=-.28, p=.27)$.

A second hierarchical regression analysis was conducted with changes in household gas consumption after 26 weeks of feedback as the dependent variable. The independent variables entered consecutively in the analysis were the estimated annual consumption (entered in step one), changes in commitment (entered in step two), and changes in the number of times households had received negative feedback about their gas consumption (entered in step three). The analysis revealed that the estimated annual consumption explained $26 \%$ of the variation in changes in household gas consumption ( $\beta$ $=-.51), p=.02$ ), meaning that the more gas households had consumed prior to the feedback and goal setting intervention, the more they saved during the intervention. Changes in goal commitment ( $\beta=-12, p=.62$ ) did not contribute significantly, whereas the number 
of times households had received negative feedback accounted for $17 \%$ of the variation in the changes in gas consumption $(\beta=-.49, p=.04)$. These analyses for water and gas consumption made it clear that the relations between repeated negative feedback and changes in consumption levels were not mediated by the cognitive factors examined in this study.

\section{Discussion}

T he main purpose of the present study was to examine the effect of repeated negative feedback in a non-hierarchical and non-competitive setting on both cognitive factors and performance. In line with our predictions, we found that the households' initial high self-efficacy expectations and success expectancy with regard to attaining their water and electricity savings targets were negatively influenced by the number of times they received negative feedback about their consumption level. Remarkably, these negative relations between the number of times they received negative feedback and changes in self-efficacy and success expectancy were not confirmed for gas. An explanation might be that the households were less familiar with economizing on electricity and water use than with reducing their gas consumption for an efficient regulation of the inside temperature. Most western countries have a long tradition in education about energy saving in relation to regulation of the inside temperature (see Geller, Winett and Everett, 1982), but not in education on electricity (insofar as it is not used for heating) and water saving. Therefore, people may have more stable and less easy to change cognitions about saving gas than about saving water and electricity.

In line with the results of Bandura (1997) we found that repeated negative feedback decreased the households' initially high commitment to attaining their savings targets for water (after 14 and 26 weeks of feedback) and gas (after 26 weeks of feedback). This relationship between repeated negative feedback and goal commitment proved to be borderline significant for electricity after 14 weeks of feedback. These results suggest that repeated negative feedback may have negative effects on relevant cognitions like self-efficacy and goal commitment.

In contrast to our expectations, we found that the households' motivation to attain their water, electricity, and gas savings targets was not affected by the number of times they received negative feedback.

Additionally, we found a relation between the number of times households received negative feedback and changes in water and gas consumption, which indicates that the water and gas savings declined more strongly the more often negative feedback was received over a longer period of time ( 26 weeks of feedback). Although this effect of repeated negative feedback on savings was not confirmed for electricity, the results suggests that in some situations, repeated negative feedback may lead to poorer perfor- 
mance in the long run. This may especially be the case in situations that are not hierarchical or competitive, in which not doing one's utmost carries no cost in the sense of getting a penalty or losing/ a reward (as in an organizational setting), or feeling bad after a weak performance (as would be the case in a competitive setting).

Finally, we found no evidence that the relationship between the number of times households received negative feedback and changes in household water and gas consumption was mediated by changes in self-efficacy, success expectancy or goal commitment. An explanation might be that the effect of repeated negative feedback on performance took place via changes in affective reactions like unconcern, losing interest in conservation activities or becoming frustrated after repeated failure. This would be in line with the results of a study conducted by Cervone, Jiwani and Wood (1991), who found, arnong other things, that a more positive mood caused by a successful experience after the first block of trials led to higher levels of effort on subsequent complex tasks. They concluded that mood influenced performance on complex tasks through processes other than self-evaluative processes like self-efficacy perception.

The present study was characterized by certain special strengths and limitations that deserve some attention. A methodological limitation of this study was the small study group, which may have caused a loss of power with regard to confirming the mediating effect of the cognitive factors on changes in energy and water consumption. The strength of the current study was that it provides more insight into the cognitive and behavioral reactions of members of households exposed to repeated negative feedback in a non-hierarchical and non-competitive setting. Our study provided some evidence that repeated negative feedback first has a negative effect at a cognitive level, and when it continues, also negatively affects performance. This finding may be specific for the non-competitive and non-hierarchical setting of this study. 
REFERENCES

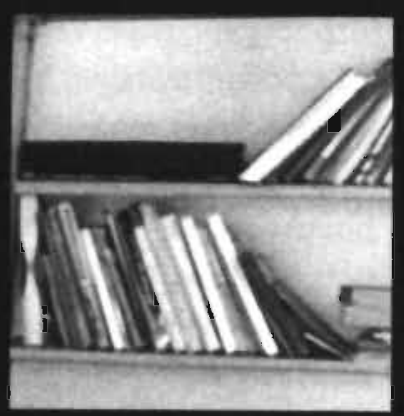




\section{REFERENCES}

Ajzen, I. (1991). The theory of planned behavior. Organizational Behavior and Human Decision Processes, 50, 179-211.

Atkinson, J. W. (1964). An introduction to motivation. Princeton, N.J.: Van Nostrand.

Bandura, A. (1997). Health promotion from the perspective of social cognitive theory. Psychology and Health, 13, 623-649.

Bandura, A., \& Cervone, D. (1983). Self-evaluative and self-efficacy mechanisms governing the motivational effects of goal systems. Journal of Personality and Social Psychology, 45, 1017-1028.

Baum, A., \& Singer, J.E. (Eds.). (1981). Advances in environmental psychology. Volume 3 Energy: psychological perspectives. Hillsdale, New Jersey: Lawrence Erlbaum Associates.

Becker, LJ. (1978). Joint effect of feedback and goal setting on performance: A field study of residential energy conservation. Journal of Applied Psychology, 63, 428-433.

Becker, L.J., \& Seligman C. (1978). Reducing air conditioning waste by signaling it is cool outside. Personality and Social Psychology Bulletin, 4, 412-415.

Berk, R.A., Cooley, T.F., LaCivita, C.J., Parker, S., Sredl, K., \& Brewer, M. (1980). Reducing consumption in periods of acute scarcity: The case of water. Social Science Research, 9, 99-120.

Berkowitz, M.K., \& Haines, G.H. (1980). Multi-attribute analysis of solar and other space heating preferences. In J.D. Claxton, C.D. Anderson, J.R.B. Ritchie \&

G.H.G. McDougall Eds., Consumers and energy conservation:International perspectives on research and policy options, New York: Praeger, pp.108-114.

Bettman, J.R. (1979). An information processing theory of consumer choice, Reading: Addison Wesley Publishing Company, pp.173-228.

Bittle, R.G., Valesano, R., \& Thaler, G. (1979). The effects of daily cost feedback on residential electricity consumption. Behavior Modification, 3, 187-202.

Brandon, G., \& Lewis, A. (1999). Reducing households energy consumption: A qualitative and quantitative field study. Journal of Environmental Psychology, 19, 75-85.

Campion, M. A., \& Lord, R.G. (1982). A control systems conceptualization of the goal setting and changes process. Organizational Behavior and Human Performance, 30, 265-287.

Cervone, D. (1993). The role of self-referent cognitions in goal setting, motivation, and performance. In M. Rabinowitz (Ed) Cognitive science foundation of instructions, New Jersey: Lawrence Erlbaum Associates, pp. 57-95.

Cervone, D., Jiwani, N., \& Wood, R. (1991). Goal setting and differential influence of self-regulatory processes on complex decision-making performance. 
Journal of Personality and Social Psychology, 61, 257-266.

Cherulnik, P.D. (1993). Applications of environment-behavior research: case studies and analysis, New York: Cambridge University.

Cook, S.W', \& Berrenberg, J.L. (1981). Approaches to encouraging conservation behaviour: a review and conceptual framework. Journal of Social Issues, 37, 73-107.

Corporate and Consumer Affaires. (1998). A fair deal for consumers: Modernizing the framework.

Cramer, D. (1998). Fundamental statistics for social research: step-by-step calcula tions and computer techniques using spss for windows, London: Routledge.

Darley, J.M., \& Beniger, J.R. (198i ). Diffusion of energy-conserving innovations. Journal of Social Issues, 37, 150-171.

Department of Economic Affaires. (1999). Action program energy conservation (vos no. 13b63). Brecia: Louis Vermijs.

Deveiopment Research Group, Infrastructure and Environment. Energy Center of the Netherlands (1999). Energie verslag Nederland [Dutch energy report]. Petten: Author.

Donovan, J.J., \& Radosevich, D.J. (1998). The moderating role of goal commitment. and the goal-difficulty performance relationship: A metä-analytic review and critical reanalysis. Journal of Applied Psychology, 2, 308-315.

Dwyer, W.O., Leeming. F.C., Cobern, M.K., Porter, B.E., \& Jackson, J.M. (1993). Critical review of behavioral interventions to preserve the environment. Environment and Behavior, 25, 275-32:1.

Ellerman, A.D., Jacoby, H.D., \& Deceaux, A. (1998). The effects on developing countries of the Kyoto Protocol and carbon dioxide emissions trading. Washington: The World Bank.

Erez, M., \& Zidon, I. (1984). Effect of goal acceptance on the relationship of goa! difficulty to performance. Journal of Applied Psychology, 69, 69-78.

European Community (2000). Het EU-beleid: Zuiver water [European Union policy: pure water]. Luxembourg: Bureau for official publications of the European Community:

Fiske, S.T., \& Taylor, S.E. (1991) Social Cognition, New York; McGraw-Hill.

Geller, E.S. (1989). Applied behaviour analysis and social marketing: An integra tion for environmental preservation. Journal of Social Issues, 45, 17-36.

Geller, E.S. (1995). Integrating behaviorism and humanism for environmental protection. Journal of Social issues, 51, 179-195.

Geller, E.S., Winett, R.A.* \& Everett, P.B. (1982). Preserving the environment: new strategies for behavior change. New York: Pergamon Press.

Hayes, S.C., \& Cone, J.D. (1977). Reducing residential electrical energy use: Payments, information, and feedback. Journal of Applied. Behavior Analysis, 


\section{$10,425-435$.}

Hayes, S.C., \& Cone, J.D. (1981). Reduction of residential consumption of electricity through simple monthly feedback. Journal of Applied Behavior Analysis, 14, 81-88.

Hollenbeck, J.R., Williams, C.R., \& Klein, HJ. (1989). An empirical examination of the antecedents of commitment to difficult goals. Journal of Applied Psychology, 74, 18-23.

Houghton, J.T., Meir Filho, L.G., Callander, B.A. Harris, N., Kattenberg, A. \& Maskell, K. (1996). Climate change 1995- the science of climate change. Cambridge: Universal press.

Houten van, R., Nau, P.A., \& Merrigan, M. (1981). Reducing elevator energy use: A comparison of posted feedback and reduced elevator convenience. Journal of Applied Behavior Analysis, 14, 377-387.

Houwelingen van, J.H., \& Raaij van,W.F. (1989). The effect of goal-setting and daily electronic feedback on in-home energy-use. Journal of Consumer Research, 16, 98-105.

Hutton, R.B., Mauser,G.A., Filiatrault, P., \& Ahtola, O.T. (1986). Effects of cost-related feedback on consumer knowledge and consumption behavior: A field experimental approach. Journal of Consumer Research, 13, 327-336.

Ilgen, D.R., Fisher, C.D., \& Taylor, M.S. (1979). Consequences of individual feedback on behavior in organizations. Journal of Applied Psychology, 4, 349-371.

Locke, E. A., \& Latham, G.P. (1990). A theory of goal setting \& task performance. Englewood Cliffs: Prentice Hall.

Intomart (1993). Actie; Zuinig stoken zuinig aan [Campaign; Be Economic, Heat Economically] (4.9377/EB/jvdg). Hilversum: Intomart.

Kant, P., \& Völlink, T. (1996). Elektronische feedback over energie- en waterverbruik aan huishoudens en MKB, Tega-Cai project. In K.F.B. Paauw, W.L.E. Aarts, M. Wolsink, A.M. Smits \& T. Völlink (Eds), Verbruikers in het klein. Verslag van de vierde studiedag energie en gedragspatronen. Petten: ECN.

Kasulis, J.J., Huettner, D.A., \& Dikeman, N.J. (1981). The feasibility of changing elec tricity consumption patterns. Journal of Consumer Research, 8, 279-290.

Katzev, R., Cooper, L., \& Fisher, P. (1981). The effect of feedback and social rein forcement on residential electricity consumption.Journal Environmental Systems, 10, 215-227.

Kempton, W., Darley, J.M., \& Stern, P.C. (1992). Psychologica! Research for the new energy problems: strategies and opportunities. American Psychologist, 47, 1213-1223.

Kluger A.N., \& DeNisi, A. (1996). The effect of feedback interventions on performance: A historical review, a meta-analysis, and a preliminary feedback. intervention theory. Psychological Bulletin, 119, 254-284. 
Labay, D.G., \& Kinnear, T.C. (1980). Consumer adoption of solar energy systems.

In J.D. Claxton, C.D. Anderson, J.R.B. Ritchie \& G.H.G. McDougall Eds., Consumers and energy conservation: International perspectives on research and policy options, New York: Praeger, pp. 115-122.

Leonard-Barton, D. (1988). Implementation characteristics of organizational in novations: limits and opportunities for management strategies. Communication Research, 15, 603-631.

Locke, E.A., \& Latham, G.P. (1990). A theory of goal setting \& task performance. Englewood Cliffs: Prentice Hall.

Locke, E. A., \& Latham, G.P. (2002). Building a practically useful theory of goal set ting and task motivation: A 35-year odyssey. American Psychologist, 57, 705-717.

McCalley, L.T., \& Midden, C.J.H. (2002). Energy conservation through productintegrated feedback: The roles of goal-setting and social orientation. Journal of Economic Psychology, 23, 589-603.

McCleland, L., \& Cook, S.W., Energy conservation effects of continuous in-home feedback In all-electric homes. Journal of Environmental Systems, 9, 169173.

McDougall, G.H., Gordon, H., Claxton, J.D., Ritchie, J.R., \& Anderson, C.D. (1981). Consumer energy research. Journal of Consumer Research, 8, 343-354.

Ministry of Housing, Spatial Planning and the Environment (1998). Nationaal Milieubeleidsplan 3 [National Environmental Policy Plan 3]. The Hague: Sdu Uitgeverij.

Midden, J.H., Meter, J.E., Weenig, M.H., \& Zieverink, H.J.A. (1983). Using feedback, reinforcement, and information to reduce energy consumption in households: a field-experiment. Journal of Economic Psychology, 3, 65-86.

National Institute for Public Health and the Environment (2000). Waterwinning en waterverbruik bij doelgroepen. [Analysis of water abstraction and water demand in the Netherlands] (RIVM Report 703717003). Bilthoven: Muelschlegel, J.H.C., \& Kragt, F.J.

Nease, A.A., Mudgett, B.O., \& Quinos, M.A. (1999). Relationship among feedback sign, self-efficacy, and acceptance of performance feedback. Journal of Applied Psychology, 84, 806-814.

Palmer, M.H., Lloyd, M.E., \& Lloyd, K.E. (1977). An experimental analysis of electricity conservation procedures. Journal of Applied Behavior Analysis, 10,665671.

Paauww, K.F.B., Aarts, W.L.E., Wolsink, M., Smits, A.M., \& Völlink, T. (1996) (Eds), ECN. Verbruikers in het klein. Verslag van de vierde studiedag energie en gedragspatronen. Petten: ECN. 
Raaij, van, W.F.(1986). Cognitieve en affectieve aspecten van informatieverwerking en besluitvorming. In P. Lebelle \& SJ. Muller (Eds), Bes/uitvorming wat weten wij ervan?[Decision making what do we know about it?] Deventer: Kluwer, pp. 79-96.

Rogers, E. M.(1983,1995). Diffusion of innovations (3th \& 4th ed.), New York: The Free Press.

Sarason, I.G., Sarason, B.R., \& Pierce, G.R. (1990). Social support, personality and performance. Journal of Applied Sport Psychology, 2, 117-127.

Seligman, C., \& Darley, J.M. (1977). Feedback as a means of decreasing residential energy consumption. Journal of Applied Psychology, 62, 363-368.

Seligman, C., \& Hutton, R.B. (1981). Evaluating energy conservation programs. Journal of Social /ssues, 2, 51-72.

Sexton, R.J., Brown Johnson, N., \& Konakayama, A. (1987). Consumer response to continuous-display electricity-use monitors in a time-of-use pricing experiment. Journal of Consumer Research, 14, 55-62.

Siero, W.S., Bakker, A.B., Dekker, G.B., \& Burg van den, M.T.C. (1996). Changing organizational energy consumption behaviour through comparative feedback. Journal of Environmental Psychology, 16, 235-246.

Thorndike, E.L. (1927). The law of effect. American Journal of Psychology, 39, 212-222.

Tornatzky, L.G., \& Klein, K.J. (1982). Innovation characteristics and innovation adoption implementation: A meta-analysis of findings. IEEE Transactions on Engineerings Management, 29, 28-45.

United States Environmental Protection Agency (2002, november). EPA acid rain program 2001 progress report. Retrieved May 10, 2003, from http://www.epa.gov/airmarkets/cmprpt/arp01/2001 report.pdf

Vermeer, B. (1998). Praktijkproef prepayment gasmeter: Communiceren via de chipkaart [A field study about the prepayment gas meter: Communicating via a smart card]. Gas Tijdschrift in de energiemarkt, 118,16-19.

Völlink, T.(1995). Adoptie en implementatie van energiebesparende projecten bij energie-distributiebedrijven. In: Siswo. Zevende marktdag milieu en samenleving. Amsterdam: Siswo.

Völlink, T. (1995). Electronic feedback by teletext for households and retailtrade. In: Novem (Eds)., Means and strategies to influence energy-related behavior in Europe. Second save-conference. Utrecht: Novem.

Völlink, T., \& Meertens, R.M. (1997).Verklarende factoren voor de adoptie van effectieve energiebesparende interventies door energiedistributiebedrijven. In:R.M. Meertens, W. Otten, A. Pruyn \& D. Daamen (Eds), Toegepaste Sociale Psychologie. Delft:Eburon.

Völlink, T., \& Meertens, R.M. (1999). De effectiviteit van elektronische Feedback over het energie- en waterverbruik door middel van teletekst bij huishoudens. In: R.M. 
Meertens, R.Vermunt, J.B.F. de Wit \& J.F. Ybema, (Eds), Toegepaste Sociale Psychologie. Delft: Eburon.

Völlink, T., Meertens, R. M., \& Midden, CJ.H. (2002). Innovating "diffusion of innovation theory": Innovation characteristics and the intention of utility companies to adopt energy conservation interventions. Journal of Environmental Psychology, 22, 333-344.

Völlink, T., \& Meertens, R.M. (2003). Goal-setting and feedback toward a sustainable future: an intervention to reduce household water and energy consumption. Manuscript submitted for publication.

Völlink, T., \& Meertens, R.M. (2004). Technological innovations and the promotion of energy conservation: The case of goal-setting and feedback. In P.P.Verbeek \& A. Slob (Eds), Technology, Behavior, and the Environment a multidisciplinary approach. Manuscript in Preparation.

Völlink, T., Meertens, R.M., Midden, C.J.H. (2004). Diffusion of technical innovations: The promotion of the large-scale use of technology. In P.P Verbeek \& A. Slob (Eds), Technology, Behavior, and the Environment a multidisciplinary approach. Manuscript in preparation.

Völlink, T., \& Meertens, R.M. (2004). The effect of the prepayment meter on residential gas consumption. Manuscript in Preparation.

Völlink, T., \& Meertens, R. M. (2004). Goal-setting and feedback toward a sustainable future: an intervention to reduce household water and energy consumption. Introduction. Manuscript in Preparation.

Völlink, T., \& Meertens, R.M. (2004). Effects of repeated negative feedback on cognitive factors and performance in a non-hierarchical and non-competitive field setting. Manuscript in Preparation.

Warkov, S. (1981). Community characteristics predicting public interest in household soiar. Paper presented at the international symposium-workshop on solar energy, Cairo, Egypt.

Wijngaart van den, R., \& Ybema, J.R. (2002). Referentieraming broeikasgassen emissieraming voor de periode 2001-2010 [Reference projections for greenhouse gases: emission projections 2001-2002]. Bilthoven: RIVM.

Winett, R.A., Hatcher, J.W., Fort, T.R., Leckliter, I.N., Love, S.Q., Riley, A.W., \& Fishback,

J.F. (1982). The effects of videotape modeling and daily feedback on residential electricity conservation, home temperature and humidity, perceived comfort, and clothing worn: winter and summer. Journal of Applied Behavior Analysis, 15, 381-402.

Winett, R.A., Kaiser, S., \& Haberkorn, G. (1977). The effects of monetary rebates and daily feedback on electricity conservation. Journal of Environmental Systems, 6, 329 341.

Winett, R.A., Kagel, J.H., Battalio, C., \& Winkler R.C. (1978). Effects of Monetary Rebates, 
Feedback, and information on residential electricity consumption. Journal of Applied Psychology, 63, 73-80.

Winett, R.A., \& Neale, M.S. (1979). Psychological framework for energy conservation in buildings: strategies, outcomes, directions. Energy and Buildings, 2, 101116.

Wood, R., Bandura, A., \& Bailey, T. (1990). Mechanisms governing organizational performance in complex decision-making environments. Organizational Behavior and Human Decision Processes, 46, 181-201.

Zaltman, G., Duncan, R., \& Holbeck, J. (1984). Innovations \& Organizations, Malabar, Florida: Robert E. Krieger Publishing Company. 
NOTES

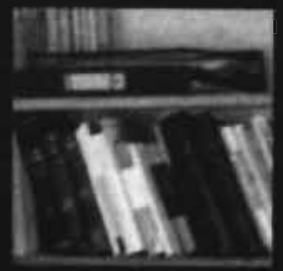




\section{Nores}

The concept of 'degree-days' was designed as a quantitative indication of the heating needed on a particular day with a particular outdoor temperature. One degreeday is a deviation of the average outside daytime temperature by one degree below $18^{\circ} \mathrm{C}$. Since a decrease in temperature from $2^{\circ} \mathrm{C}$ to $-3^{\circ} \mathrm{C}$ has a greater impact on the gas consumption level than a decrease from $18^{\circ} \mathrm{C}$ to $13^{\circ} \mathrm{C}$, an extra correction has been applied: the degree-days for the period from November to February were multiplied by a factor of 1.1, whereas the degree-days from March to October were multiplied by a factor of 1.0 and the degree-days from April to September by a factor of 0.8 .

2

The period during which gas was consumed (in the year preceding the project as well as in the year of the intervention) differed per household. Therefore, the annual consumption data used in the present study were calculated as follows. The total gas consumption of the households was divided by the total number of degree-days in that period and multiplied by the mean total number of degree days over a period of thirty years ( $=3277.45$ ). The outcome of this computation was the annual gas consumption used in the present study.

3

Since the predictors might be correlated, we checked for collinearity between the predictors, but found that there was no collinearity problem (all tolerance values were more than .55).

4

We had intended to start the automatic meter readings for the experimental group and the waiting-list control group 1 month before the intervention. Technical problems resulted in automatic meter readings starting several months later for the waitinglist control group. Therefore, the total energy and water consumption for both groups was calculated by subtracting the consumption from $T 3$ to $T 5$ (where we had data on) from the year consumption as measured by the distribution company.

5

It was not useful to compare the consumption levels of the experimental group and the waiting-list control group since the latter started receiving the information pages after T3. 
SUMMAKY

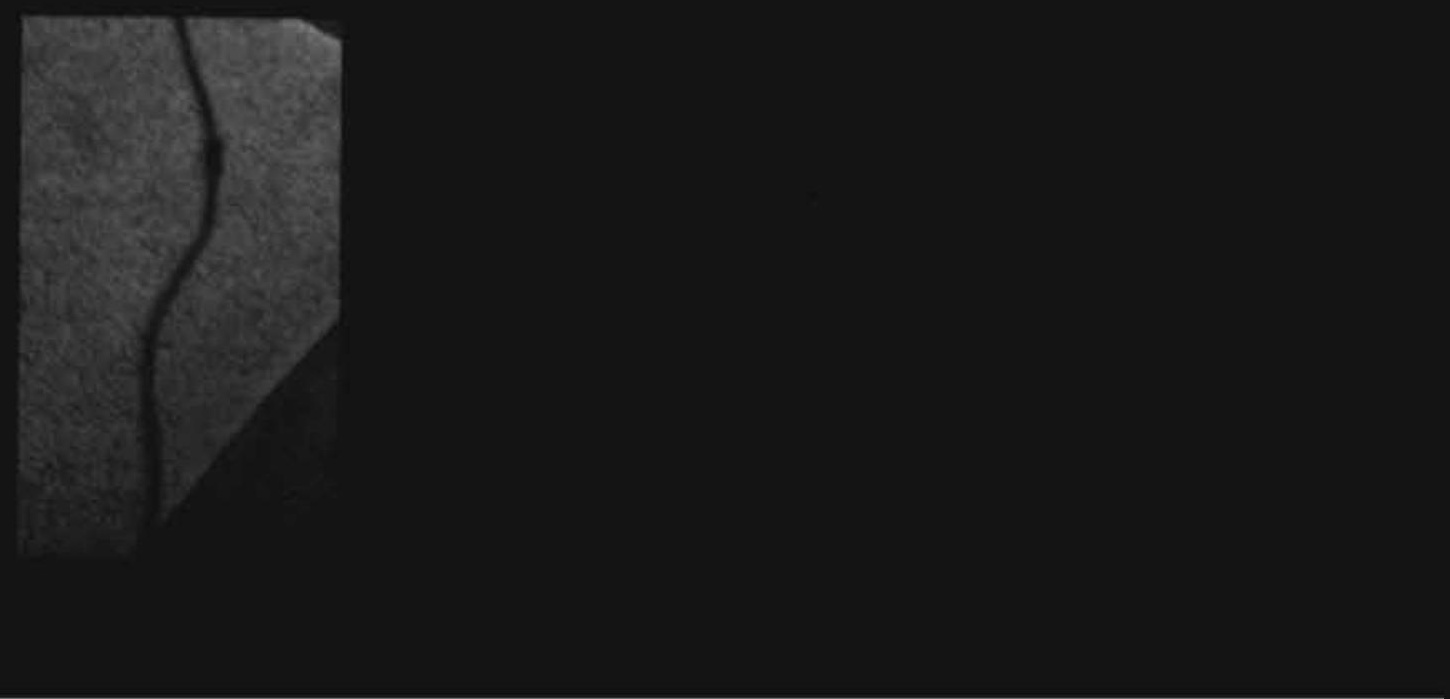




\section{SUMMARY}

\section{Introduction}

Households tribute significantly to some of the environmental problems western countries are confronted with, for example the emission of carbon dioxide $\left(\mathrm{CO}_{2}\right)$, the most important green house gas, caused by burning fossil fuels. To prevent further damage to the environment, governments may promote the use of alternative energy sources like solar and wind energy and implement a variety of measures to reduce energy and water consumption, like subsidizing energy and water saving measures. In addition, governments may also utilize behavioral strategies to promote energy and water conservation. In this dissertation it is first investigated what kind of behavioral intervention would make a good chance to get widely accepted by relevant policymakers. Acceptation by relevant policymakers of effective interventions is important for its wide scale implementation, so that it can contribute significantly to the reduction of the $\mathrm{CO}_{2}$ emission by households. Then this dissertation focuses on the behavioral method that seems to be accepted best: providing feedback about energy and water consumption in relation to goals that are set by households to limit their water, gas and electricity consumption. The effect of feedback, in combination with goal setting, has proved effective in a wide variety of educational, organizational, industrial and laboratory settings (see Locke \& Latham, 1990).

The research projects that are reported on in this dissertation have practical as well as theoretical goals. The practical aims of these projects were:(1) to select an intervention that might be implemented on a large scale because it is favorably judged by relevant policymakers and (2) to examine the effectiveness of this selected intervention in saving household water, electricity and gas consumption. The theoretical aims of these projects were to provide more insight into (3) the effects of goal setting and feedback on cognitions and (energy-relevant) behavior and (4) the possible negative effects of repeated negative feedback on cognitions and water and energy saving behaviors. An intervention can only contribute to the solution of environmental problems if it is implemented on a large scale. Therefore, another theoretical aim of this thesis is (5) to shed some light on how responsible policymakers decide to reject or accept an innovative energy conservation intervention.

Chapter 1 provides a general overview of the dissertation. First, the environmental protlems this dissertation is concerned with are depicted, and the energy and water consump. tion of households and the conservation policy of western countries are described. The theoretical background and empirical findings that are relevant to this dissertation follow this. The theoretical ideas behind feedback and goal setting are discussed, and the main empirical findings are summarized, with a focus on the studies that investigated the effect of goal setting and feedback on energy use in households. The diffusion of innovation theory of Rogers (1995) is introduced and an overview is provided of the relevant empirical studies. Thereafter, a brief discussion of the findings of the studies reported in this 
dissertation follows. Finally, the most important conclusions and recommendations of our studies are considered.

Chapter two reports a study in which we examined the evaluation of four effective energy conservation interventions by policymakers. These successful energy conservation interventions were selected from a literature review. The selected interventions were: (1) Load management for washing machines, which means that a washing program could only be started during off-peak periods, (2) Electronic feedback on household in-home energy consumption combined with goal-setting (the "electronic indicator"), (3) A communitybased communication intervention aimed at stimulating the adoption of insulation and energy saving behavior and (4) Personalized advice on energy saving given to the retail trade by a consultant of the utility companies.

Although these interventions proved to be successful, large-scale implementations failed to occur, because neither consumers, nor responsible policymakers seem to use or adopt successful interventions automatically. In this study we wanted to get more insight in the barriers of adopting an innovation and in the process of judging an innovation on its innovation attributes. This study was based on Rogers' diffusion of innovation theory (Rogers, 1995).

According to Rogers, the decision to adopt an innovation is affected by five innovation attributes: observability, relative advantage, compatibility, trialability and complexity. The first four of these attributes are positively related to adoption rate while complexity is asserted to be inversely related to the adoption rate of an innovation.

In this study we examined which of the four energy conservation interventions might be widely employed because of a positive evaluation by policymakers. Also, the predictive value of advantage, compatibility, trialability and complexity to predict adoption intentions were examined, and a first test was provided of some refinements to Rogers' theory, proposed by Darley \& Beniger (1981). Finally, the study examined whether the assessment of innovation attributes is a stepwise process. It was hypothesized that not all innovation attributes are relevant at the same time in the decision process and potential adopters use a non-compensative decision rule to judge an energy conservation intervention on its attributes. Policymakers are expected to be first of all interested in the relative advantage (like the cost-effectiveness) of an energy conservation intervention. When the relative advantage reaches a minimum cut-off value, an energy conservation intervention is in a subsequent step judged on the degree of compatibility.

The study group existed of $\mathbf{4 1}$ co-ordinators of the Environmental Action Plan of the energy distribution companies. The judgment of the energy conservation interventions by these co-ordinators is important because of their key position in implennenting the energy conservation interventions among households on a wide scale.

The results showed that the electronic indicator had the largest part of positive judgments: $48 \%$ of the co-ordinators had a moderate to very positive intention to adopt this intervention. For three of the four energy conservation interventions it was confirmed 
that the intention to adopt an energy conservation intervention was positively related to perceived compatibility. Furthermore, for one of the innovations (the electronic indicator) it was found that the intention to adopt was positively correlated with perceived advantage. These results showed that only compatibility was a consistent predictor of the policymaker's intention to adopt the four selected energy conservation interventions. We hypothesized that one of the main reasons for the low predictive value of the other innovation attributes was that an innovation is evaluated one-by-one on the innovation attributes and that not all innovation attributes are relevant to the potential adopter at the same time. For two of four interventions (for the innovation community interventions and for the electronic feedback) the results suggested that an energy conservation intervention is firstly judged on it advantages and in a second step on its compatibility. These findings were also confirmed in the face-to-face interviews with the relevant policymakers. Finally, qualitative findings suggested that the five innovation attributes of Rogers (1995) might become stronger predictors for the intention to adopt energy conservation interventions if they are further specified and extended.

Chapter three described the results of a field experiment, examining the effect of a prepayment meter on household gas consumption. With a prepayment meter, households pay for their gas as they use it and a display on the meter shows the amount of credit left, the emergency credit and the price of the gas per $\mathrm{m}^{3}$. Additionaly, they could see the cumulative amount of gas used above the display. The prepayment could be charged by means of a smart card that could be recharged at the local super market. The prepayment meter was not originally designed to give feedback on gas consumption and it did not indicate a reference consumption rate. Therefore, half of the participants received a notebook in which they could compare the cost of their gas consumption with the cost of a target consumption. In this way, a gas saving target was set, and the feedback was made more meaningful.

The study aims were to examine (1) whether households were satisfied with the prepayment meter, (2) whether the prepayment meter (with or without goal setting) affected household gas consumption and (3) whether (changes in) self-reported specific gas-saving activities and their determinants were related to (changes in) objective gas consumption.

The participants of this study consisted of 116 heads of households who rented or owned houses at a new housing development in a Dutch village. The design of this study was an experimental pretest-posttest design.

The results showed that households were highly satisfied with the prepayment meter and that the expected disadvantages of the prepayment meter had decreased after the meter had been used for one year. Furthermore it was found that the prepayment meter reduced the gas consumption of households by $4.7 \%$ compared to the control group. No significant difference was found in gas consumption between the study groups with 
and without a saving target. An explanation might be that the procedure of comparing the actual use with the target use was too laborious and too complex. Furthermore we found that attitude change toward gas-saving activities was positively related to changes in objective gas consumption, whereas no significant relation was found between changes in self reported gas consumption reducing activities and changes in objective gas consumption.

Chapter four described the results of the second field experiment, in which households received feedback about their water, gas and electricity consumption on five information pages on channel 37 of their television sets. The information pages informed households about their weekly water, gas and electricity consumption compared to a saving target of $5 \%, 10 \%$ or $15 \%$. The purpose of the study was to examine the reduction effect of feedback and goal setting on household gas, water and electricity consumption. Additionally we examined which conservation activities households specifically changed to reduce their gas, water and electricity consumption.

In this study we combined an experimental design with a quasi-experiment pretest-post-test design. Participants were 62 homeowners living in the same energy-efficient new housing development in a Dutch village who were randomly assigned to an experimental or waiting-list control group. We suspected test effects in the waiting-list control group because they were well informed about the electronic feedback project, and had to answer questions on energy and water saving behavior. Therefore, 22 households were selected random from a comparable district (extra control group) and data of the experimental group were compared with both control groups.

The results revealed that the information pages were effective in reducing household water consumption (a reduction of $15 \%$ ) and electricity consumption (a reduction of $22 \%$ ) when the experimental group was compared with the waiting-list control group. For gas we found no reduction when the experimental group was compared with the waiting-list control group, but when the experimental group was compared with the extra control group a reduction of $25 \%$ was found. Furthermore, the results gave further insight in what kind of behaviors people changed to reduce their consumption.

Chapter five describes the effect of repeated negative feedback on people's cognitions and reduction of water, electricity and gas consumption after 14 weeks and 26 weeks of feedback. We expected that repeated negative feedback would negatively affect people's self-efficacy, success expectancy, goal commitment and motivation to attain their target. Furthermore we expected that when negative feedback continued, it could also affect people's performances.

For this study we used the data of the experimental group of the field study described in chapter four. From this group we gathered the necessary data and examined the association between the number of times people received negative feedback and 
people's cognitive and behavioral reactions.

Results showed that the number of times households received negative feedback negatively affected their self-efficacy and success expectancy after 14 and 26 weeks of feedback (confirmed for water and electricity). Furthermore, analyses revealed that the number of times households received negative feedback negatively affected their goal commitment after 14 weeks (confirmed for water) and after 26 weeks of feedback (confirmed for water and gas). The number of times households received negative feedback did not affect changes in households' consumption levels after 14 weeks of feedback. However, in the long run (after 26 weeks of feedback) the number of times households received negative feedback did negatively affect the reduction in water and gas consumption as expected.

From these results it is concluded that repeated negative feedback may have a negative effect on a cognitive level and in the long run also at a performance level. However, the negative effects we found between repeated negative feedback and people's cognitions and performance might be specific for a non-competitive and nonhierarchical setting.

\section{Main conclusion}

This dissertation has clear practical and theoretical implications. In practical terms, its main implication is that TV information system providing households with weekly feedback about their water, electricity and gas consumption (compared to a target consumption level) can reduce household water, electricity and (maybe) gas consumption. Our results look very promising, as reductions from 10 to $25 \%$ were found, which may be considered substantial. Given these positive results and given that the most important conditions for wide-scale use seem to be met, electronic feedback and goal setting interventions may considerably contribute to the solution of environmental problems like the greenhouse effect and the shortage of clean drinking water in the near future.

The main theoretical implication of this dissertation is that innovation attributes (e.g., relative advantage, compatibility)) are not evaluated simultaneously, but one-by-one. This contribution to Rogers' (1995) diffusion of innovation theory deserves more research because of its practical as well as theoretical significance. 
SAMENVATTING 


\section{SAMENVATTING}

\section{Introductie}

Huishoudens leveren een belangrijke bijdrage aan bepaalde milieuproblemen van de westerse geindustrialiseerde landen, zoals de emissie van koolstofdioxide ( $\left.\mathrm{CO}_{2}\right)$, het belangrijkste gas voor het ontstaan van het broeikaseffect. Kooldioxide ontstaat door het verbranden van fossiele brandstoffen. Om verdere schade aan het milieu te voorkomen, kunnen overheden het gebruik stimuleren van alternatieve energiebronnen zoals zonneen windenergie en kunnen ze diverse energie- en waterbesparende maatregelen implementeren, zoals het subsidiēren van water-en energiebesparende maatregelen. Daarnaast kunnen overheden ook gebruik maken van gedragsmatige strategieën om energie- en waterbesparing te bevorderen. In dit proefschrift wordt allereerst geïnventariseerd welke gedragsmatige interventies een goede kans zouden maken om op brede schaal geaccepteerd te worden door relevante beleidsmakers. Acceptatie door relevante beleidsmakers van effectieve interventies is belangrijk voor de grootschalige implementatie van de interventie, zodat de interventie daadwerkelijk kan bijdragen aan de reductie van de $\mathrm{CO}_{2}$ emissie. Vervolgens wordt in deze dissertatie aandacht besteed aan de gedragsmatige interventie die het beste geaccepteerd lijkt te worden: het geven van feedback over het persoonlijke energie- en waterverbruik in combinatie met het stellen van een doel om het gas-, elektriciteit- en waterverbruik van huishoudens te verlagen. Het effect van feedback in combinatie met het stellen van doelen is effectief gebleken in verschillende settings zoals in het onderwijs, in organisaties, in de industrie en in laboratoria.

De onderzoeksprojecten die in deze dissertatie worden beschreven hebben zowel praktische als theoretische doelen. De praktische doelen van de onderzoeksprojecten waren:(1) het selecteren van een interventie die mogelijk grootschalig geimplementeerd zou kunnen worden omdat deze positief werd beoordeeld door relevante beleidsmakers en (2) het onderzoeken van de effectiviteit van deze geselecteerde: interventie voor het besparen van het huishoudelijk water-, elektriciteit- en gasverbruik. De theoretische doelstellingen van deze projecten waren het vergroten van het inzicht in (3) het effect van goal setting en feedback op cognities en water- en energie-relevante gedragingen en (4) de mogelijke negatieve effecten van herhaalde negatieve feedback op cognities en water- en energiebesparende gedragingen. Een interventie kan alleen een bijdrage leveren aan de oplossing van de milieuproblemen als deze op grote schaal wordt geimplementeerd. Daarom is een ander theoretisch doel van deze dissertatie (5) het geven van enig inzicht in de manier waarop verantwoordelijke beleidsmakers beslissen om een innovatieve energiebesparende interventie te verwerpen of te accepteren.

Hoofdstuk 1 geeft een algemeen overzicht van de inhoud van deze dissertatie. Ten eerste wordt een beschrijving gegeven van milieuproblemen die voor deze dissertatie relevant zijn. Tevens wordt ingegaan op het energie- en waterverbruik van huishoudens en het 
besparingsbeleid van westerse landen. Vervolgens worden de relevante theoretische achtergrond en empirische uitkomsten beschreven. De theoretische ideeën achter feedback en goal setting worden bediscussieerd en de belangrijkste empirische uitkomsten van studies waarin het effect van feedback en goal setting werd geëvalueerd worden samengevat. The diffusietheorie van Rogers (1995) wordt geïntroduceerd en er wordt een overzicht gegeven van de relevante empirische studies. Daarna volgt een bondige discussie over de onderzoeksresultaten van de studies die in deze dissertatie worden gerapporteerd. Tenslotte volgt een beschouwing van de belangrijkste conclusies en aanbevelingen van de studies.

Hoofdstuk twee rapporteert een studie waarin onderzocht werd hoe relevante beleidsmakers vier effectief gebleken energiebesparende interventies evalueerden. Deze succesvolle energiebesparende interventies werden geselecteerd op basis van een literatuurstudie. De geselecteerde interventies waren: (1) directe sturing van wasmachines, hetgeen betekende dat een wasprogramma alleen kon worden gestart gedurende de daluren, (2) elektronische feedback op het energieverbruik bij huishoudens in combinatie met het stellen van doelen (de elektronische indicator), (3) buurtgerichte voorlichting voor het stimuleren van de adoptie van isolerende maatregelen en energiebesparende gedragingen en (4) een persoonlijk energiebesparend advies voor de detailhandel door een consulent van de energiedistributiebedrijven.

Hoewel deze interventies effectief waren gebleken, bleef grootschalige toepassing van deze interventies uit omdat noch consumenten, noch beleidsmakers succesvolle interventies uit zichzelf gingen gebruiken of implementeren. In deze studie wilden we meer inzicht krijgen in de barrières voor het adopteren van een interventie en in het beoordelingsproces van een innovatie op relevante innovatiekenmerken. Dit onderzoek was gebaseerd op de diffusie theorie van Rogers (1995).

Volgens Rogers (1995) wordt de beslissing om een innovatie te adopteren beinvloed door vijf innovatiekenmerken: zichtbaarheid, relatief voordeel, inpasbaarheid, experimenteerbarheid en complexiteit. De eerste vier innovatiekenmerken worden verondersteld positief samen te hangen met de snelheid van adoptie, terwijl de mate van complexiteit negatief zou samenhangen met de adoptiesnelheid.

In deze studie hebben we onderzocht welke van de vier energiebesparende interventies mogelijk grootschalig gebruikt zou kunnen gaan worden, gelet op de positieve evaluatie door beleidsmakers. Ook werd onderzocht in hoeverre men in staat is op basis van inschattingen van het voordeel, de inpasbaarheid, de experimenteerbaarheid, en de mate van complexiteit van een interventie de intentie ten aanzien van de adoptie te voorspellen. Tevens werd een eerste aanzet gegeven om de zinvolheid van enkele verfijningen van Rogers' theorie (voorgesteld door Darley \& Beniger, 1981) te onderzoeken. Tenslotte werd in deze studie onderzocht of het beoordelen van de innovatiekenmerken een stapsgewijs proces is. De aanname was dat niet alle innovatiekenmerken tegelijkertijd relevant 
zijn in het besluitvormingsproces en dat potentiēle gebruikers een niet compenserende beslisregel toepassen om een energiebesparende interventie op de innovatiekenmerken te beoordelen. De veronderstelling is dat beleidsmakers eerst geinteresseerd zullen zijn in het relatieve voordeel (zoals de kosten effectiviteit) van een energiebesparende interventie. Pas wanneer het relatieve voordeel bij de beoordeling tenminste een bepaalde minimale waarde bereikt, zal de interventie in een volgende stap worden beoordeeld op de mate van inpasbaarheid.

De onderzoeksgroep bestond uit 41 coördinators van het Milieu Actie Plan van de energiedistributiebedrijven. De beoordeling van de energiebesparende interventies door deze coördinators is belangrijk omdat zij een sleutelpositie innemen bij het grootschalig implementeren van energiebesparende interventies onder huishoudens.

Uit de onderzoeksresultaten bleek dat de elektronische indicator het grootste aantal positieve beoordelingen had: $48 \%$ van de coördinatoren hadden een gemiddeld tot zeer positieve intentie om de interventie te adopteren. Voor drie van de vier energiebesparende interventies werd bevestigd dat de intentie om een energiebesparende interventie te adopteren positief gerelateerd was aan de waargenomen inpasbaarheid van de interventie. Voor een van de vier interventies (de elektronische indicator) werd bevestigd dat de intentie om de interventie te adopteren positief gerelateerd was aan het waargenomen voordeel van de interventie. Uit deze onderzoeksresultaten bleek dat alleen de mate van inpasbaarheid een consistente voorspeller was voor het voorspellen van de intentie van de beleidsmakers om de vier geselecteerde interventies te adopteren. We veronderstelden dat een van de redenen voor de laag voorspellende waarde van de andere innovatiekenmerken was dat een innovatie één-voor-één op de innovatiekenmerken wordt beoordeeld en dat niet alle innovatiekenmerken tegelijkertijd relevant zijn voor de beslisser. Voor twee van de vier interventies (voor de buurtgerichte voorlichtingsinterventie en voor de elektronische feedback) suggereerder de onderzoeksresultaten dat een energiebesparende interventie allereerst wordt beoordeeld op zijn voordeel en in een tweede stap op de mate van inpasbaarheid. De mondelinge interviews met relevante beleidsmakers lieten hetzelfde beeld zien. Tenslotte suggereerden de kwalitatieve gegevens dat de vijf innovatiekenmerken van Rogers (1995) betere voorspellers zouden kunnen worden van de intentie om een energiebesparende interventie te adopteren, als zij nader zouden worden gespecificeerd en uitgebreid.

Hoofdstuk drie beschrijft de resultaten van een veldonderzoek waarin het effect van een prepayment-meter op het huishoudelijk gasverbruik werd onderzocht. Middels een prepayment-meter betalen huishoudens voor het gas dat ze verbruiken. Een display op de gasmeter laat de hoogte van het tegoed zien, het noodkrediet, en de prijs van gas per $\mathrm{m}^{3}$. Daarnaast toonde het display het cumulatieve gasverbruik. Middels een 'smartcard' werd het tegoed op de meter aangevuld; de smartcard kon worden opgeladen bij een supermarkt in de buurt. De prepayment-meter was oorspronkelijk niet ontworpen om feedback 
te geven op het gasverbruik van huishoudens en de meter gaf ook geen referentiegebruik aan. Om hier alsnog voor te zorgen, kreeg de helft van de respondenten een notieboekje waarin zij hun werkelijke kosten voor hun gasverbruik konden vergelijken met de kosten van het streefverbruik. Op deze manier werd een doel gesteld en werd de feedback zinvoller.

De studie had tot doel te onderzoeken of (1) huishoudens tevreden waren met de prepayment-meter, (2) de prepayment-meter (met of zonder het stellen van een doel) het gasverbruik van huishoudens beïnvloedde, en (3) of er een relatie was tussen (veranderingen in) zelfgerapporteerde specifieke (determinanten van) gasbesparende activiteiten enerzijds en (veranderingen in) objectief gasverbruik anderzijds.

De deelnemers aan deze studie waren 116 personen die de meeste verantwoordelijkheid droegen in het huishouden en die een huis huurden of eigenaar waren van een huis in een nieuwbouwwijk. Het onderzoek had een experimenteel onderzoeksdesign met een voor- en een nameting. Uit de onderzoeksresultaten bleek dat huishoudens zeer tevreden waren over de prepayment-meter en dat men minder nadelen zag aan de prepayment-meter nadat men de meter een jaar had gebruikt. Tevens bleek dat de prepayment-meter het gasverbruik van de huishoudens verminderde met $4.7 \%$ in vergelijking tot de controlegroep. Er werden geen significante verschillen gevonden in het gasverbruik tussen de onderzoeksgroepen met en zonder een besparingsdoel. Een verklaring hiervoor zou kunnen zijn dat de procedure voor het vergelijken van het actuele energieverbruik met een streefverbruik te arbeidsintensief en te complex was. Verder vonden we dat de attitudeverandering ten aanzien van gasbesparende activiteiten positief samenhing met veranderingen in objectief gasverbruik, terwijl we geen significant verband vonden tussen veranderingen in zelfgerapporteerde gasbesparende activiteiten en veranderingen in het objectieve gasverbruik.

Hoofdstuk vier beschrijft de resultaten van het tweede veldonderzoek, waarin huishou= dens feedback ontvingen over hun water-, gas- en elektriciteitsverbruik op vijf informatiepagina's via kanaal 37 van hun televisietoestel. De informatiepagina's informeerden huishoudens over hun wekelijkse water-, gas- en elektriciteitsverbruik in vergelijking tot een besparingsdoel van $5 \%, 10 \%$ of $15 \%$. Het doel van de studie was om het besparingseffect van feedback en het stellen van doelen te onderzoeken op het huishoudelijke gas-, water- en elektriciteitsverbruik. Aanvullend werd onderzocht welke besparingsactiviteiten huishoudens met name veranderden om hun gas-, water- en elektriciteitsverbruik te verminderen.

In deze studie hebben we een experimenteel onderzoeksdesign gecombineerd met een quasi-experimenteel onderzoeksdesign. Deelnemers waren 62 huiseigenaren uit dezelfde energie-efficiënte nieuwbouwwijk die aselect werden toegewezen aan een experimentele of een wachtlijstcontrolegroep. Aangezien we testeffecten verwachtten in de wachtlijstcontrolegroep (omdat deze groep geïnformeerd was over het elektronische 
feedbackproject en vragen moest beantwoorden over energie-en waterbesparende gedragingen), werden 22 huishoudens aselect geselecteerd uit een vergelijkbare wijk (de extra controlegroep) en werden de onderzoeksdata van de experimentele groep met beide controlegroepen vergeleken.

Uit de resultaten bleek dat de informatiepagina's effectief waren om het waterverbruik en het elektriciteitsverbruik te verminderen als de experimentele groep werd vergeleken met de wachtlijstcontrolegroep (respectievelijk een besparing van 15 en 22\%). Voor gas vonden we geen vermindering in het verbruik als de experimentele groep werd vergeleken met de wachtlijstcontrolegroep. Maar als de experimentele groep werd vergeleken met de extra controlegroep werd een vermindering van het gasverbruik in de experimentele groep gevonden van $25 \%$. Tevens gaven de onderzoeksresultaten meer inzicht in het soort gedragingen mensen veranderden om het verbruik te reduceren.

Hoofdstuk vijf beschrijft het effect van herhaalde negatieve feedback op de cognities van mensen en op het verminderen van hun water-, elektriciteit- en gasverbruik na 14 weken en na 26 weken van feedback. We veronderstelden dat herhaalde negatieve feedback een negatief effect zou hebben op de eigen-effectiviteit, de succesverwachting, de betrokkenheid bij het doel en de motivatie om de besparing te halen. Verder veronderstelden we dat alsi de negatieve feedback langer door bleef gaan, het ook een negatieve invloed zou hebben op het besparingsgedrag van mensen. Voor deze studie werd gebruik gemaakt van de data van de experimentele groep van het veldonderz:oek, beschreven in hoofdstuk vier van deze dissertatie. Van deze groep werden de clata gebruikt die we nodig hadden voor het onderzoeken van de relatie tussen het aantal keren dat mensen negatieve feedback ontvingen en de cognities van mensen en hun gedrag.

De uitkomsten van het onderzoek lieten zien dat het aantal keren dat huishoudens negatieve feedback ontvingen een negatief effect had op hun eigen-effectiviteit en hun succesverwachting na 14 en nai 26 weken feedback (bevestigd voor water en elektriciteit). Verder bleek uit de analyses dat het aantal keren dat huishoudens negatieve feedback ontvingen een negatief effect had op de betrokkenheid bij hun doel na 14 weken (bevestigd voor water) en na 26 weken feedback (bevestigd voor water en gas). Het aantal keren dat huishoudens negatieve feedback ontvingen bleek na 14 weken geen effect te hebben op veranderingen in de hoogte van het verbruik. Echter, op de lange termijn (na 26 weken feedback) bleek, zoals verwacht, dat het aantal keren dat huishoudens negatieve feedback ontvingen wel een negatief effect had op de vermindering in het water-en gasverbruik.

Uit deze onderzoeksresultaten wordt geconcludeerd dat herhaalde negatieve feedback een negatieve invloed kan hebben op een cognitief niveau en op de langere termijn ook op het prestatieniveau. De negatieve effecten die wij vonden van herhaalde negatieve feedback op cognities en gedrag gelden mogelijk specifiek voor niet-competitieve en niet-hiërarchische settings. 


\section{Belangrijkste conclusies}

Deze dissertatie heeft duidelijke praktische en theoretische implicaties. In praktische termen is de belangrijkste implicatie dat de informatiepagina's die huishoudens ontvingen via kanaal 37 van hun televisie en die hen informeerden over hun wekeijikse water-, elektriciteit- en gasverbruik (vergeleken met een streefverbruik) het huishoudelijk water-, elektriciteit- en misschien ook het gasverbruik kan verlagen. De resultaten lijken veelbelovend met reducties op het verbruik tussen de $10 \%$ en $25 \%$, hetgeen een substantiële verlaging kan worden genoemd. Gegeven deze positieve resultaten en gegeven dat er is voldaan aan de belangrijkste voorwaarden voor grootschalige toepassing, zou feedback in combinatie met het stellen van doelen in de nabije toekomst een substantiële bijdrage kunnen gaan leveren aan het oplossen van milieuproblemen als het broeikaseffect en het tekort aan schoon drinkwater.

De be!angrijkste theoretische implicatie van deze dissertatie is dat een innovatie niet tegelijkertijd wordt beoordeeld op de innovatiekenmerken (bijvoorbeeld relatief voordeel en inpasbaarheid) maar één-voor-één. Deze bijdrage aan Rogers' (1995) diffusie theorie verdient meer aandacht gezien de praktische en theoretische relevantie ervan. 
몰 
DANKWOORD

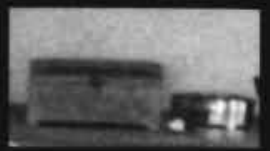




\section{DANKWOORD}

raag wil ik als eerste mijn dank uitspreken aan Ree Meertens. Ree, ik heb erg veel van je geleerd en heb zeer veel waardering voor je kritische feedback en de manier waarop je me hebt gemotiveerd bij de uitvoering van de onderzoeksprojecten en tijdens het schrijven van het proefschrift. Ik denk met veel plezier aan de hele periode terug.

Ten tweede wil ik mijn promotor Nanne de Vries bedanken, die hoewel vrij kort betrokken bij het project, duidelijk zijn betrokkenheid toonde en de mogelijkheid bood om binnen te lopen met vragen. Ook wil ik Gerjo Kok bedanken die in het begin als promotor betrokken was bij het project. Ook later bleef hij, zij het op de achtergrond, zijn interesse tonen door bij elke gelegenheid dat ik hem trof te vragen hoe het met het proefschrift ging.

Verder wil ik hier de Nederlandse Organisatie voor Energie en Milieuonderzoek (NOVEM) en GATEC Technology BV bedanken voor het meefinancieren van de onderzoeksprojecten van dit proefschrift.

Ook wil ik graag Mieke Schuurman, Anke Oenema, Priska Israel, Jascha de Nooyer, Helga Nauta, Rob Ruiter, Arjan Bos, Nicole van Kesteren en Pepijn van Empelen, bedanken voor hun steun, kritisch commentaar en hun vriendschap tijdens het schrijven van dit proefschrift.

Ook andere collega's bij GVO waarmee ik heb samengewerkt, gesport, geluncht, op de trap bij de vijver ijsjes heb gegeten en in de kroeg heb gezeten wil ik van harte bedanken. Ik vond het een leuke tijd!

Tevens wil ik graag José Trotteman en Marja Slangen bedanken. José, ik heb er erg veel bewondering voor je dat je zo makkelijk overzicht houdt over de financiën, over al die verschillende potjes. Marja, het is enorm fijn om het proefschrift voor de leescommissie bij jou in te leveren en te weten dat het goed komt.

Verder wil ik graag Geo Visser en Akkeline van den Berg bedanken voor de assistentie die zij hebben verleend bij de uitvoering van het onderzoek.

Dank ook aan mijn familie waar ik op kan rekenen als dat nodig is. Mam, helaas ben je er niet meer, ik weet dat je van dit moment zou hebben genoten.

Tot slot wil ik Tim, Sophie en Lieven beclanken. Tim, door jou werd het makkelijker het proefschrift te relativeren als ik dat nodig had. Ik ben blij met je en bewonder je. Dankzij jou ook is dit proefschrift mooi van vorm geworden. Sophie, aan jou draag ik dit proefschrift op.Voor het grootste gedeelte was jij erbij. Ik ben apetrots op je en zoaís je ziet is een proefschrift een boekje ook al ligt het niet in de boekhandel. Lieven, erg leuk dat je er bent, ook al is het schrijven van dit dankwoord met zo'n nieuwsgierig ventje die graag op alle toetsen drukt, geen eenvoudige klus. 


\section{CuRRICUlum VitaE}

Trijntje Völlink werd geboren in Schipborg op 23 januari 1965. Na haar middelbare schoolperiode in Zuidlaren en Groningen studeerde zij in 1987 jeugdwelzijnswerk aan de $\mathrm{HBO}-\mathrm{J}$ in Haren. Na haar afstuderen ging zij in 1987 Gezondheidswetenschappen studeren in Maastricht. In 1992 studeerde zij af in de studierichting Gezondheidsvoorlichting (GVO). In 1992 begon zij als onderzoeksassistent te werken aan de capaciteitsgroep Gezondheidsvoorlichting in Maastricht. Vanaf 1993 tot aan 2003 werkte zij als onderzoeker bij de capaciteitsgroep Gezondheidsvoorlichting onder anderen aan de onderzoeksprojecten beschreven in deze dissertatie. Vanaf 2000 tot aan 2002 werkte zij tevens als Universitair Docent in een samenwerkingsverband van de capaciteitsgroep GVO en de kandidaatsopleiding Humane Gezondheidskunde aan het Limburgs Universitair Centrum (LUC) te Diepenbeek. Sinds juni 2003 is zij werkzaam als Universitair Docent bij de faculteit Psychologie aan de Open Universiteit Nederland in Heerlen. 
In dit proefschrift wordt aangetoond dat de combinatie van elektronische feedback en het stellen van doelen een effectieve manier is om het energie- en waterverbruik van huishoudens te verminderen. Tevens is gebleken dat een groot aantal relevante beleidsmakers binnen energiedistribuitebedrijven, positief zijn over het implementeren van besparingsprojecten bij huishoudens. Elektronische feedback in combinatie met het stellen van doelen lijkt dan ook een van de weinige veelbelovende interventies waarvan verwacht mag worden dat het in de toekomst een bijdrage kan leveren aan het verminderen van het broeikaseffect en het tekort aan schoon drinkwater. 